\title{
Does media coverage affect governments' preparation for natural disasters?
}

\author{
CRED Research Paper No. 29
}

\author{
Pierre Magontier \\ University of Bern, \\ CRED
}

August, 2020

\begin{abstract}
While natural hazards have never been so frequent in modern history, the political economy of disaster preparation remains largely understudied. To prepare for natural disasters, local governments can adopt mitigation measures (e.g., infrastructure elevation, retrofitting, shelter construction, etc.). However, in doing so, there is a trade-off between risk reduction and risk disclosure as these initiatives may signal latent dangers of a place to unsuspecting homebuyers. Increased media coverage may ease this trade-off by revealing these dormant risks. I develop a measure of newspaper coverage of storms using data on newspapers' circulation and occurrence of storms at the ZIP code level in the United States. Using the variation in this measure, I identify the effects of heightened media attention on local governments' mitigation efforts under the Hazard Mitigation Grant program managed by FEMA. I find that when newspaper coverage is high, jurisdictions that have experienced severe storms tend to implement significantly more mitigation projects. Conversely, when coverage of storms is low, jurisdictions do not undertake mitigation projects after being hit by a storm. My results are primarily driven by ZIP codes with high pre-treatment levels of vacant housing units, housing units occupied by renters, and housing units owned with a mortgage. I argue that local governments may be strategically underinvesting in disaster preparation to avoid revealing their jurisdictions' inherent risk to otherwise uninformed property investors.
\end{abstract}




\section{Introduction}

It is a common mistake to confuse extreme weather events and natural disasters. Both are generally perceived as powerful, violent, unavoidable life hazards, or 'acts of God.' Yet, for disasters to occur, at least some buildings need to exist, and there need to be inadequate protective infrastructures. 'Nature did not construct twenty thousand houses of six to seven stories' on a seismic breach - wrote Genevan philosopher Jean-Jacques Rousseau in $1755^{1}$. But quite often, individuals lack information about the risks they take when investing in a location. If individuals are not aware of their actual risk exposure, should we not expect their local governments to prepare for disasters on their behalf? Today, the preparation puzzle has never been so pressing. While the Federal Emergency Management Agency (FEMA) advertises that 1 dollar spent on mitigation saves taxpayers 6 dollars of potential losses ${ }^{2}$, natural disasters cost the United-States' economy a record 306 billion dollars in $2017^{3}$. In the meantime, local administrations spent a more modest amount of 8.6 billion dollars worth of FEMA mitigation subsidies on that same year ${ }^{4}$. What explains local governments' apparent reluctance when it comes to mitigation?

The core assumption of this paper is that local governments face a trade-off between risk reduction and risk disclosure. Indeed, mitigation projects are designed to protect individuals and their wealth against future disasters - but their implementation also signals a place's hazard exposure. Where there is a floodwall, there is likely a flood risk, and where there is a storm shelter, there are surely strong winds. On the one hand, mitigation infrastructures

\footnotetext{
${ }^{1}$ This quote is extracted from a famous epistolary dispute between French philosopher Voltaire and Genevan philosopher Rousseau about the Great Lisbon earthquake of 1755 which caused the death of approximately 100,000 persons. Voltaire was shocked by what he perceived as an absurd, awful, unavoidable hazard. Rousseau argued that if the city had been less concentrated, and if the population had been evacuated in time, lives would have been spared. Strömberg (2007) also quotes this quarrel.

${ }^{2}$ National Institute of Building Sciences, "Natural Hazard Mitigation Saves: 2017 Interim Report"(2018), https://www.nibs.org/page/mitigationsaves. This report considered 23 years of federal grants awarded by FEMA, the Economic Development Administration, and the Department of Housing and Urban Development. Estimated savings (i.e., benefits) are derived from reductions in property losses; deaths, injuries, and post-traumatic stress disorder; direct and indirect business interruption; and other losses (https://www.pewtrusts.org/en/research-and-analysis/issue-briefs/2018/09/naturaldisaster-mitigation-spending-not-comprehensively-tracked)

${ }^{3}$ https://www.cbsnews.com/news/us-record-306-billion-natural-disasters-last-year-hurricanes-wilidfires/

${ }^{4}$ Among which 8.3 billion were granted (https://www.fema.gov/openfema-dataset-hazard-mitigationassistance-projects-v1). About 315 million dollars worth of subsidies were denied to applicants in 2017 (FOIA request - 2019-FEFO-00367).
} 
might certainly reassure homevoters and well-informed homebuyers by reducing the perceived risks of suffering from future natural disasters. On the other hand, they can push a priori unaware investors to update their perception of local risks by signaling the inherent liability of a location, hence putting this location at a competitive disadvantage. The ensuing question is: why would a local government take mitigation measures if it reveals its liabilities?

In this paper, I study how local risks' awareness fosters local governments' decisions to prepare for storms. In particular, I look at how an increase in local newspapers' coverage of storms impacts the decision to provide storm mitigation. In a world of complete information, shrouding risk exposure by not taking mitigation measures is likely to hurt the local housing market as homebuyers are already aware of the risks (Milgrom, 1981; Jovanovic, 1982). However, in the presence of incomplete information, local governments seeking to protect property values in their jurisdiction have incentives not to disclose latent risks to otherwise uninformed investors (Gabaix and Laibson, 2006; Brown, Hossain, and Morgan, 2010). Increased press coverage of locations hit by a storm is likely to foster prospective homebuyers' risk awareness. In turn, governments ruling over these jurisdictions are encouraged to invest in mitigation infrastructures to compensate for this negative effect on reputation. In the absence of any information shock, places hit by a storm remain virtually risk-free to prospective investors. In this case, I contend that governments who suffered a disaster have fewer incentives to invest in risk-signaling mitigation infrastructures, as uninformed homebuyers will adversely select into their jurisdiction (Akerlof, 1978) ${ }^{5}$.

I focus on local newspapers' coverage because the local press remains a key source of information on the activities of U.S. communities. According to a 2011 survey conducted by the Pew Research Center ${ }^{6}$, the American population classifies local newspapers as their top source of information when it comes to housing and real estate, local politics, and community events. Local television is preferred for watching sports or weather forecasts. The Internet is favored when individuals seek information about local jobs, restaurants, or schools. Yet,

\footnotetext{
${ }^{5}$ Note that in the seminal Rosen-Roback model (Rosen, 1974; Roback, 1982), individuals are perfectly aware of a city's attributes. This assumption is relaxed in this paper. Generally, considering that individuals' spatial sorting differs with the information they receive about potential destination leads to broader questions on the valuation of local quality of life and local amenities.

${ }^{6}$ Pew Research Center - 'How people learn about their community' - https://www.pewinternet.org/ 2011/09/26/part-3-the-role-of-newspapers /
} 
when it comes to learning about a community's daily life and its housing market, local press appears to be the favorite medium. Therefore, if storm risks matter for a given community's well-being, it is likely to be reported in the local newspapers. Additionally, according to a 2013 survey by the National Association of Realtors (2014), the typical investment property is only 20 miles from the buyer's primary residence (Gao, Sockin, and Xiong, 2018). The main reasons for investing in a new property are to derive a rental income $(37 \%)$, because of low prices or because the buyer found a good deal (17\%), and for potential price appreciation $(15 \%)^{7}$. These finding suggests that the representative investor is living close to his investments and plans to extract a rent from these latter. The typical investor is then likely to read local newspapers before performing a property purchase. Finally, to measure local governments' mitigation initiatives, I will focus on the universe of local administrations' applications to the Hazard Mitigation Grant (HMGP) program, the largest subsidized program for mitigation activities available to local governments in the United States. Several reasons are indicating that this program captures local governments' will for mitigation. First, federal entities largely finance mitigation projects (at least $75 \%$ of the project cost) ${ }^{8}$, so local administrations' budgets are not likely going to be dramatically affected by a project. Second, it is not a competitive program (contrary to the other mitigation programs proposed by FEMA) - which alleviates the risk of federal or state selection. Finally, local governments must send their applications within the year following a presidentially declared disaster, so the mitigation decision can be directly associated with a disaster. I further develop these arguments in Section 3.

An obvious challenge in identifying the impact of press coverage on these mitigation initiatives is that both local governments' preparation for storms and the amount of local news about storms are both driven by unobservable characteristics. For instance, constituents' beliefs regarding natural disasters and climate change are a direct cofounder of this effect. Local politicians' beliefs might also matter to the extent that media capture is always a latent risk. To establish causality, I compute the match between newspapers' markets and the

\footnotetext{
${ }^{7}$ https://www.prnewswire.com/news-releases/vacation-home-sales-soar-to-record-high-in-2014investment-purchases-fall-300059334.html

${ }^{8}$ Depending on the local legislation, the State administration typically participates in the payment of the remaining $25 \%$.
} 
spatial extent of storms at the ZIP code level. The rationale behind this measure, inspired by Snyder and Strömberg (2010), is that the more a newspaper's readership is hit by a storm, the more this newspaper is likely to report about this event ${ }^{9}$. I show that this measure is a good predictor of the number of articles published about storms by scraping data from the website Newslibrary.com. I argue that conditional on location, and county-year fixed effects, the socio-economic determinants that shape local newspaper markets are unrelated to the topographical and climate factors that explain a storm's exact extent, so the match between local newspapers' markets and the spatial extent of storms is haphazard. I then average this match based on the market share of each newspaper in a given jurisdiction. The empirical strategy then consists in comparing, within counties whose local authorities are eligible to the Hazard Mitigation Grant Program, storm mitigation projects in ZIP code areas where media coverage of storms is high to ZIP code areas where it is low.

My findings are striking. My main results suggest that conditional on being hit by a storm, a one standard deviation increase in my treatment leads to an increase of $54 \%$ in the mean number of mitigation projects. In the absence of any information shock, communities do not invest in mitigation technologies. I interpret these results as indicative that local governments strategically underinvest in mitigation to avoid signaling the latent risk of storms to investors who would have remained otherwise uninformed. Indeed, I find that the information shock especially matters for mitigation infrastructure projects, rather than non-structural mitigation projects like land acquisitions, which are less likely to signal the dormant risks. Additionally, right after being hit by a storm, a one standard deviation increase in storm coverage leads to a decrease both in housing sales and in the emission of new building permits, by almost $2 \%$ and $1 \%$, respectively ${ }^{10}$. These substantial figures suggest that land investors divert their investment towards what appears as safer areas when information about risks circulates. Finally, I present some evidence suggesting that these results

\footnotetext{
${ }^{9}$ If the match is one, then all readers of a given newspaper suffered a storm. If the match is null, then none of them suffered a storm. All things being equal, a local newspaper located in Maryland is less likely to report about a storm occurring in Colorado than Colorado's newspapers whose readers have been directly experiencing the disaster.

${ }^{10}$ As a means of comparison, the National Association of Realtors indicated that sales plunged by $13 \%$ in March 2007 compared to March 2006, in the midst of the mid-2000's housing bubble. As for the period of analysis, between 2010 and 2018, the Census Bureau reported that the average 12-month change in seasonally-adjusted housing sales was approximately $-1.15 \%$.
} 
are driven by non-resident investors. In particular, the heterogeneous analysis shows that they are primarily induced by locations with high pre-treatment levels of renter-occupied housing, vacant housing units, housing units owned with a mortgage, and areas having experienced higher inflows of populations before a storm - which is consistent with the real-estate investment patterns described by the anecdotal evidence.

This paper relates to a growing body of literature on natural disasters. So far, this literature has mostly focused on individuals' perception of these tail events (Leiserowitz, 2006; Taleb, 2007; Myers, Maibach, Roser-Renouf, Akerlof, and Leiserowitz, 2013) and on the individuals' reaction to this latter (Boustan, Kahn, and Rhode, 2012; Bunten and Kahn, 2017). In particular, Gallagher (2014) shows that individuals update their beliefs of the likelihood of flood occurrence based on the discounted history of floods, and are more likely to get flood insurance when these beliefs are strong. In the political economy literature, most studies focus on the links between natural disasters and the provision of disaster relief (Besley and Burgess, 2002; Strömberg, 2004; Eisensee and Strömberg, 2007; Healy and Malhotra, 2009; Gasper and Reeves, 2011; Bechtel and Hainmueller, 2011) or between natural disasters and the adoption of green bills (Pattachini, Paserman, and Gagliarducci, 2019; Kahn, 2007). Interestingly, Healy and Malhotra (2009) argue that, contrary to disaster relief measures, voters do not seem to value risk preparedness a priori. Kahn (2005) notes that the quality of institutions is a strong determinant of proactive mitigation measures, as they foster political accountability. This paper also relates to the political economy of mass media (Besley and Burgess, 2002; Strömberg, 2004; Eisensee and Strömberg, 2007; Snyder and Strömberg, 2010; Enikolopov, Petrova, and Zhuravskaya, 2011; Prat and Strömberg, 2013; Durante, Pinotti, and Tesei, 2019) and shows how the distribution of risk information may influence local policies. Finally, some recent works explore the links between risk perception of natural disasters and housing prices (Barrage and Furst, 2019; Coulomb and Zylberberg, 2019; Singh, 2019; Bakkensen and Barrage, 2017). To my knowledge, this paper is the first to document why local governments might not prepare their jurisdictions for natural disasters while being effectively threatened, and to consider that mitigation infrastructures may signal the inherent risk of disaster. 


\section{Theoretical Framework}

\subsection{Conceptual Background}

The seminal Rosen-Robach model (Rosen, 1974; Roback, 1982) assumes that individuals know ex-ante city attributes. Yet, while individuals are land consumers, all lands do not only display unshrouded features. We all recognize a forest, but inferring the risks of wildfires requires costly information. Most individuals do not often think about the hidden costs of a location when they decide where to settle. That is to say, they rarely think about the shrouded attributes of their new community.

This matter is particularly salient when it comes to anticipating a rare event's probability, like a natural disaster. Chapman University Survey on American fears $(2014)^{11}$ showed that while storms are respondents' number one natural disaster phobia, an overwhelming majority of them do not prepare - even in the riskiest places like Tornado Alley.

This form of consumers' myopia gives local governments incentives to hide risks from prospective investors. Indeed, revealing the dormant dangers to unsuspecting renters or homebuyers would put their jurisdiction at a competitive disadvantage. This is particularly salient when governments budgets critically depend on property sales and taxes. Appendix section B provides anecdotal evidence of such behavior in the United-States ${ }^{12}$. Equivalently, not exposing these dangers to well-informed consumers will also put their jurisdiction at a competitive disadvantage, since sophisticated investors will expect the worst from a community that puts efforts in hiding its known liabilities. For that "all actions $[\ldots]$ are unjust if their maxim is not consistent with their publicity" (Kant, 1795), rational investors shall be suspicious of places where they believe there is something to hide.

In this section, I build on the setting proposed by Gabaix and Laibson (2006) to show that

\footnotetext{
${ }^{11}$ Chapman Survey of American Fears, Wave 1 (2014) - http://www.thearda.com/Archive/Files/ Descriptions/CSAF2014.asp

${ }^{12}$ According to the Urban Institute, property taxes in the United-States are generally an essential source of revenues for local governments. In 2015, they amounted 472.74 billion dollars, and they were the first source of local jurisdictions' own-collected revenues. Between 2000 and 2015, the share of local property taxes in local government revenues rose from $26.8 \%$ to $29.8 \%$. This increase is partially explained by the decrease of intergovernmental transfers to local governments over the same period. In 2015, property taxes represented, on average, $46.6 \%$ of local governments' own-collected revenues and $72 \%$ of local governments' taxes on average. At a minimum, they amounted $41.5 \%$ of total local tax revenues in Alabama and more than $99 \%$ of total local tax revenues at a maximum in New Hampshire.
} 
local governments might strategically underinvest in mitigation actions to avoid revealing the hidden risks to otherwise uninformed land investors. In my model, mitigation actions both reduce and signal latent risks to uninformed individuals. Non-resident investors are initially unaware of the dangers but might become sophisticated as they receive exogenous shocks of information. Residents are always aware of the local risks in their community, but they might be ignorant of the state of risks in the neighboring communities.

To develop the intuition for my results, consider a region made of two independent, but similar cities. In particular, they both display a high chance of being hit by a natural disaster. The cost for the local governments of providing public mitigation is null. Assume that the first city - call it city $M$, has implemented a policy of systematic infrastructure elevation and wind retrofitting. On the contrary, the second city - call it city $N$, has not.

The population of this region receives different levels of information regarding the risks of natural disasters. Non-residents vary in their location decision based on their level of sophistication. A myopic risk-averse non-resident will speculate that the cost of living in $N$ is cheaper, as there are no apparent risks there ${ }^{13}$. She will choose to settle in this virtually risk-free location. A sophisticated risk-averse consumer, on the other hand, will question the lack of preparedness of city $N$ and grow wary that it is, actually, the riskiest location. She will then choose to locate in city $M$, as engaging in private mitigation in city $N$ would come at a personal cost.

As mentioned earlier, residents living in both cities are ex-ante aware of the dangers in their city of residence but might be ignorant of the risks in the neighboring town. In the case of city $M$, residents already benefit from public mitigation. Migrating to city $N$ and possibly engaging in private mitigation would, therefore, be inefficient. Residents of city $N$, on the other hand, do not benefit from such public resilience policies. If sophisticated, they will migrate to city $M$ if it is cheaper than enduring the disaster. If myopic, they will prefer to stay as there is no apparent reason to make a costly move.

Local governments, who wish to maximize land value in their jurisdictions, solve this game backward. In a world of incomplete information, investing in mitigation infrastructures

\footnotetext{
${ }^{13}$ Note that a myopic risk-neutral agent would be indifferent between living in $N$ where the risk is virtually null, and living in $M$ where the dangers are possibly offset by the investment in mitigation infrastructures.
} 
might reassure incumbents, but will scare uninformed outsiders. Consequently, if a sufficient share of non-residents becomes aware of the dangers, local officials will take mitigation measures. However, if a sufficient share of non-residents is ignorant of the latent risks of natural disasters, local officials will remain inactive, and hence hide these dormant dangers from prospective investors.

\subsection{The model}

Consider an economy with a population density of mass 1 . Consider two similar cities, $A$ and $B$, with the same high probability of being hit by a natural disaster. Each one is populated with a share $\alpha / 2$ of residents. A share $1-\alpha$ of the population does not live in any of the cities and wishes to locate in either $A$ or $B$ (see Figure 1). The cost of living in either one of the cities is $p \in \mathbb{R}^{+}$, and the individual cost of a natural disaster is $\hat{p}$. Individuals are either myopes $(m)$ if they are ignorant of the disaster risk, or sophisticated $(s)$ if they are aware. The level of public mitigation efforts is defined by $m \in] 0 ; \hat{p}[$. Public mitigation is costless to both individuals and governments.

At any moment, sophisticated individuals take into account the level of risks in both location, while myopics infer the risks if they observe that the government has taken mitigation measures. Formally:

$$
\mathbb{E}(\hat{p} \mid m=0)= \begin{cases}0 & \text { if the individual is myopic } \\ \hat{p} & \text { if the individual is sophisticated }\end{cases}
$$

$$
\mathbb{E}(\hat{p} \mid m>0)=\hat{p}-m \quad \text { whether the individual is myopic or sophisticated }
$$

In other words, for sophisticated individuals, $\mathbb{E}(\hat{p} \mid m>0)<\mathbb{E}(\hat{p} \mid m=0)$; whereas for myopics, $\mathbb{E}(\hat{p} \mid m=0)<\mathbb{E}(\hat{p} \mid m>0)$. That is to say, for sophisticated individuals, the expected cost of a disaster is higher in the absence of mitigation, whereas for myopics it is lower. Note that residents are always informed about their community level of risks, but might be ignorant of the other city's status. 
Figure 1: Conceptual representation of the effect of media coverage on Natural Disaster mitigation

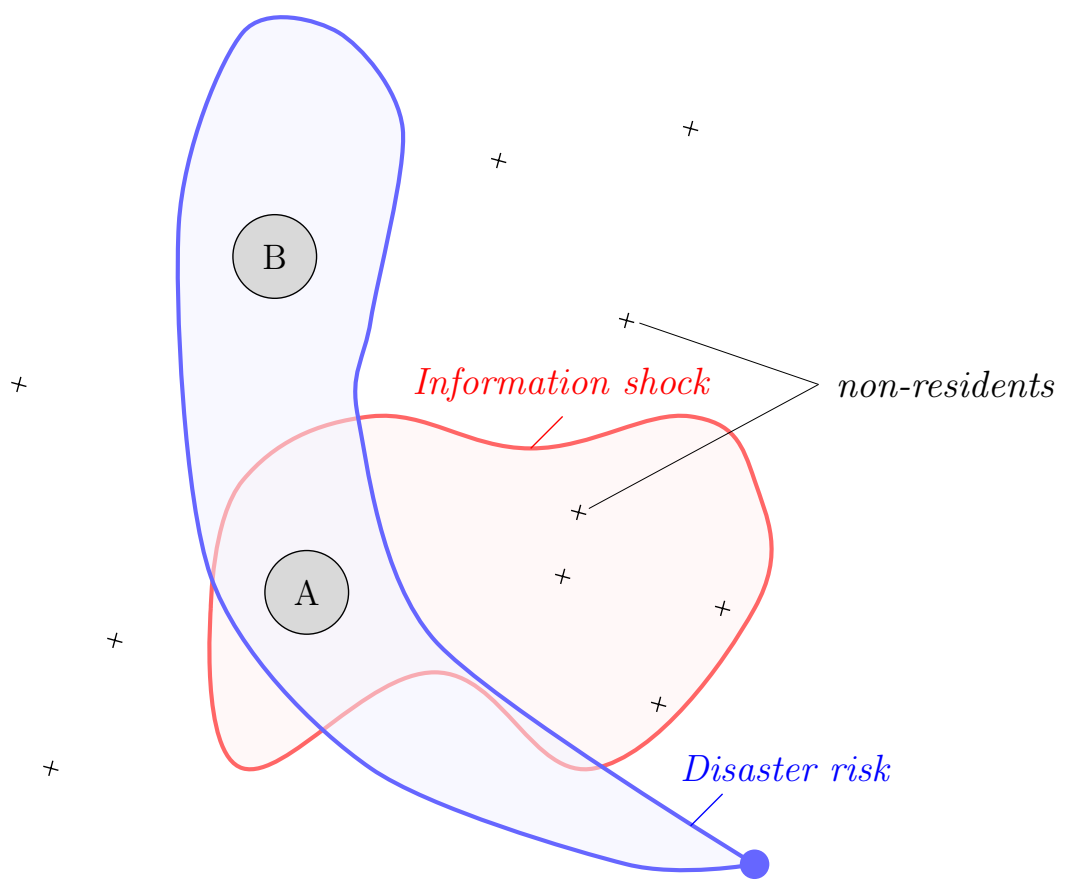

Note: Non-residents must decide whether to move to $A$ or $B$. Meanwhile, residents must choose whether to leave their hometown, and local governments in each city must decide whether to prepare or not for the local dangers. Residents are always aware of their hometown liabilities but might be ignorant of the risks in the other city. At the beginning of the game, a share $\lambda \in[0,1]$ of the population becomes informed of the local risks.

The game unfolds as follows: in the initial period, a share of the population learns from an exogenous shock of information about the dormant risks in both communities. In the meantime, local governments must decide whether or not to take mitigation measures. In period 1, residents decide whether to stay in their hometown or to move, and residents choose where to settle. To do so, each category of individual compares his net gains from staying to his net gains from moving - that is to say, the difference between each city's rent net of the expected cost of a disaster. At the end of the game, each government collects individuals' rent. Therefore, to maximize their revenues, local authorities need to solve this game backward.

To do so, each government makes a mitigation decision conditional on the other's action, the share of the resident population, and the share of sophisticated individuals. If 
individuals are well-informed, not preparing for the dangers can scare away prospective residents. On the contrary, if individuals are unaware of the risks, preparing for a disaster that virtually does not exist can potentially put a community at a competitive disadvantage too. Conditional on the shares of residents and informed individuals, there are two possible equilibria: a Shrouded one, under which it is never in the best interest of a government to take mitigation measures, and an Unshrouded one, under which it is always in their best interest to take mitigation measures.

Formally, each period unravels as follow:

\section{Period 0:}

- Non-residents are by default unaware of the risks present in each location.

- Residents are by nature sophisticated regarding their community as they observe the local risks. However, they are by default unaware of the risks in the other location.

- At the end of the period, both residents and non-residents receive different levels of information about the latent dangers in $A$ and $B$. A share $\lambda \in[0 ; 1]$ of the population becomes sophisticated, while the remaining $1-\lambda$ remains myopic.

- Both governments $A$ and $B$ observe the information shock and decide whether or not to take mitigation action, $m_{A}$ and $m_{B}$, respectively.

\section{Period 1:}

- Non-residents $(n r)$ choose a location between $A$ and $B$. Conditional on their sophistication status $w \in\{m, s\}$, the anticipated net surplus from choosing city $i \in\{A ; B\}$ is:

$$
x_{i, w, n r}=\left[-p_{i}-\mathbb{E}\left(\hat{p} \mid m_{i}\right)\right]-\left[-p_{-i}-\mathbb{E}\left(\hat{p} \mid m_{-i}\right)\right]
$$


- Residents $(r)$ choose whether to stay, or to move to the other city at a cost $c$. Conditional on their sophistication status $w \in\{m, s\}$, their anticipated net surplus from staying in city $i$ is:

$$
x_{i, w, r}=\left[-p_{i}-\mathbb{E}\left(\hat{p} \mid m_{i}\right)\right]-\left[-p_{-i}-c-\mathbb{E}\left(\hat{p} \mid m_{-i}\right)\right]
$$

- The demand for a location $i$ is defined as:

$$
D_{i, w,\{r ; n r\}}=\left\{\begin{array}{llll}
1 & \text { if } & x_{i, w,\{r ; n r\}}>0 \\
1 / 2 & \text { if } & x_{i, w,\{r ; n r\}}=0 \\
0 & \text { if } & x_{i, w,\{r ; n r\}}<0
\end{array}\right.
$$

Period 2: At the end of the game, government $i$ receives:

$$
\begin{array}{r}
\Pi_{i}=p \cdot\left\{\frac{\alpha}{2}\left[\lambda\left(1+D_{i, s, r}-D_{-i, s, r}\right)+(1-\lambda)\left(1+D_{i, m, r}-D_{-i, m, r}\right)\right]\right. \\
\left.+(1-\alpha)\left[\lambda D_{i, s, n r}+(1-\lambda) D_{i, m, n r}\right]\right\}
\end{array}
$$

We can now characterize the sequential equilibrium of the game. The proof of the following proposition is demonstrated in Appendix A.

Proposition 2.1. When the share of sophisticated individuals, $\lambda$, is larger than $\frac{1}{2-\alpha}$, there exists a Non-Shrouded equilibrium in which governments systematically take mitigation measures. On the contrary, when the share of myopes, $1-\lambda$, is larger than $\frac{1}{2-2 \alpha}$ there exists a Shrouded equilibrium in which governments systematically avoid mitigation.

Figure 2 illustrates the existence of these equilibria. Indeed, solving the above game involves considering several cases. Namely, (i) when the migration cost $c$ is larger than both mitigation gains $m_{i}$, and the net disaster cost $\hat{p}-m_{i}$; (ii) when the migration cost is larger 
than mitigation gains, but not the net disaster cost; (iii) when the migration cost is smaller than both mitigation gains, and the net disaster cost; (iv) when the migration cost is smaller than mitigation gains, but not the net disaster cost.

Red lines in Figure 2 depict, for each of these cases, the shares of sophisticated and residents individuals, $\lambda$ and $\alpha$, for governments to be indifferent between preparing and not preparing for natural disasters. The area above each line depicts situations in which the government prefers to provide mitigation. Respectively, the area under each line depicts situations in which the government prefers to shroud risks by not taking mitigation measures.

The area under the lower plain red line in Figure 2, $S$, represents a Shrouded Risks Equilibrium in which local governments decide to systematically not take mitigation measures to avoid disclosing their latent jurisdiction's dangers to myopic land consumers. Uninformed agents adversely sort in riskier location and the anticipated rent $p$ paid by these uninformed individuals does not capture the actual costs, $p+\hat{p}$, of living in a place that shrouds its liabilities.

The area above the higher plain red line in Figure 2, $U$, represents an Unshrouded Risks Equilibrium in which local governments decide to systematically take mitigation measures as not doing so would put them at a competitive disadvantage. Note that, the larger the share of residents, $\alpha$, the larger must be the share of informed individual, $\lambda$, for a government to systematically invest in mitigation.

Corollary 2.2. In particular, when the population is only made of non-residents (i.e., $\alpha=0$ ), governments implement (avoid) mitigation measures if more (less) than half of the population is sophisticated. Respectively, when the population is only made of residents, it is never in the interest of the government to implement mitigation measures.

In other words, high levels of resident population, $\alpha$, require high levels of informed individuals, $\lambda$, for governments to take mitigation actions. In a real-world situation, these residents could be local homeowners, who are generally less mobile, possibly bonded by a mortgage, and responsible for the modification of their own infrastructures ${ }^{14}$. Following a

\footnotetext{
${ }^{14}$ Note that, between 2010 and 2018, homeowners were present in approximately $74 \%$ of all occupied
} 
Figure 2: Depiction of the Shrouded and Unshrouded Equilibria

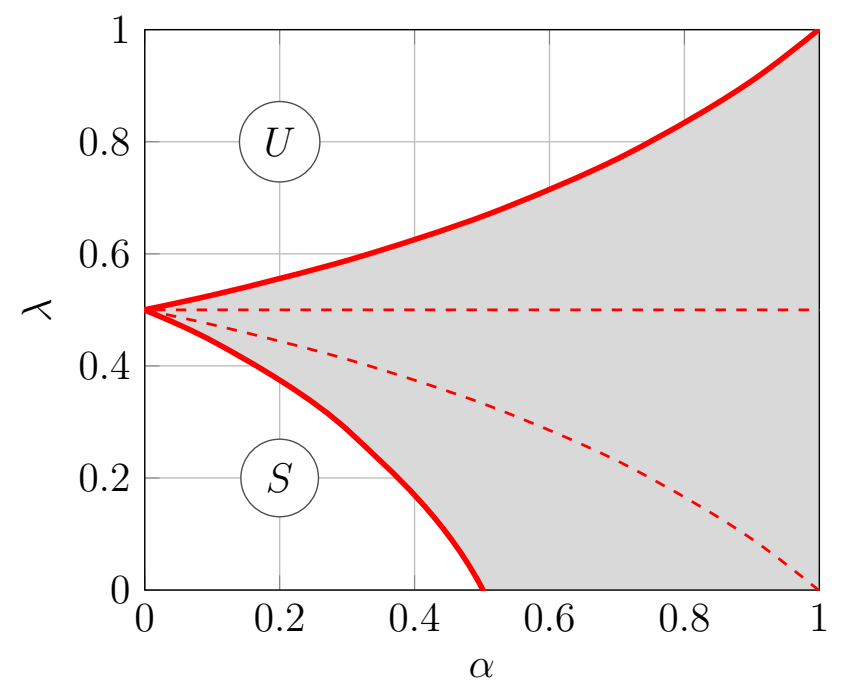

Note: Red lines correspond to different subcases detailed in Appendix A. From top to bottom: (i) when the migration cost is larger than both mitigation gains, and the net disaster cost; (ii) when the migration cost is larger than mitigation gains, but not the net disaster cost; (iii) when the migration cost is smaller than both mitigation gains, and the net disaster cost; (iv) when the migration cost is smaller than mitigation gains, but not the net disaster cost. The upper blank area designates the Unshrouded $(U)$ equilibrium, while the lower blank area depicts the Shrouded $(S)$ one.

natural disaster, visitors (i.e. renters, tourists, secondary homeowners) are more likely to move first. To replace this leaving population, it is then in the best interest of local officials to continue shrouding their jurisdictions' liabilities if prospective future residents are unaware of the risks.

\subsection{Discussion}

This set-up naturally makes several simplifying assumptions. Hereafter, I discuss three of them. First, having individuals make only a location decision, I disregard the possibility for them to vote in ballots rather than with their feet. Second, the model does not address the possibility for sophisticated individuals to invest in private mitigation. Finally, by assuming that local governments might not invest in preparation measures to hide the latent dangers to prospective investors, I presume that local officials are a priori aware of the possibility of mitigation measures.

First, could homevoters petition their representatives in adopting protective measures? housing units (Census Bureau). 
It is possible that the affected populations did not know their government could develop a mitigation plan and learn it through media reports. In this case, they could indeed petition their local officials for action. More generally, when a disaster receives increased media attention, the political response is likely to become a salient issue (Besley and Burgess, 2002). Therefore, increased media coverage in places hit by the disaster is likely to foster mitigation action.

That being said, this political accountability approach should be considered with care. Indeed, it is not clear that resident voters respond to disaster preparedness - as opposed to disaster relief (Healy and Malhotra, 2009). Indeed, benefits from disaster preparedness are less observable and generally less immediate. For instance, between 2010 and 2018, mitigation projects undertaken under the Hazard Mitigation Grant program took on average one year and a half before being initially approved, and almost four extra years before being closed. Preparation to future disasters is also more complicated to evaluate, as voters usually lack a proper counterfactual situation to assess the policy. On the contrary, disaster relief measures lead, in general, to more instantaneous, clear-cut, measurable gains that easily allow myopic voters to reward or punish their local officials.

Second, could sophisticated residents invest in private mitigation to protect themselves? Yes, but it is not clear how the private mitigation decision relates to the public one. In particular, if private mitigation acts as a substitute to public mitigation, the model's predictions remain unchanged - a risk-averse individual will prefer, conditional on potential migration costs, to locate where he benefits from the additional, costless, protection of public mitigation. However, this would also be assuming that individuals value any additional unit of mitigation similarly. For instance, would one be willing to invest in a personal tailor-made tornado safehouse, if his jurisdiction has already provided him one? Studying how risk aversion and the desire for preparation are affected by the knowledge, or experience, of a natural disaster, requires further hypothesis which are, although very interesting, beyond the scope of this paper ${ }^{15}$.

\footnotetext{
${ }^{15}$ Note that while the literature largely considers that risk aversion is constant over time (Stigler and Becker, 1977), there is a debate on whether repeated negative experiences pushes individuals towards to more riskaverse (Jakiela and Ozier, 2019; Malmendier and Nagel, 2011; Brown, Montalva, Thomas, and Velásquez, 2019), or more risk-prone behaviors (Eckel, El-Gamal, and Wilson, 2009; Voors, Nillesen, Verwimp, Bulte, Lensink, and Van Soest, 2012; Callen, Isaqzadeh, Long, and Sprenger, 2014).
} 
Finally, this model assumes that local governments are ex-ante aware of the possibility to provide costless mitigation, and voluntarily choose not to prepare as it would signal the risks to unsuspecting residents. Here, a possible pitfall is that local officials may not be sophisticated, and learn about the mitigation possibilities in the news. In this case, local governments would avoid mitigation measures simply because they are unaware of them. Fortunately, some federal mitigation programs in the United-States require the granting authorities to notify eligible applicants. How to measure 'enlighten' mitigation efforts is, ultimately, an empirical question.

\section{Natural Disasters and Mitigation Policies in the US}

\subsection{How to measure mitigation efforts?}

Measuring local governments' mitigation efforts is challenging. In particular, it is difficult to identify a common mitigation policy applying to all local governments in the United States. Local governments' finances neither disclose the details of local initiatives, nor the location of the projects. Most of all, it is complicated to disentangle the true will for mitigation of budget-constrained administrations from other unobserved policies.

In that respect, the Hazard Mitigation Grant (HMG) program from FEMA provides a unique setting for capturing real mitigation efforts. First of all, it is only available to local administrative entities. The State is required by law to let these local administrations know they are entitled to apply to this program. Second, it is not as competitive as the other mitigation grants proposed by FEMA ${ }^{16}$. The HMG program's eligibility rules are more lenient, and the rejection rate is very low ${ }^{17}$. This reduces the risk of federal selection of the project. Third, mitigation projects are largely financed by FEMA. The rest is shared between non-federal entities. Local governments' participation in the project cost is typically smaller than $25 \%$ of the project's cost. Finally, local governments are required to apply within 12 months following a major disaster, allowing me to associate the mitigation decision with the corresponding level of information circulation. In the following paragraphs, I review the

\footnotetext{
${ }^{16}$ Such as the Pre-Disaster Mitigation Grant, the Flood Mitigation Assistance program.

${ }^{17}$ Between 2010 and 2018, about 2\% of HMGP applications were downturned by FEMA.
} 
historical set-up and the details of the Hazard Mitigation Grant program's procedure.

\subsection{Historical and Institutional Set-up}

Since 1978, the Federal Management Emergency Agency (FEMA) centralizes most of the emergency competencies previously shared between several federal departments. The agency is under the direct authority of the President of the United States. The 1988 Stafford Act gives the President the authority to issue Emergency or Major Disaster declarations, which allow federal intervention. With the end of the Cold War, funds allocated to disaster response started to benefit the preparation for non-nuclear hazards. The 1990's denuclearization treaties and the Great Flood of 1993 (320,000 squared miles flooded) fostered further political action in that sense. The Volkmer Amendment of December 1993 increased FEMA funds for hazard mitigation or relocation assistance and increased from 50 to $75 \%$ the federal subsidy to mitigation projects. By the mid-'90s, the agency's primary objective was officially to build resilient communities, away from hazard-prone areas.

In October 1997, the Clinton administration launched the program 'Project Impact', supported by FEMA. The goal was to build resilient communities through public-private partnerships. Three years later, the Disaster Mitigation Act amended the Stafford Act to include a program of technical and financial assistance designed to foster pre-mitigation disasters. However, it has been claimed that both policies have had a relatively small impact owing to the difficulty for federal governments to compel local governments to engage in mitigation efforts (Sylves (2019)). That being said, FEMA remains by far the most important agency for funding hazard mitigation grants and loans. Since 2003, and in the context of the war on terror, the Department of Homeland Security is in charge of the Federal Emergency Management Agency.

\subsection{FEMA's Hazard Mitigation Grant Program}

A Presidential Declaration of Disaster (PDD), as defined by the Stafford Act of 1988, identifies counties eligible for federal assistance. Between 2010 and 2018, 2.841 counties have received a PDD. The Hazard Mitigation Grant (HMG) is available for local governments or 
state agencies after a PDD is issued for their county. Contrary to other mitigation grants program, the HMG program is not per se a federal program. It is rather a state and local program for which FEMA determines the total amount of available funds and ensures basic eligibility rules are respected. The total amount available under the HMG program is determined as a percentage of the total FEMA funds allocated to a State for a declared disaster ${ }^{18}$.

Within 30 days after a disaster is declared, State emergency management agencies must send FEMA a letter of intent indicating whether or not the State will request HMG funds. Local governments and state agencies interested in applying to HMG funds must write an application project for the properties they think need to receive mitigation against potential future risks. Local governments are eligible to the Hazard Mitigation Grant Program as long as the county to which it belongs has received a Presidential Declaration of Disaster, unconditional on having been directly hit by the disaster or not. Individuals and businesses are not eligible for HMG funds, but they may request their local representatives to apply on their behalf.

State emergency management agencies then review applications for general eligibility, project cost-effectiveness, feasibility, and environmental compliance. They are also in charge of prioritizing projects in case the total amounts requested would be higher than the total amount available under HMG fundings. Later we show that media coverage at the ZIP code level does not matter for the State emergency management agencies ranking. All applications must be submitted to FEMA by State emergency management agencies within the 12 months following a Presidential Declaration of Disaster. FEMA then officially selects projects following State's agency priorities subject to the total amount allocated in HMG funds. Federally-obligated share amounts 75 percent of the total project amount. The remaining 25 percent is split between non-federal entities.

When awarded with an HMG funding, sub-applicants (i.e., local governments or state agencies) are notified by their State emergency management agency and FEMA. Mitigation

\footnotetext{
${ }^{18}$ The sliding scale formula for the determination of HMG funds (also called 'lock-in' amount) is the following: $15 \%$ of the first 2 billion dollars, $10 \%$ of the next 8 billion, and $7.5 \%$ of the next 25.33 billion. If the State for which the disaster is declared has an enhanced plan of mitigation, total funds can go up to $20 \%$ of the first 35.33 billion dollars provided for the disaster under the other FEMA programs.
} 
work may only start after receiving this notification. Project monitoring is undertaken by both the State emergency management agency and FEMA. In particular, the grant recipient must send quarterly progress reports to FEMA regional offices. Upon the project's closure, State emergency management agency staff visits the project's site to ensure conformance with the previously agreed application's scope of work.

\section{Empirical Strategy}

The empirical strategy consists in comparing (within counties having received a Presidential Disaster Declaration) areas where information circulation related to storms is high to areas where it is low, conditional on being hit by a storm or not. I am primarily interested in the number of mitigation projects implemented under the HMG Program. To proxy for information circulation and avoid endogeneity issues, I construct a measure of congruence between media markets and storms' spatial extent inspired by Snyder and Strömberg (2010). This measure is essentially a weighted average fit of the newspapers' markets to storms' spatial extents. My main identifying assumption is that the match between media markets and storm extents is haphazard. In other words, I expect the socio-economic determinants that shape media markets to be unrelated to the topographical and climate factors that would explain the exact spatial extent of a given natural disaster at the ZIP code level. I explore more thoroughly this assumption in what follows.

\subsection{Databases}

Newspapers Circulation — I collect data on newspapers' sales at ZIP code level ${ }^{19}$. This data was kindly provided by the Alliance for Audited Media (AAM), formerly known as the Audit Bureau of Circulations (ABC) for the years 2010-2018. AAM independently verifies and collects print and digital circulation of most newspapers in the U.S. and Canada. I have circulation data for 2,403 newspapers from 2010 until 2018. Newspaper's circulation appears to have dropped by $31 \%$ during this period. Such a huge decrease is in line with the

\footnotetext{
${ }^{19}$ ZIP code areas are geographically defined by ZCTAs. ZCTA stands for ZIP Code Tabulation Area. It is a geographical representation of ZIP code areas computed by the Census Bureau. There are 33,144 ZCTAs covering the contiguous United-States, Alaska, Hawaï and Porto Rico.
} 
figures already published in the media and by some think tanks. For each newspaper-ZIP code, I compute the average monthly circulation in a given year. I then compute the market share of each newspaper in each ZIP code, which I will use for my fit measure. Most ZIP codes $(62.9 \%)$ have a normalized Herfindahl index above .25 - seemingly indicating a highly concentrated market ${ }^{20}$.

Storms extent — Storm data is extracted from the Storm Events Database, which is maintained by the National Oceanic and Atmospheric Administration (NOAA). This database contains records on significant weather events 'having sufficient intensity to cause loss of life, injuries, significant property damage, and/or disruption to commerce'. It is the same data NOAA uses for its monthly Storm Data Publication. I collect this storm data for the years 2010-2018. I am able to locate each episode both in time and space and thus associate each event to a given ZIP code-year. The database includes multiple subtypes of extreme climate events, which I sort in 3 categories: floods ( $42 \%$ of all events), wind-related events (tornados, thunderstorm, tropical storms, etc. : $34.4 \%$ of all events), and hail (18.6\% of all events). The remaining $5 \%$ are mostly unclassifiable events (lightenings, dust flows, avalanches, etc.). For simplicity reasons, I will be referring to the wind-related events as 'storms.' Note that an episode might not be exclusive of a given subtype. Sometimes, the same episode is associated with a tornado, a thunderstorm, or flash floods depending on its evolution in time and space. The main reason for focusing on storms rather than floods is because the spatial extent of a storm is typically exogenous, as opposed to the spatial extent of floods which is correlated with a multitude of local patterns (i.e., the geomorphology of the terrain, the degree of impervious soil, previous mitigation actions, etc.). The Storm Event Database also informs us about the potential damages of an event: the number of direct and indirect deaths or injured individuals, the property, and crop damages. Most storm events in my sample (97.5\%) do not imply deaths nor injuries. Nevertheless, more than half $(56.4 \%)$ of the ZIP codes hit by at least a storm in a given year display some property damages. The

\footnotetext{
${ }^{20}$ This latter statistic shall be considered with caution, especially because newspapers may not be competing in the type of news they report. Moreover, even though ZIP codes are pretty small spatial units (the average land surface is 86 square miles - the equivalent of Beaumont city, Texas - and the median land area is 35 square miles - the equivalent of Manhattan, New-York), newspapers might not necessarily be competing spatially either.
} 
median cumulated property damage estimate for these areas is $\$ 10,000$. More generally, $90 \%$ of the ZIP codes hit by at least a storm in a given year and who suffered property damages display cumulated property damage under $\$ 175,000$. The other climate-related variables (rainfall, wind speed, snowfall, ...) are extracted from the Integrated Surface Database's daily summary files and the U.S. Historical Climatology Network, both hosted by NOAA.

Mitigation Projects — I gather information on HMGP mitigation accepted projects, which are publicly provided by FEMA. Thanks to a Freedom of Information Act request made to the Department of Homeland Security (2019-FEFO-00367), I complete this dataset with the denied projects. Very few projects (about $2 \%$ of the whole sample) were downturned. This is explained by the fact that the HMGP is not a competitive program (contrary to other mitigation grants provided by FEMA), and because eligibility rules are quite lenient. Among other things, I am able to observe which type of mitigation action was undertaken (wind retrofitting, structural elevation, property acquisition, etc.), which PDD and which extreme climate event is associated to the project, which type of properties are targeted (public or private, residential, owned or rented, etc.), the project's amount, the program's fiscal year, and the location's ZIP code. Most mitigation projects (68.7\%) are associated with a storm event. Among all mitigation actions, the development of saferooms (almost $40 \%$ of mitigation projects) appears to be preferred. When the associated extreme climate event is a storm, this statistic goes up to $54.4 \%$. In general, investments in structural mitigation infrastructures represent about $60 \%$ of all mitigation actions. Among non-structural mitigation investments, acquisition of lands and damaged properties appears to be the preferred option. All the storm mitigation projects and the vast majority $(82.2 \%)$ of mitigation actions, in general, are subsidized through the HMG program described in the previous sections. Table C.1 of the Appendices summarizes the different types of mitigation projects undertaken during the period. Percentages in parentheses are shares to the total. Figure C.2 in the Appendices displays the location of mitigation projects.

Additional Databases — Last but not least, I compile ZIP code-level social and economic data from the Census of Population and the Zillow website. I have information on 
the age distribution, the racial composition, educational attainment, employment status, employment sectors, the number of housing sales, etc. The building permits data comes from the Building Permits Survey, which is also extracted from the Census website. The spatial unit is the individual permit-issuing jurisdiction. Most of them are municipalities; the remainder is counties, townships, or unincorporated towns. I have information on the number and the value of building permits emitted for both new residential units and for residential units' repairs. I will focus on the permits for new residential units. In the case of building permits emission, I aggregate my media coverage data at the permit-issuing jurisdiction level in order to approximate the average media coverage of natural disasters in these regions. Figure C.3 in the Appendices displays the location of building permits for new residences.

\subsection{Media coverage measure}

My media coverage measure is a weighted average of the fit between natural disasters spatial extent and newspaper markets:

$$
\text { Coverage }_{i t}=\sum_{j} \text { Fit }_{j t} \times \text { MarketShare }_{i j t}
$$

The Fit measure is computed as the ratio between the number of copies of newspaper's $j$ distributed in a zone hit by a natural disaster in year $y$, to the total number of copies distributed by this newspaper in this same year. Market Share is simply the number of copies of newspaper $j$ that circulate in a given ZIP code in a given year to the total circulation of newspapers in this same ZIP code and in this same year. While $F i t_{j t}$ is intended to capture the propensity of a newspaper to report about storm events in a given year, MarketShare ijt $_{\text {. }}$ is intended to capture how much of this propensity reaches a given ZIP code. This implies that if there is only one newspaper circulating in ZIP code $i$, MarketShare ijt $_{\text {is }}$ equal to 1 , and then Coverage $i t$ is equal to Fit . $_{j t}$. Note that Coverage is not embedding newspapers' penetration in ZIP code (i.e., the share of households receiving a given newspaper), which could be correlated with social characteristics like wage or education.

As said earlier, the main identifying assumption is that the socio-economic determinants 
that shape media markets are unrelated to the topographical and climate factors that would explain the exact spatial extent of any given natural disaster, such that the resulting match between these two aspects is haphazard. This is a pretty weak assumption to make to the extent that communities have little control over local meteorological variations. I provide a graphical explanation of this statement in what follows.

To understand how Coverage varies at the national level, first, consider Figure 3, which represents the total number of storm events identified at the ZIP code level between 2010 and 2018. What the media refers to as the "Tornado Alley" and the "Dixie Alley" are clearly visible here. Although these areas have no clear-cut borders, they both extend in the greater mid-west plains along with the Rocky and the Appalachian Mountains, respectively. Tornado outbreaks are more frequent and more violent in theses regions where the hot, humid air drifting up north from the equator meets the cold and dry mountain air. These two alleys display similar characteristics both in the frequency and intensity of the outbreaks. However, they differ in terms of related casualties. Indeed, Dixie Alley storms are often hidden by other meteorological phenomenons such as heavy rains. They also tend to happen more at night and on hilly terrain. These combined factors end up causing more damages and injuries. Moreover, Figure 3 informs us of the propensity of coastal storms, which clearly appears to be higher along the eastern shoreline. These storms are generally referred to as hurricanes, typhoons, or cyclones. Hurricanes are specific storms that form above the Atlantic or the Pacific ocean. The warm air above the ocean's surface rises, causing lower air pressure below. The air from the surrounding higher pressure areas flows in, gets warmer, rises above too, and so on. Because of Earth's axis of rotation, hurricanes in the northern hemisphere spin counter-clockwise, thereby moving west-north-west. Additionally, the Gulf Stream in the Atlantic is a constant source of warmth that triggers their formation and maintenance. This is why they often encounter the U.S. eastern shores when they form in the Atlantic ocean while drifting away from California coastline when they form in the Pacific. The need for warm air above the ocean surface is also why increasing temperatures caused by climate change are likely to foster the creation and intensity of those hurricanes.

Newspapers are published in cities mostly located in the north-east of the United-States (see Figure C.1 of the Appendices). Newspapers' copies then circulate all over the country, 
Figure 3: Storms Distribution (2010 - 2018)

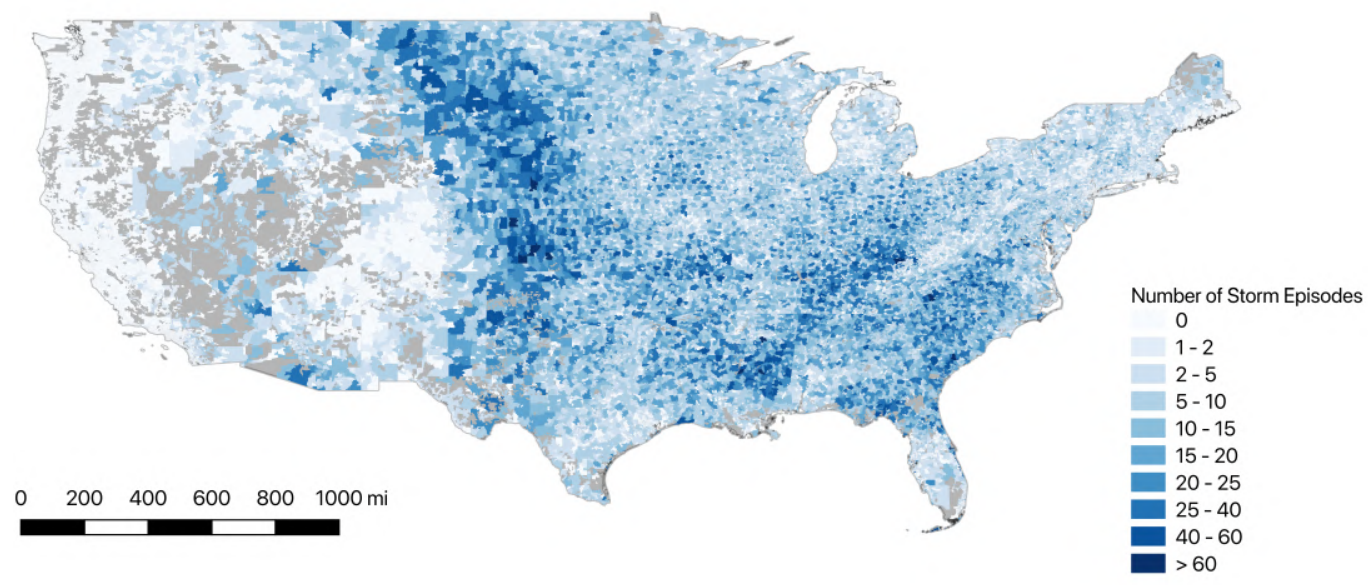

Notes: Spatial distribution of storm episodes by ZIP code areas between 2010 and 2018. In this figure, storms were summed by ZIP code over the period 2010-2018. Tornado Alley is depicted by the dark blue band east of the Rocky Mountains. Dixie Alley Data is the thiner blue band west of the Appalachians. Information on the location of storms was extracted from the NOAA Storm Events Database. Gray zones correspond to unpopulated areas.

Figure 4: Average Monthly Newspaper Circulation (2010 - 2018)

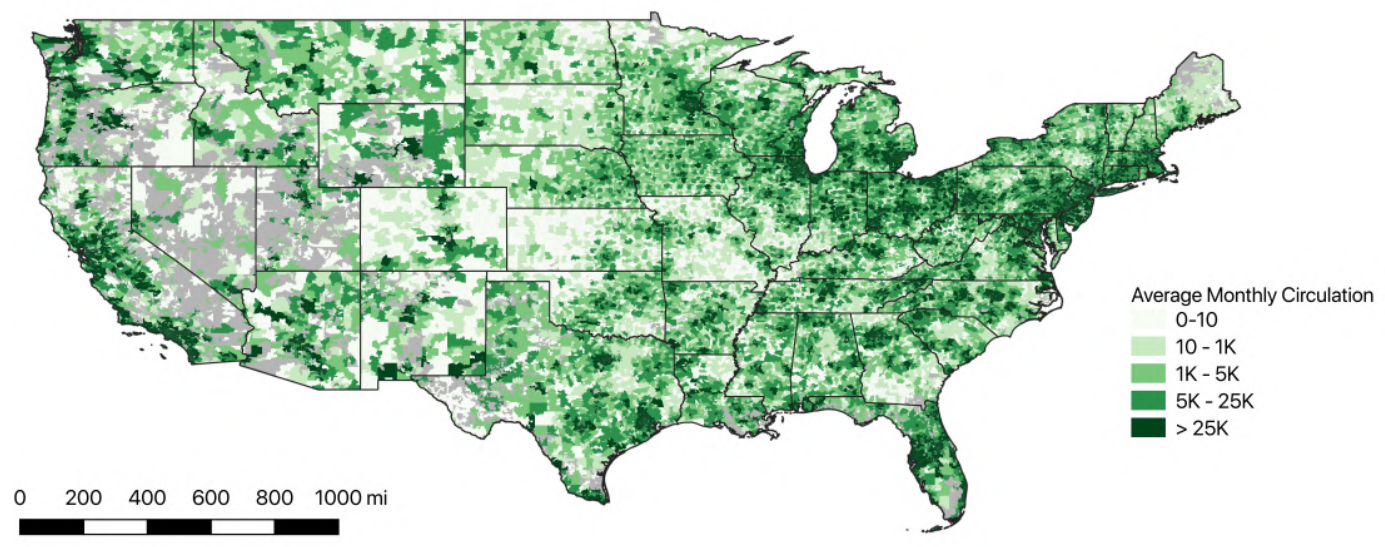

Notes: Spatial distribution of newspaper copies by ZIP code areas between 2010 and 2018. In this figure, monthly circulation was averaged per ZIP code over the period 2010-2018. This information was graciously provided by the Alliance for Audited Media (AAM). Gray zones correspond to unpopulated areas. 
Figure 5: Media Coverage of Storms (2010 - 2018)

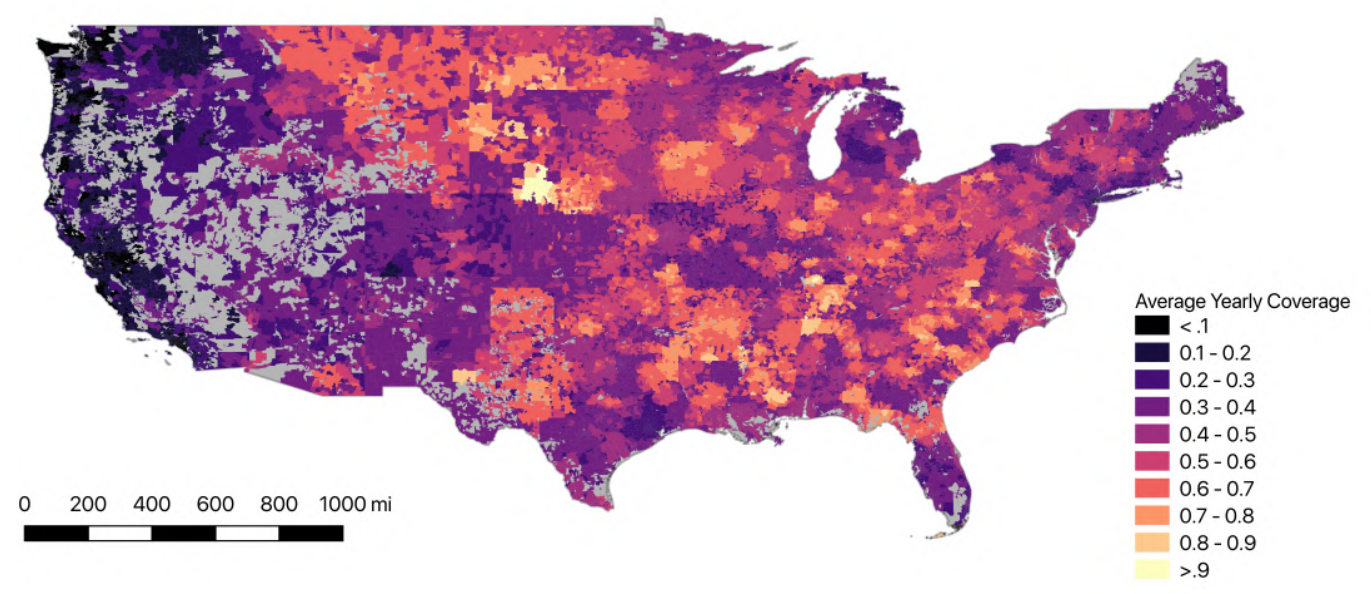

Notes: Spatial distribution of Coverage by ZIP code areas between 2010 and 2018. Coverage was computed following equation 1. It corresponds to the average Fit between storm extents and newspaper circulation. In this figure, Coverage was averaged per ZIP code over the period 2010-2018. Information on was graciously provided by the Alliance for Audited Media (AAM). Gray zones correspond to unpopulated areas.

primarily to urban areas, as represented by Figure 4. When we interact with this information the storm distribution data, we can display the average media Coverage of storms as depicted by Figure 5. If newspaper markets were uniform, we would observe an image similar to the storm distribution. However, the main storm zones described earlier are clearly less apparent here. Regions having suffered storm events do not necessarily display high media coverage (e.g., in western Kansas), while zones apparently safer may display high coverage ratios (e.g., Pennsylvania). A closer inspection also allows us to see how Coverage varies greatly within states, at a very local level. Indeed, apart from some states west of the Rocky Mountains, almost every region displays Coverage of all degrees.

To describe how Coverage works at such a local level, first consider Figure 6. It shows newspaper $j$ 's market and zones that were hit by one or many storm events. The lighter are the red regions, the lower is $j$ 's circulation. Clearly, this newspaper's fit would have been lower if the storm extent had been lagged by one ZIP code unit on the left, and higher if it had been lagged by one ZIP code unit on the right. If we assume that the medium red areas display a circulation twice higher than the light red areas, and the dark red areas display a circulation three times higher than the light red areas, then the $F i t_{j, t}$ is about $47.7 \%$. 
Figure 6: Example of newspaper Fit decomposition

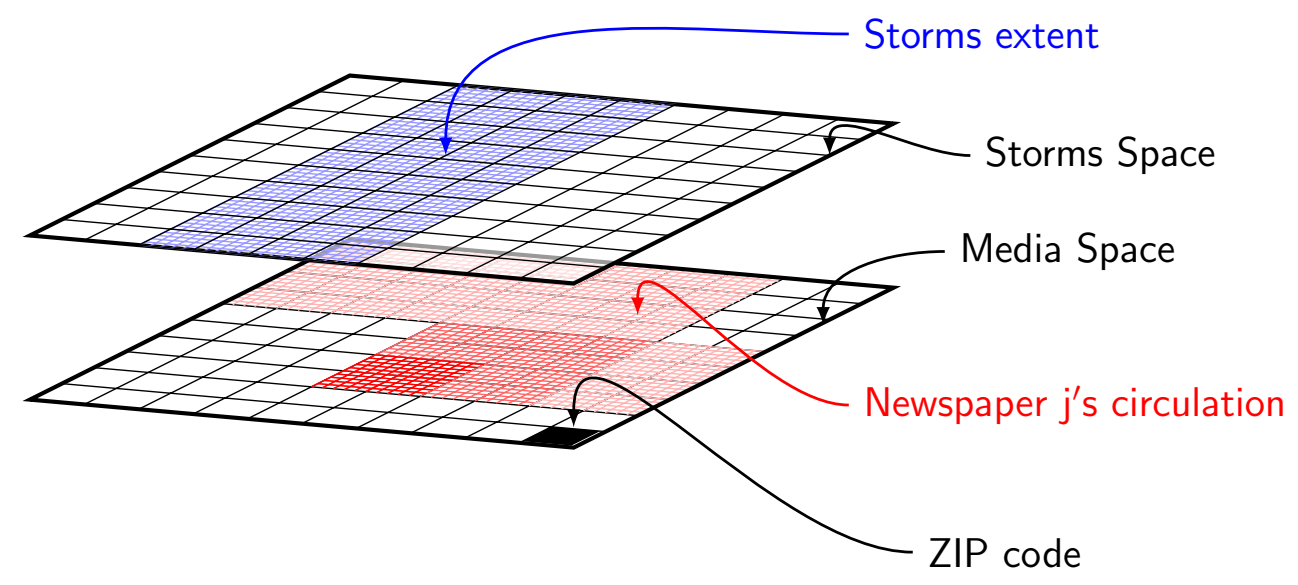

Notes: Spatial decomposition of the Fit between storms extent and newspaper circulation. Blue areas correspond to the extent of storms over ZIP code areas in a given year. Red areas correspond to newspaper $j$ 's circulation in the same region, in the same year. Darker red ZIP codes depict areas where newspaper $j$ 's circulation is stronger. The $F i t$ between newspaper $j$ and storms extent is the ratio between the number of copies circulating in ZIP codes hit by storms and the total number of newspaper $j$ 's copies in circulation in a given year.

The large dispersion in both the extent and the frequency of storms and the dispersion of newspaper markets ensure the high variation of Coverage at the local level.

The main reason for using this Coverage measure is that the propensity of a given newspaper to report about a given natural disaster increases with the number of readers who were impacted by this disaster. Several studies have already described such a relationship. When the fit between media markets and congressional jurisdictions is high, readers are more likely to be exposed to news related to their local politicians (Snyder and Strömberg (2010)). Similarly, when the fit is high between media markets and judicial jurisdictions, readers are more likely to be exposed to news related to court sentencing (Lim, Snyder, and Strömberg (2015)). The rationale driving this assumption is that newspapers report noteworthy news, that is to say, news their readers are interested in. In other words, major newspapers, like the New-York Times, are less likely to report about small tornado events that only hit $1 \%$ of their readers, but they are more likely to report about major hurricane events. Similarly, a small local newspaper, like The Milford Times (Milford, MI), is more likely to report about an extreme climate event hitting their readership than to write about an equivalent event located in Hot Springs, Arkansas. 
Table 1: Effect of Newspaper Coverage of Storms

\begin{tabular}{lccc}
\hline & \multicolumn{3}{c}{ Articles about storms } \\
& $(1)$ & $(2)$ & $(3)$ \\
\hline \multirow{2}{*}{ Newspapers' Fit } & $0.699^{* * *}$ & $0.694^{* * *}$ & $0.710^{* * *}$ \\
& $(0.232)$ & $(0.232)$ & $(0.234)$ \\
\hline Weather Controls & $\mathrm{N}$ & $\mathrm{Y}$ & $\mathrm{Y}$ \\
Socio-Economic Controls & $\mathrm{N}$ & $\mathrm{N}$ & $\mathrm{Y}$ \\
Observations & 3,753 & 3,753 & 3,753 \\
$R^{2}$ & 0.42 & 0.42 & 0.42 \\
\hline
\end{tabular}

Note: The dependent variable is the number of articles mentioning 'storm' in its headline $(\mu=1.47 ; s=.06)$. The unit of observation is a newspaper's market by year. All regressions include year and newspaper fixed effects and standard errors are robust to heteroskedasticity. ${ }^{*}: \mathrm{p}<0.1$; $^{* *}: \mathrm{p}<0.05 ;{ }^{* *}: \mathrm{p}<0.01$. Standard errors are reported in parentheses.

To test for this relationship, I scrapped news articles mentioning at least the word 'storm' in its headline and 'weather' in their main body from the website Newslibrary.com. I was able to associate journals' names to their circulation data for 417 newspapers. Table 1 presents the results of regressing the number of articles about storms against $F i t_{j t}$. Column (2) and (3) include several controls that are likely to influence the coverage of storms. These regressors are related to the local weather (extreme precipitations, winds, and temperatures), economic and social conditions (log population, the share of population above 60 years old, educational attainment, unemployment). Table 1 informs us that a strong positive relationship exists between the number of articles published about storms and my variable of interest, the newspapers' fit to storm extents. Indeed, when the fit between storms and newspaper markets is perfect, newspapers tend to publish more articles about storms (about .7 more). In other words, the number of articles reporting about storms increases by almost $47 \%$ of its mean when the fit between newspaper markets and storms increases from 0 to 1. This relation appears to be relatively robust to the introduction of the aforesaid controls and remains significantly different from zero at the 1\%-level in all specifications. Figure 7 presents a local polynomial depiction of this relationship. 
Figure 7: Relation between newspapers' Fit and the Number of articles mentioning storms

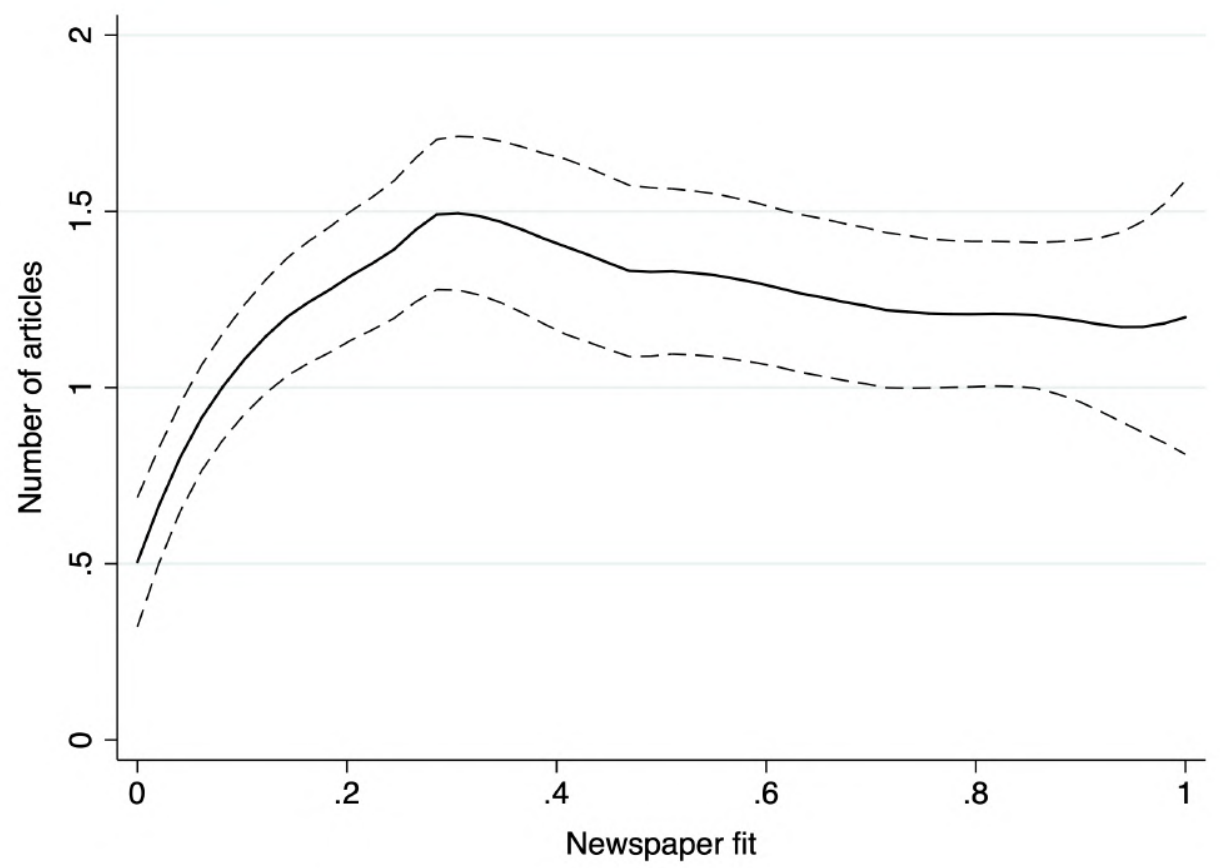

Note: Local polynomial fit of the relation between newspaper $j$ 's circulation and storms' spatial extents in $t, F i t_{j} t$, and the number of articles published by the mentioning 'storm' in its headline $(\mu=1.47 ; s=.06)$. The unit of observation is a newspaper's market by year. Dashed lines correspond to the $95 \%$ confidence interval bounds.

\subsection{Empirical design}

My main variable of interest is Coverage. In order to facilitate its interpretability, I center Coverage at its ZIP code mean. An increase in my treatment captures a positive information shock about storms with respect to the average amount of news a location receives about storms. I build on a reduced-form setting to analyze the impact of such information shock on local governments' mitigation initiatives when their county receives a Presidential Declaration of Disaster. My main empirical model studies the impact of Coverage on the number of mitigation projects undertaken under the HMGP conditional on being hit by a storm:

$$
\begin{gathered}
\text { Mitigation }_{i t}=\beta_{1} \cdot \text { Coverage }_{i t}+\beta_{2} \cdot \text { Storm }_{i t}+\beta_{3} \cdot\left[\text { Coverage }_{i t} \times \text { Storm }_{i t}\right] \\
+\delta \cdot X_{i t}+\alpha_{i}+\gamma_{c t}+\epsilon_{i t}
\end{gathered}
$$


where Mitigation is the number of mitigation infrastructures projects undertaken in a given ZIP code $i$ in year $t$. Storm is a dummy variable equal to one if the ZIP code has been hit by at least one storm in year $t$. The regression model includes ZIP code area fixed effects, $\alpha_{i}$, and county-year fixed effects, $\gamma_{c t}$. I match county and ZIP code areas with the amount of residential addresses located in a county. About $80 \%$ of all ZIP codes areas belong entirely to a single county, and more than $93 \%$ of all ZIP codes have at least $75 \%$ of their residential addresses identified in a single county, and less than 1\% have less than half of their residential addresses in a single county. Finally, $X$ is a vector of control variables, which I think could possibly impact both on media Coverage and the demand for Mitigation. These controls include information on (1) demographics (population, age, immigration, racial distribution, newspapers' readership); (2) income and education (household revenues, distribution by educational attainment); (3) labor composition (labor force, employment, sectors of employment); (4) weather (average temperatures, wind speed, and precipitations); and finally (5) the housing composition (number of housing units, sales, median value, the number of vacant units, occupied by their owner, with mortgage status, and the unit's age). The main descriptive statistics of these variables for the sample of counties having received a Presidential Declaration of Disaster are available in Tables C.2a to C.2c of the Appendices.

\section{Results}

\subsection{Main Results: Impact on mitigation initiatives}

Table 2 reports the impact of Coverage on the number of mitigation projects implemented under the HMGP. Columns (1) - (2) report the unconditional effect of Coverage, columns (3) - (4) the unconditional effect of Storm, and columns (5) - (6) report the interaction of both terms. The results indicate that both Coverage and Storm have a significant positive unconditional impact on the number of mitigation actions occurring at a given location. Yet, this effect appears to be mostly driven by the interaction term. It is quite substantial: conditional on being hit by a storm, a one standard deviation increase in Coverage increases the number of mitigation projects by $54 \%$ of its average. 
Table 2: Impact on mitigation initiatives

\begin{tabular}{|c|c|c|c|c|c|c|}
\hline & \multicolumn{6}{|c|}{ All Mitigation Projects } \\
\hline & $(1)$ & $(2)$ & (3) & (4) & $(5)$ & (6) \\
\hline Coverage & $\begin{array}{c}0.113^{* * *} \\
(0.042)\end{array}$ & $\begin{array}{c}0.114^{* *} \\
(0.049)\end{array}$ & & & $\begin{array}{l}-0.030 \\
(0.045)\end{array}$ & $\begin{array}{l}-0.054 \\
(0.060)\end{array}$ \\
\hline Storm & & & $\begin{array}{c}0.021^{* *} \\
(0.009)\end{array}$ & $\begin{array}{c}0.024^{* *} \\
(0.010)\end{array}$ & $\begin{array}{l}-0.003 \\
(0.010)\end{array}$ & $\begin{array}{l}-0.003 \\
(0.011)\end{array}$ \\
\hline Coverage $\times$ Storm & & & & & $\begin{array}{c}0.443^{* * *} \\
(0.131)\end{array}$ & $\begin{array}{c}0.486^{* * *} \\
(0.147)\end{array}$ \\
\hline ZIP Code FE & $\mathrm{Y}$ & $\mathrm{Y}$ & $\mathrm{Y}$ & $\mathrm{Y}$ & $\mathrm{Y}$ & $\mathrm{Y}$ \\
\hline County-year FE & Y & Y & Y & Y & Y & Y \\
\hline All Controls & $\mathrm{N}$ & Y & $\mathrm{N}$ & Y & $\mathrm{N}$ & Y \\
\hline Baseline Population & $\mathrm{N}$ & Y & $\mathrm{N}$ & Y & $\mathrm{N}$ & Y \\
\hline Observations & 82,360 & 82,360 & 82,360 & 82,360 & 82,360 & 82,360 \\
\hline$R^{2}$ & 0.57 & 0.57 & 0.57 & 0.57 & 0.57 & 0.57 \\
\hline
\end{tabular}

Note: Coverage is centered at its mean $(\mu=0 ; s=0.101)$. The outcome variable includes the total number of properties having received mitigation against future storms under the HMG program between 2010 and $2018(\mu=0.083 ; s=0.975)$. $*$ : p $<0.1$; $* *:$ p $<0.05 ; * * *:$ p $<0.01$. Standard errors are clustered at the county level and reported in parentheses.

The magnitude of these latter results indicates that local governments' decision to take mitigation initiatives is very responsive to how the information about the risks in the jurisdiction circulates. Neither an increase above mean Coverage conditional on not experiencing a storm nor experiencing a storm at mean Coverage, has any significant effect on the number of mitigation projects. These results are consistent with the theory: jurisdictions affected by the storm remain virtually risk-free to investors in the absence of any information shock. In this case, local governments have fewer incentives to take mitigation actions. Note that the combination of these findings also implies that local governments are not incentivized to take mitigation action because local voters are updating their beliefs about storm risks. Indeed, in this case, experiencing a storm in the absence of news reports would affect the mitigation decision. 


\subsection{Design Validity}

Selection on covariates - A major identification concern would arise if pre-determined variables were to be correlated with either Storm or Coverage. Tables C.3a - C.3f present balance tests for more than 60 pre-treatment characteristics related to the local demography, labor, composition income and education levels, as well as housing markets. Tables C.3a C.3c investigate these correlations for Storm and Coverage, respectively; while tables C.3d C.3f look at these same correlations when following the main specification. All tables report means and standard deviations of the pre-treatment covariates in the last column.

Overall, these tests are quite reassuring. The Storm dummy is balanced across almost all characteristics, and the few unbalances are both economically and statistically insignificant above the 10\%-level when controlling for county-year fixed effect. As in Snyder and Strömberg (2010), and Lim, Snyder, and Strömberg (2015), I find that my Coverage measure is mechanically correlated with changes in log population, the share of elderlies, and the share of the population employed in the agricultural sector ${ }^{21}$. These correlations are expected as a newspaper's market share tends to be lower in densely populated areas, where competition for readership is strong. Additionally, regions with a lower density of population also tend to be on average older and working more in the agricultural sector. Snyder and Strömberg (2010) argue that using the temporal variation in jurisdiction redistricting ${ }^{22}$ to include location fixed-effects mitigates the risk of omitted variable bias (OVB) related to population and location characteristics. However, in this case, using the temporal variation in storms' spatial extent does not fully alleviate this possibility. That said, controlling for baseline population removes most of the correlations with pre-treatments, as with the share of elderlies. Generally, my Coverage treatment is balanced across almost all characteristics, and only a couple of unbalances remain out of 61 covariates. Testing for the joint orthogonality of these variables against my treatment (and omitting a category when suited to avoid collinearity issues) returns an insignificant $\mathrm{F}$-statistic $\left(F_{56,1774}=1.25, p>0.1\right)$.

While these results are encouraging, I cannot fully exclude the risk of omitted variable

\footnotetext{
${ }^{21}$ Snyder and Strömberg (2010) and Lim, Snyder, and Strömberg (2015) control for the share of the rural area instead of the share of the population working in the agricultural sector.

${ }^{22}$ The treatment variable used in Snyder and Strömberg (2010) is a weighted average across newspapers of the share of readers belonging to a specific congressional district. It is computed at the county level.
} 
Table 3: Selection on unobservables

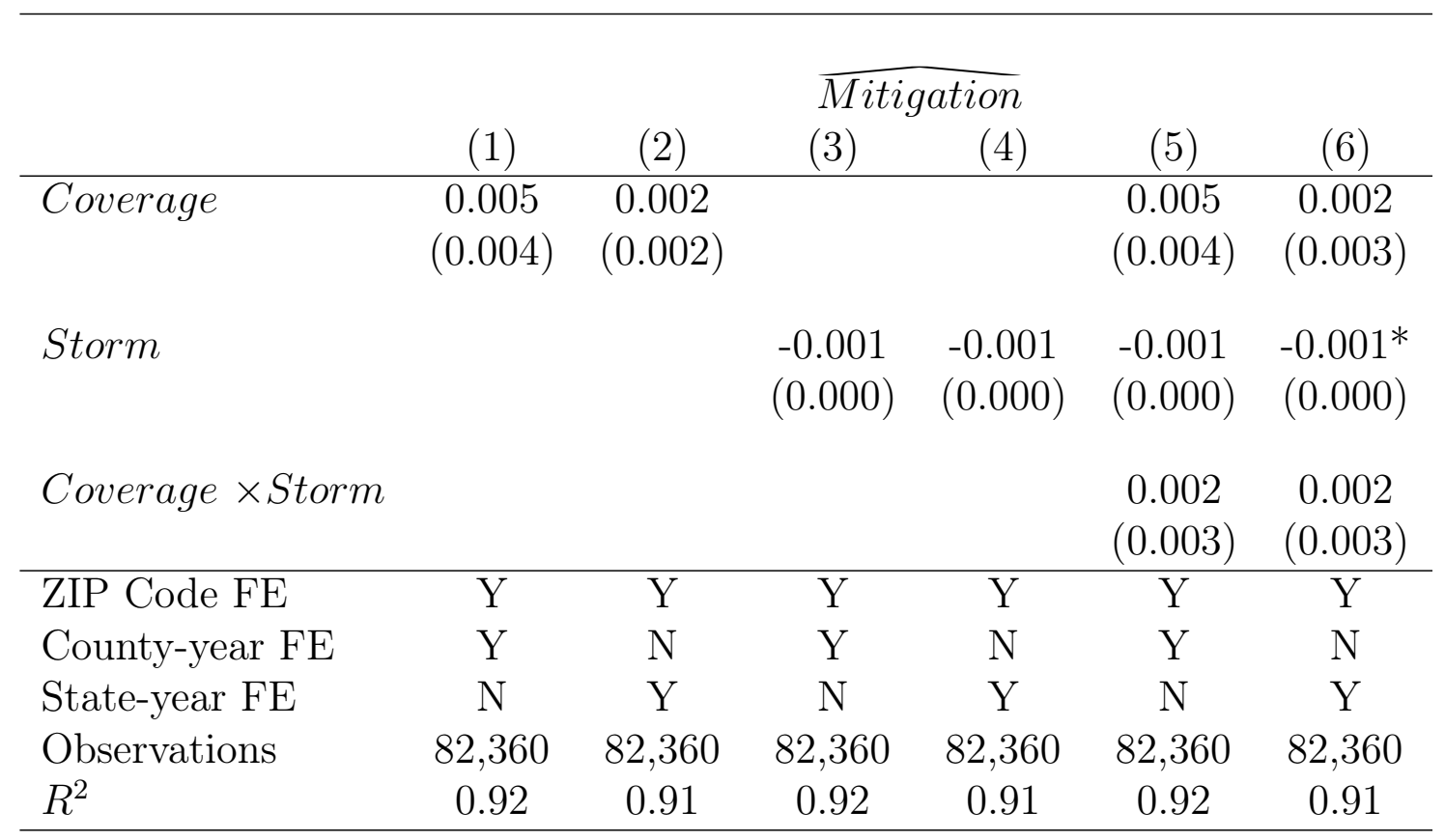

Note: Coverage is centered at its mean $(\mu=0 ; s=0.101)$. The outcome variable includes the total number of properties having received mitigation against future storms under the HMG program between 2010 and 2018, as predicted by observable charactistics $(\mu=.0745 ; s=0.091){ }^{*}: \mathrm{p}<0.1 ;{ }^{* *}: \mathrm{p}<0.05 ;{ }^{* *}: \mathrm{p}<0.01$. Standard errors are clustered at the county level and reported in parentheses.

bias. Following Altonji, Elder, and Taber (2005), I further infer the degree of selection on unobservable based on the selection on observables ${ }^{23}$. To this end, I study whether the variation of Mitigation predicted by observable characteristics (excluding location and region-year fixed effects), $\overline{\text { Mitigation }}$, is correlated with the variation of my main treatments, Coverage and Storm. I use the large set of covariates presented in Tables C.3a to C.3f, excluding a variable by category of regressors to avoid collinearity issues. Results are reported in Table 3. The high $R^{2}$ statistic indicates that almost all of the variation of $\overline{\text { Mitigation }}$ is indeed captured by location fixed effects. It is reassuring to see that there is little if no selection on these observables characteristics, which considerably alleviates the fear of cofounding factors.

Finally, the inclusion of the different categories of control variables in my main specification does not change the estimates significantly - which further mitigates the concern for

\footnotetext{
${ }^{23}$ This procedure is also followed by Lim, Snyder, and Strömberg (2015), who do not have any exogenous temporal variation in redistricting since they study judicial districts and that media markets are quite immobile through time
} 
Table 4: Placebo tests

\section{All Mitigation Projects}

\begin{tabular}{|c|c|c|c|c|c|c|}
\hline & \multirow{2}{*}{\multicolumn{2}{|c|}{ Lagged Outcome }} & & \multirow{2}{*}{\multicolumn{2}{|c|}{ Fake Treatment }} \\
\hline & & & Shuffled & Treatment & & \\
\hline & (1) & $(2)$ & $(3)$ & (4) & $(5)$ & $(6)$ \\
\hline \multicolumn{7}{|c|}{ Panel A: Unconditional Effects of Coverage } \\
\hline \multirow[t]{2}{*}{ Coverage } & 0.046 & 0.024 & -0.053 & -0.050 & 0.019 & 0.010 \\
\hline & $(0.037)$ & $(0.048)$ & $(0.052)$ & $(0.065)$ & $(0.033)$ & $(0.036)$ \\
\hline \multicolumn{7}{|c|}{ Panel B: Unconditional Effects of Storm } \\
\hline \multirow[t]{2}{*}{ Storm } & -0.008 & -0.012 & -0.007 & -0.007 & -0.004 & -0.007 \\
\hline & $(0.010)$ & $(0.012)$ & $(0.00$ & $(0.0$ & $(0.0$ & $(0.011)$ \\
\hline \multicolumn{7}{|c|}{ Panel C: Main Specification } \\
\hline \multirow[t]{2}{*}{ Coverage } & 0.074 & 0.058 & -0.046 & -0.046 & 0.001 & -0.004 \\
\hline & $(0.046)$ & $(0.058)$ & $(0.054)$ & $(0.070)$ & $(0.040)$ & $(0.044)$ \\
\hline \multirow[t]{2}{*}{ Storm } & -0.005 & -0.008 & -0.007 & -0.007 & -0.004 & -0.007 \\
\hline & $(0.010)$ & $(0.011)$ & $(0.009)$ & $(0.009)$ & $(0.010)$ & $(0.011)$ \\
\hline \multirow[t]{2}{*}{ Coverage $\times$ Storm } & -0.078 & -0.092 & -0.020 & -0.012 & 0.072 & 0.053 \\
\hline & $(0.068)$ & $(0.073)$ & $(0.073)$ & $(0.076)$ & $(0.055)$ & $(0.059)$ \\
\hline ZIP Code FE & $\mathrm{Y}$ & $\mathrm{Y}$ & $\mathrm{Y}$ & $\mathrm{Y}$ & $\mathrm{Y}$ & $\mathrm{Y}$ \\
\hline County-year FE & Y & Y & $\mathrm{Y}$ & Y & $\mathrm{Y}$ & $\mathrm{Y}$ \\
\hline All Controls & $\mathrm{N}$ & $\mathrm{Y}$ & $\mathrm{N}$ & $\mathrm{Y}$ & $\mathrm{N}$ & Y \\
\hline Observations & 62,329 & 62,329 & 82,360 & 82,360 & 82,360 & 82,360 \\
\hline$R^{2}$ & 0.47 & 0.49 & 0.57 & 0.57 & 0.57 & 0.57 \\
\hline
\end{tabular}

Note: The main coefficients are as in Table 2. Standard errors are clustered at the county level and reported in parentheses. *: $\mathrm{p}<0.1$; $^{* *}: \mathrm{p}<0.05 ;{ }^{* * *}: \mathrm{p}<0.01$. Standard errors in parentheses.

potential cofounding factors (see Table C.4 in the Appendices).

Placebo tests - Table 4 present the results for a battery of different placebo tests. The first two panels look at the unconditional effect of Coverage and Storm, respectively, and the third type of regression focuses on the interaction of both coefficients. In Columns (1)(2) are the results when the outcome is lagged by one period. Columns (3)-(4) present the results with the predicators of interest being randomly attributed to another ZIP code area within the same county. Finally, in columns (5) - (6), I generate a fake random Storm 
dummy with the same mean and standard deviation of the original variable. With these new placebo storms, I recompute the corresponding placebo Coverage, thus generating a pair of fake treatments. The results are reassuring overall. None of these coefficients are significantly different from zero, and some even take a different sign compared to the main regression table. The results suggest that Coverage is neither subject to any anticipatory effects nor is it correlated with the level of mitigation in a random ZIP code area, even when this latter lies in the same county.

State Selection — One potential source of concern arises when considering the selection of mitigation projects. Indeed, States' administrations are an intermediary in the attribution of the HMG grants. If the total hazard mitigation funding allocated after a declared disaster is lower than the total funds requested, then the selection of the mitigation projects will be based on the State's emergency agency priorities. This may be a problem if States' priorities are somehow determined by Coverage. As a matter of fact, the literature has

Table 5: State Selection

\begin{tabular}{lcccccc}
\hline & \multicolumn{5}{c}{ All Mitigation Projects } \\
& $(1)$ & $(2)$ & $(3)$ & $(4)$ & $(5)$ & $(6)$ \\
\hline Coverage & -0.008 & -0.018 & & & 0.001 & 0.002 \\
& $(0.041)$ & $(0.056)$ & & & $(0.053)$ & $(0.067)$ \\
Storm & & & & & & \\
& & & -0.019 & -0.022 & -0.018 & -0.020 \\
CoveragexStorm & & & $(0.015)$ & $(0.018)$ & $(0.013)$ & $(0.016)$ \\
& & & & & & \\
\hline ZIP Code FE & $\mathrm{Y}$ & $\mathrm{Y}$ & $\mathrm{Y}$ & $\mathrm{Y}$ & $\mathrm{Y}$ & $\mathrm{Y}$ \\
County-year FE & $\mathrm{Y}$ & $\mathrm{Y}$ & $\mathrm{Y}$ & $\mathrm{Y}$ & $\mathrm{Y}$ & $\mathrm{Y}$ \\
All Controls & $\mathrm{N}$ & $\mathrm{Y}$ & $\mathrm{N}$ & $\mathrm{Y}$ & $\mathrm{N}$ & $\mathrm{Y}$ \\
Baseline Population & $\mathrm{N}$ & $\mathrm{Y}$ & $\mathrm{N}$ & $\mathrm{Y}$ & $\mathrm{N}$ & $\mathrm{Y}$ \\
Observations & 82,360 & 82,360 & 82,360 & 82,360 & 82,360 & 82,360 \\
$R^{2}$ & 0.38 & 0.38 & 0.38 & 0.38 & 0.38 & 0.38 \\
\hline
\end{tabular}

Note: Coverage is centered at its mean $(\mu=0 ; s=0.101)$. The outcome variable includes the total number of properties having received mitigation against future storms under the HMG program between 2010 and 2018 when the subgrantee was a State administration $(\mu=0.007 ; s=0.733)$. Standard errors are clustered at the county level and reported in parentheses. $*: \mathrm{p}<0.1$ $;^{* *}: \mathrm{p}<0.05 ;{ }^{* * *}: \mathrm{p}<0.01$. Standard errors in parentheses. 
already demonstrated that differences in media coverage of national events matter for political priorities, thereby generating a bias in the targeting of public transfers. However, this literature looks at media coverage of specific events in regions administratively close to the government deciding of the transfer. For instance, Snyder and Strömberg (2010) looks at transfers overseen by Congress representatives to specific counties in the congressional jurisdiction. Strömberg (2004) looks at how state administration distributed economic federal relief grants given radio distribution in counties as well. I essentially study the same process but for much smaller geographies (ZIP codes). For this reason, it seems unlikely that States' emergency agencies account for the level of Coverage at the ZIP code level. Indeed, there are, on average, 650 ZIP code areas per state, and I already control for county-year variation. It seems unlikely that state emergency administration specifically targets a ZIP code area based on Coverage.

That being said, in order to fully convince that the main results are indeed driven by local governments and not by any upper-government administration, I split my sample between grant recipients: I reproduce my empirical specification only considering local administration subgrantees $^{24}$ and only state administration subgrantees, respectively. Projects with a state administration subgrantee represent about $25 \%$ of all projects. The reason for doing this is that if state administrations indeed prioritize storm mitigation projects according to the local media coverage of storms, then we should expect a positive and significant impact of Coverage on the number of projects whom subgrantee is a state administration. Table 5 presents such results for mitigation projects. As expected, the variable of interest does not seem to have any influence on the State's decision to apply for mitigation projects - as compared to local government's applications. Although I cannot exclude that State administrations select projects on other aspects, it is at least reassuring to know these projects are not selected based on local media coverage. Additionally, this reinforces the fact that the theory is actually suited for local government dynamics rather than for any upper-level administration.

\footnotetext{
${ }^{24}$ In an HMG procedure, the subgrantee is the administration in charge of applying for the grant. In case of approval, it is also the administration in charge of managing the funds and supervising the project at the community level.
} 
Figure 8: Effect of Coverage conditional on Storm

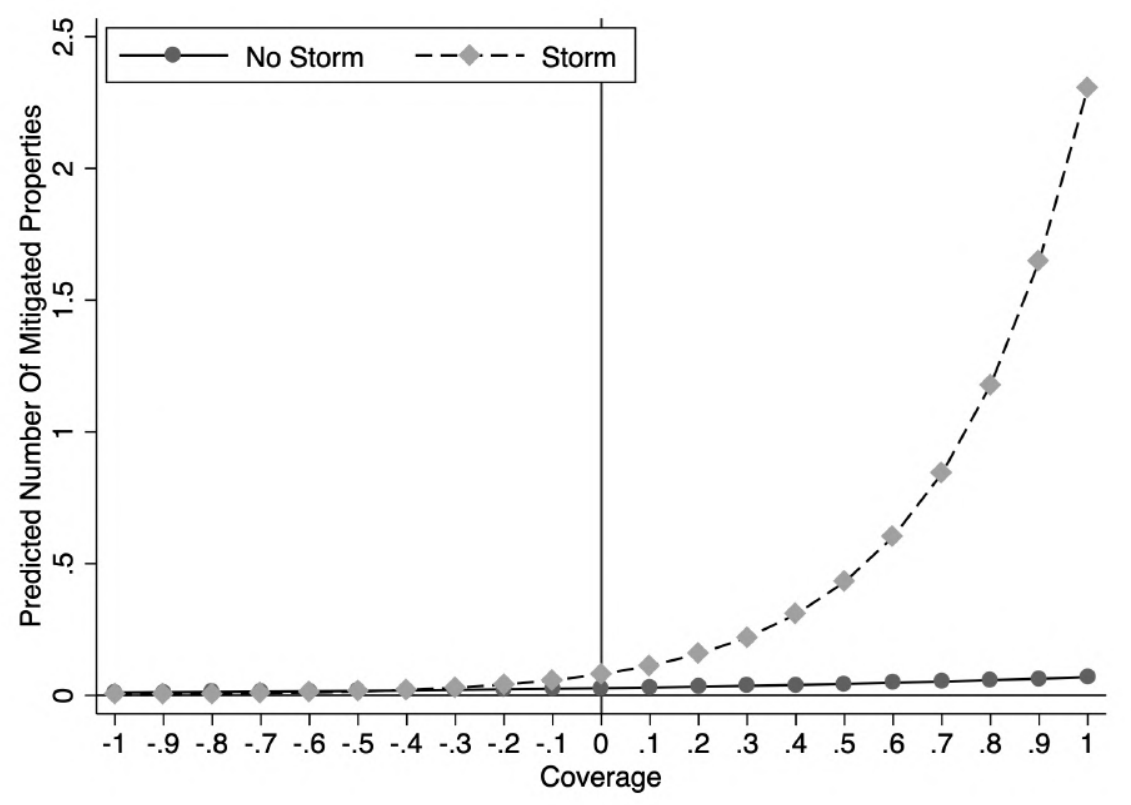

Notes: Marginal impact of Coverage conditional on Storm when estimated with a zero-inflated negative binomial model.

Exploring Non-Linearities — Although fixed effects provide a flexible approach to estimating the impact of Coverage on new mitigation initiatives, the results might be complicated to grasp because of the outcome distribution. Because the number of mitigation projects is count data that exhibits both overdispersion and excess zeros, I also estimate a zero-inflated negative binomial model. Zero-inflated models assume that excess zeros are generally generated by an independent process that can be modeled separately. Here, I use population density as the main predictor of excess zeros. Figure 8 displays the impact of Coverage conditional on being hit by a storm on the number of mitigation projects, as predicted by this empirical approach. Like in the main table, a positive shock above mean Coverage has a strongly significant positive effect on the number of mitigation projects. Local governments do not seem to implement any mitigation measure under mean Coverage. Note that most of the effect occurs at high levels of Coverage, which is consistent with the theory. Indeed, high levels of the resident population require high levels of information shock to motivate mitigation action. In the United States, about $83 \%$ of all housing units are occupied, and $73.5 \%$ of them are occupied by their owner. 


\subsection{Impact on the local housing markets}

The theory also suggests that local governments react to storm coverage because prospective investors respond to increased media attention by shifting their demand towards what appears as safer places. In this case, we should expect a negative impact on both housing sales and housing values driven by places having received strengthen media attention. Consequently, a revenue-maximizing local government whose jurisdiction has been hit by a storm will emit less building permits when information about storm risks circulates. The impact of Coverage on the number of housing sales, the number of building permits emitted by a permit-issuing jurisdiction, and on the subsequent property tax revenues collected by the local government in the following year, are presented in Table 6, 7, and 8, respectively. Like in the previous tables, columns (1) - (2) report the unconditional effect of Coverage, columns (3) - (4) the unconditional effect of Storm, and columns (5) - (6) report the interaction of both terms. Once the location and county-year fixed effects are discounted, a Storm impacts negatively the housing markets only if when is a positive information shock. Neither being hit by a storm at mean Coverage nor an increased Coverage in the absence of a storm has any impact on the housing markets. However, conditional on being hit by a storm, a one standard deviation increase in Coverage decreases the number of housing sales and property tax revenues by $1.5-1.8 \%$, and the number of newly emitted building permits by $.8 \%$. These results suggest that local governments accommodate the demand shift generated by the information shock through a decreased housing supply when prospective investors become aware of the risks.

\subsection{Heterogenous analysis}

So far, I have argued that because they wish to protect property values, local governments underinvest in mitigation measures to avoid disclosing their jurisdiction's latent risks to otherwise uninformed individuals. First of all, if this signaling assumption is true, we should observe that the effect of media coverage on mitigation actions is stronger when these mitigations are actually observable. This is the case of mitigation infrastructures, which take time to build, and which are built to last over the years. Because it is more costly for 
Table 6: Housing sales

\begin{tabular}{|c|c|c|c|c|c|c|}
\hline & \multicolumn{6}{|c|}{ Log Number of Property Sales (Zillow) } \\
\hline & $(1)$ & $(2)$ & $(3)$ & $(4)$ & $(5)$ & (6) \\
\hline Coverage & $\begin{array}{l}-0.001 \\
(0.036)\end{array}$ & $\begin{array}{c}0.005 \\
(0.040)\end{array}$ & & & $\begin{array}{c}0.061 \\
(0.038)\end{array}$ & $\begin{array}{c}0.059 \\
(0.043)\end{array}$ \\
\hline Storm & & & $\begin{array}{l}-0.007 \\
(0.006)\end{array}$ & $\begin{array}{l}-0.006 \\
(0.006)\end{array}$ & $\begin{array}{c}0.003 \\
(0.006)\end{array}$ & $\begin{array}{c}0.002 \\
(0.007)\end{array}$ \\
\hline Coverage $\times$ Storm & & & & & $\begin{array}{c}-0.188^{* * *} \\
(0.044)\end{array}$ & $\begin{array}{c}-0.157^{* * *} \\
(0.046)\end{array}$ \\
\hline ZIP Code FE & Y & $\bar{Y}$ & $\bar{Y}$ & $\bar{Y}$ & $\mathrm{Y}$ & $\mathrm{Y}$ \\
\hline County-year FE & Y & Y & Y & Y & Y & Y \\
\hline All Controls & $\mathrm{N}$ & Y & $\mathrm{N}$ & Y & $\mathrm{N}$ & Y \\
\hline Baseline Population & $\mathrm{N}$ & $\mathrm{Y}$ & $\mathrm{N}$ & $\mathrm{Y}$ & $\mathrm{N}$ & $\mathrm{Y}$ \\
\hline Observations & 82,360 & 82,360 & 82,360 & 82,360 & 82,360 & 82,360 \\
\hline$R^{2}$ & 0.96 & 0.96 & 0.96 & 0.96 & 0.96 & 0.96 \\
\hline
\end{tabular}

Note: Coverage is centered at its mean $(\mu=0 ; s=0.101)$. The outcome variable includes the log number of properties sold in a ZIP code area between 2010 and 2018 when the related county received a Presidential Disaster Declaration $(\mu=3.176$; $s=2.049)$. Standard errors are clustered at the county level and reported in parentheses. $*: \mathrm{p}<0.1 ; * *: \mathrm{p}<0.05 ; * * *: \mathrm{p}<$ 0.01. Standard errors in parentheses.

Table 7: Housing Supply

\begin{tabular}{lcccccc}
\hline & \multicolumn{5}{c}{ Log Number of Building Permits } & \multicolumn{3}{c}{ (new residence) } \\
& $(1)$ & $(2)$ & $(3)$ & $(4)$ & $(5)$ & $(6)$ \\
\hline Coverage & -0.000 & 0.004 & & & 0.020 & 0.024 \\
& $(0.023)$ & $(0.024)$ & & & $(0.024)$ & $(0.025)$ \\
Storm & & & & & & \\
& & & -0.006 & -0.006 & -0.003 & -0.003 \\
Coverage $\times$ Storm & & & $(0.005)$ & $(0.005)$ & $(0.005)$ & $(0.005)$ \\
& & & & & $-0.083^{* * *}$ & $-0.079^{* * *}$ \\
ZIP Code FE & $\mathrm{Y}$ & $\mathrm{Y}$ & $\mathrm{Y}$ & $\mathrm{Y}$ & $\mathrm{Y}$ & $\mathrm{Y}$ \\
County-year FE & $\mathrm{Y}$ & $\mathrm{Y}$ & $\mathrm{Y}$ & $\mathrm{Y}$ & $\mathrm{Y}$ & $\mathrm{Y}$ \\
All Controls & $\mathrm{N}$ & $\mathrm{Y}$ & $\mathrm{N}$ & $\mathrm{Y}$ & $\mathrm{N}$ & $\mathrm{Y}$ \\
Baseline Population & $\mathrm{N}$ & $\mathrm{Y}$ & $\mathrm{N}$ & $\mathrm{Y}$ & $\mathrm{N}$ & $\mathrm{Y}$ \\
Observations & 180,623 & 180,623 & 180,623 & 180,623 & 180,623 & 180,623 \\
$R^{2}$ & 0.91 & 0.91 & 0.91 & 0.91 & 0.91 & 0.91 \\
\hline
\end{tabular}

Note: Coverage is centered at its mean $(\mu=0 ; s=0.145)$. The unit of observation is a permit-issuing jurisdiction per year. The outcome variable includes the log number of new residential building permits issued by a permitting jurisdiction, between 2010 and $2018(\mu=1.6 ; s=1.667)$. A spatial distribution of these building permits is presented in Figure C.3 of the Appendices. Standard errors are clustered at the county level and reported in parentheses. $*$ : p < $0.1 ; * *: \mathrm{p}<0.05 ; * * *$ : $\mathrm{p}<0.01$. Standard errors in parentheses. 
potential homebuyers to investigate ownership - and infer location's risk from this ownership, Coverage should not matter much for non-structural actions like land acquisitions. To study the differences between non-structural and structural mitigation, I split the sample between properties that received infrastructure projects and properties that were subject to acquisition projects. The results are presented in Table 9.

As expected, structural mitigation projects drive the main results. Conditional on being hit by a storm, a one standard deviation increase in Coverage increases the number of properties receiving mitigation infrastructures by almost $77 \%$ of its average. On the contrary, the interaction term does not seem to have any significant effect on land acquisitions. These findings support the idea that local policymakers are reluctant to undertake mitigation projects when the risks are ignored, especially if the so-called project is more likely to signal the presence of risks.

The theory presented in Section 2 suggests that the impact of new information about local risks on governments' mitigation initiatives is first and foremost driven by mobile

Table 8: Housing taxes

\begin{tabular}{|c|c|c|c|c|c|c|}
\hline & \multicolumn{6}{|c|}{ Lead Log Property Tax Revenues } \\
\hline & $(1)$ & $(2)$ & $(3)$ & $(4)$ & $(5)$ & $(6)$ \\
\hline Coverage & $\begin{array}{l}-0.034 \\
(0.064)\end{array}$ & $\begin{array}{l}-0.001 \\
(0.063)\end{array}$ & & & $\begin{array}{c}0.015 \\
(0.071)\end{array}$ & $\begin{array}{c}0.050 \\
(0.070)\end{array}$ \\
\hline Storm & & & $\begin{array}{c}0.000 \\
(0.005)\end{array}$ & $\begin{array}{c}0.000 \\
(0.005)\end{array}$ & $\begin{array}{c}0.006 \\
(0.006)\end{array}$ & $\begin{array}{c}0.007 \\
(0.006)\end{array}$ \\
\hline Coverage $\times$ Storm & & & & & $\begin{array}{c}-0.148^{* * *} \\
(0.046)\end{array}$ & $\begin{array}{c}-0.156^{* * *} \\
(0.046)\end{array}$ \\
\hline ZIP Code FE & Y & $\bar{Y}$ & $\mathrm{Y}$ & $\mathrm{Y}$ & $\mathrm{Y}$ & $\mathrm{Y}$ \\
\hline County-year FE & Y & Y & Y & Y & Y & Y \\
\hline All Controls & $\mathrm{N}$ & $\mathrm{N}$ & $\mathrm{N}$ & $\mathrm{N}$ & $\mathrm{N}$ & $\mathrm{N}$ \\
\hline Baseline Population & $\mathrm{N}$ & Y & $\mathrm{N}$ & Y & $\mathrm{N}$ & $\mathrm{Y}$ \\
\hline Observations & 71,505 & 71,505 & 71,505 & 71,505 & 71,505 & 71,505 \\
\hline$R^{2}$ & 0.96 & 0.96 & 0.96 & 0.96 & 0.96 & 0.96 \\
\hline
\end{tabular}

Note: Coverage is centered at its mean $(\mu=0 ; s=0.101)$. The outcome variable includes the aggregated property tax revenues in the aftermath of a Presidential Declaration of Disaster $(\mu=14.16 ; s=2.30)$. Standard errors are clustered at the county level and reported in parentheses. *: $\mathrm{p}<0.1 ; * *: \mathrm{p}<0.05 ;{ }^{* * *}: \mathrm{p}<0.01$. Standard errors in parentheses. 
non-residents. The larger the share of non-residents, the smaller the information shock needs to be to motivate the government to prepare for a disaster. In this setting, residents are less responsive to the information shock because they are tied to their hometowns. Although there is no proper way to empirically measure individuals' mobility or individuals' bounds to their town of residence in the wake of a natural disaster, I can interact with my coefficients different pre-treatment variables positively correlated to these aspects. Table 10 then presents the interaction of the Coverage and Storm regressors with pre-treatment measures of (1) the log number of vacant housing units, (2) the log number of renter-occupied housing units, (3) the log number of housing units owned with a mortgage, (4) a dummy for an above-median inflow of population in the ZIP code, (5) the log of the median household income, and (6) a dummy for positive growth in real-estate tax revenues in the ZIP code.

First, the main results from 2 seem to be driven by ZIP codes areas with high levels of vacant housing units, housing units occupied by renters, housing units owned with a mortgage,

Table 9: Heterogenous analysis by Mitigation type

\begin{tabular}{lcccccc}
\hline & \multicolumn{2}{c}{ All Projects } & \multicolumn{2}{c}{ Infrastructures } & \multicolumn{2}{c}{ Land acquisitions } \\
& $(1)$ & $(2)$ & $(3)$ & $(4)$ & $(5)$ & $(6)$ \\
\hline Coverage & -0.030 & -0.054 & 0.026 & 0.012 & -0.028 & -0.033 \\
& $(0.045)$ & $(0.060)$ & $(0.032)$ & $(0.039)$ & $(0.026)$ & $(0.039)$ \\
Storm & & & & & & \\
& -0.003 & -0.003 & $-0.014^{* *}$ & $-0.013^{*}$ & 0.008 & 0.008 \\
& $(0.010)$ & $(0.011)$ & $(0.007)$ & $(0.007)$ & $(0.006)$ & $(0.007)$ \\
Coverage $\times$ Storm & $0.443^{* * *}$ & $0.486^{* * *}$ & $0.353^{* * *}$ & $0.346^{* * *}$ & 0.097 & 0.134 \\
& $(0.131)$ & $(0.147)$ & $(0.099)$ & $(0.111)$ & $(0.083)$ & $(0.095)$ \\
\hline ZIP Code FE & $\mathrm{Y}$ & $\mathrm{Y}$ & $\mathrm{Y}$ & $\mathrm{Y}$ & $\mathrm{Y}$ & $\mathrm{Y}$ \\
County-year FE & $\mathrm{Y}$ & $\mathrm{Y}$ & $\mathrm{Y}$ & $\mathrm{Y}$ & $\mathrm{Y}$ & $\mathrm{Y}$ \\
All Controls & $\mathrm{N}$ & $\mathrm{Y}$ & $\mathrm{N}$ & $\mathrm{Y}$ & $\mathrm{N}$ & $\mathrm{Y}$ \\
Baseline Population & $\mathrm{N}$ & $\mathrm{Y}$ & $\mathrm{N}$ & $\mathrm{Y}$ & $\mathrm{N}$ & $\mathrm{Y}$ \\
Observations & 82,360 & 82,360 & 82,360 & 82,360 & 82,360 & 82,360 \\
$R^{2}$ & 0.57 & 0.57 & 0.69 & 0.71 & 0.42 & 0.43 \\
\hline
\end{tabular}

Note: Coverage is centered at its mean $(\mu=0 ; s=0.101)$. Infrastructures includes the total number of properties having received structural mitigation against future storms under the HMG program between 2010 and $2018(\mu=0.0457 ; s=0.705)$. Land acquisitions includes the total number of properties having been subject to a complete or a partial land acquisition under the same program $(\mu=.0265 ; s=0.621)$. Standard errors are clustered at the county level and reported in parentheses. *: $\mathrm{p}<$ $0.1 ; * *: \mathrm{p}<0.05 ;{ }^{* * *}: \mathrm{p}<0.01$. Standard errors in parentheses. 
and by ZIP code areas having experienced immigration above their median levels previous to the treatment. In particular, conditional on being hit by a storm and for every one-standarddeviation increase in Coverage, a $1 \%$ increase in the pre-treatment number of vacant units in a ZIP code lead to a $0.47 \%$ increase in the subsequent average number of mitigation projects. Under these conditions, a 1\% increase in the pre-treatment number of renter-occupied units, and housing units owned with a mortgage, lead to a $0.35 \%$ and a $0.5 \%$ increase respectively, in the subsequent average number of mitigation projects. Additionally, Coverage seems to affect preparation efforts in places that recently experienced above-median immigration levels. In particular, conditional on being hit by a storm, a one-standard-deviation increase in Coverage leads to a $120 \%$ increase in the average number of mitigation projects in these ZIP codes compared to ZIP codes that experienced below-median immigration before the treatment. Finally, note that unconditional on being hit by a storm, the impact of media coverage on mitigation efforts is larger when households residing in the ZIP code were richer previous to the treatment (see column (5)).

These results are in line with the theory, which states that larger shares of mobile individuals, and generally lower migration costs, foster mitigation initiatives. Non-resident investors, who seek to derive a rental income ${ }^{25}$, could either react to the information shock by diverting their investment towards places that appear safer to renters - or if they have already acquired their property, pressuring the local administration in taking mitigation action to maintain their previous rents. The local government would then be incentivized to invest in mitigation projects to preserve revenues from housing taxes and sales.

As a matter of fact, ZIP code areas that experienced growing real-estate tax revenues before the treatment were more likely to receive mitigation infrastructures (see column (6) in Table 10). In particular, conditional on being hit by a storm, a one standard-deviation increase in Coverage lead to an $82 \%$ increase in the average number of mitigation projects in these ZIP codes compared to ZIP codes that did not experience growing real-estate tax revenues before the treatment.

\footnotetext{
${ }^{25}$ As mentioned earlier, these investors typically live near their housing investments (20 miles in 2013$)$, and a majority (37\%) seeks to derive rental income ${ }^{26}$.
} 
Table 10: Heterogenous analysis by Pre-Treatment $X$

\begin{tabular}{lcccccc}
\hline & & & All Mitigation Projects & $(1)$ \\
& $-0.229^{*}$ & $-0.357^{* *}$ & $-0.413^{* * *}$ & 0.047 & $-2.561^{* * *}$ & 0.018 \\
& $(0.132)$ & $(0.168)$ & $(0.156)$ & $(0.056)$ & $(0.837)$ & $(0.060)$ \\
Coverage & & & & & & \\
Coverage $\times X$ & $0.050^{*}$ & $0.082^{* *}$ & $0.083^{* * *}$ & -0.133 & $0.230^{* * *}$ & -0.079 \\
& $(0.029)$ & $(0.037)$ & $(0.031)$ & $(0.082)$ & $(0.075)$ & $(0.081)$ \\
Storm & -0.004 & -0.014 & -0.018 & $-0.053^{* * *}$ & 0.264 & $-0.036^{* *}$ \\
& $(0.037)$ & $(0.031)$ & $(0.037)$ & $(0.018)$ & $(0.300)$ & $(0.016)$ \\
Storm $\times X$ & -0.001 & 0.001 & 0.000 & $0.074^{* * *}$ & -0.025 & $0.042^{* * *}$ \\
& $(0.007)$ & $(0.006)$ & $(0.007)$ & $(0.024)$ & $(0.027)$ & $(0.021)$ \\
Storm $\times$ Coverage & $-1.664^{* * *}$ & $-1.282^{* *}$ & $-2.274^{* * *}$ & -0.015 & 0.071 & 0.114 \\
& $(0.636)$ & $(0.603)$ & $(0 . .881)$ & $(2.228)$ & $(0.187)$ & $(0.131)$ \\
Storm $\times$ Coverage $\times X$ & $0.390^{* * *}$ & $0.289^{* *}$ & $0.413^{* * *}$ & $0.959^{* * *}$ & 0.045 & $0.673^{* * *}$ \\
& $(0.130)$ & $(0.115)$ & $(0.148)$ & $(0.312)$ & $(0.203)$ & $(0.254)$ \\
$X$ & & & & & & \\
$X$ & $-0.015^{* *}$ & 0.005 & $-0.031^{* * *}$ & $-0.022^{* * *}$ & 0.011 & -0.002 \\
& $(0.007)$ & $(0.006)$ & $(0.012)$ & $(0.008)$ & $(0.011)$ & $(0.006)$ \\
\hline ZIP Code FE & $\mathrm{Y}$ & $\mathrm{Y}$ & $\mathrm{Y}$ & $\mathrm{Y}$ & $\mathrm{Y}$ & $\mathrm{Y}$ \\
County-year FE & $\mathrm{Y}$ & $\mathrm{Y}$ & $\mathrm{Y}$ & $\mathrm{Y}$ & $\mathrm{Y}$ & $\mathrm{Y}$ \\
All Controls & $\mathrm{N}$ & $\mathrm{N}$ & $\mathrm{N}$ & $\mathrm{N}$ & $\mathrm{N}$ & $\mathrm{N}$ \\
Baseline Population & $\mathrm{N}$ & $\mathrm{N}$ & $\mathrm{N}$ & $\mathrm{N}$ & $\mathrm{N}$ & $\mathrm{N}$ \\
Observations & 62,329 & 62,329 & 62,329 & 62,329 & 62,329 & 62,329 \\
$R^{2}$ & 0.62 & 0.62 & 0.62 & 0.62 & 0.62 & 0.62 \\
\hline
\end{tabular}

Note: The main regressors descriptive statistics are as in Table 2. $X$ is a pre-treatment variable corresponding to: (1) the log number of vacant housing units, (2) the log number of renter-occupied housing units, (3) the log number of housing units owned with a mortgage, (4) a dummy for an above-median inflow of population in the ZIP code, (5) the log of the median household income, and (6) a dummy for a positive growth in real-estate tax revenues in the ZIP code. The impact of an increased media attention on the mitigation efforts. Standard errors are clustered at the county level and reported in parentheses. ${ }^{*}: \mathrm{p}<0.1$; $* *: \mathrm{p}<0.05 ; * * *: \mathrm{p}<0.01$. Standard errors in parentheses.

\section{Conclusion}

In this paper, I study the impact of media coverage on the implementation of local resilience policies - namely, mitigation investments - designed to reduce the risks of future natural disasters. I challenge the view that investments in mitigation actions are solely driven by the objective risk. I make the central assumption that these mitigation actions might signal the true risk to potential investors. Because of this risk-signaling process, local governments who seek to protect housing values in their jurisdiction are reluctant to invest in mitigation 
infrastructures when investors are not aware of the risks.

The main results suggest that conditional on being hit by a storm, more mitigation projects are implemented when information about storms does circulate. I interpret this result as meaning that local policymakers are not prone to disclose risks through mitigation when prior risk information is inexistent. A one standard deviation increase in the treatment variable leads to an increase of $54 \%$ of the average number of mitigation projects in a ZIP code area that suffered a storm. In the absence of increased media coverage, jurisdictions hit by the disaster do not implement mitigation projects. Additionally, the number of housing sales, the revenues from property taxes, and the number of building permits issued in the affected jurisdictions decrease significantly when newspaper coverage is higher than its mean. This suggests that developers and prospective investors might be reacting to the demand shock by shifting their demand towards virtually risk-free locations. Local governments whose jurisdiction suffers from this redistribution are incentivized to invest in mitigation technologies to signal that the risks are under control - when investors are informed about this risk. These findings seem to be primarily driven by structural projects - which supports the risk-signaling channel; and by places with high pre-treatment levels of vacant housing units, housing units occupied by renters, or housing units owned with a mortgage, seemingly indicating that non-resident property investors are the ones primarily reacting to the information shock. This latter result brings up new insights as well as new questions about the potential capture of local disaster preparation policies by developers and real-estate buyers.

Overall, this paper provides novel evidence on local governments' motivations to prepare for natural disasters. In particular, local information distribution appears to be paramount to explain policymakers' incentives to make their jurisdiction resilient to storms. Less informed places end up being more vulnerable, thereby fostering spatial inequalities in the capacity to resist the consequences of climate change. Considering both the decline of local news and the increase in the frequency of natural disasters, these results could help designing more comprehensive mitigation policies both at the local and federal governments levels. 


\section{References}

G. A. Akerlof. The market for "lemons": Quality uncertainty and the market mechanism. In Uncertainty in economics, pages 235-251. Elsevier, 1978.

J. G. Altonji, T. E. Elder, and C. R. Taber. Selection on observed and unobserved variables: Assessing the effectiveness of catholic schools. Journal of Political Economy, 113(1):151$184,2005$.

L. A. Bakkensen and L. Barrage. Flood risk belief heterogeneity and coastal home price dynamics: Going under water? NBER Working paper No. 23854, 2017.

L. Barrage and J. Furst. Housing investment, sea level rise, and climate change beliefs. Economics Letters, 177:105-108, 2019.

M. M. Bechtel and J. Hainmueller. How lasting is voter gratitude? an analysis of the shortand long-term electoral returns to beneficial policy. American Journal of Political Science, $55(4): 852-868,2011$.

T. Besley and R. Burgess. The political economy of government responsiveness: Theory and evidence from india. The Quarterly Journal of Economics, 117(4):1415-1451, 2002.

L. P. Boustan, M. E. Kahn, and P. W. Rhode. Moving to higher ground: Migration

response to natural disasters in the early twentieth century. American Economic Review, $102(3): 238-44,2012$.

J. Brown, T. Hossain, and J. Morgan. Shrouded attributes and information suppression: Evidence from the field. The Quarterly Journal of Economics, 125(2):859-876, 2010.

R. Brown, V. Montalva, D. Thomas, and A. Velásquez. Impact of violent crime on risk aversion: Evidence from the mexican drug war. Review of Economics and Statistics, 101 (5):892-904, 2019.

D. Bunten and M. E. Kahn. Optimal real estate capital durability and localized climate change disaster risk. Journal of Housing Economics, 36:1-7, 2017. 
M. Callen, M. Isaqzadeh, J. D. Long, and C. Sprenger. Violence and risk preference: Experimental evidence from afghanistan. American Economic Review, 104(1):123-48, 2014.

R. Coulomb and Y. Zylberberg. Rare events and risk perception: Evidence from fukushima accident. GRI Working Papers 229, Grantham Research Institute on Climate Change and the Environment, 2019.

R. Durante, P. Pinotti, and A. Tesei. The political legacy of entertainment tv. American Economic Review, 109(7):2497-2530, 2019.

C. C. Eckel, M. A. El-Gamal, and R. K. Wilson. Risk loving after the storm: A bayesiannetwork study of hurricane katrina evacuees. Journal of Economic Behavior $\mathscr{G}$ Organization, 69(2):110-124, 2009.

T. Eisensee and D. Strömberg. News droughts, news floods, and us disaster relief. The Quarterly Journal of Economics, 122(2):693-728, 2007.

R. Enikolopov, M. Petrova, and E. Zhuravskaya. Media and political persuasion: Evidence from russia. American Economic Review, 101(7):3253-85, 2011.

X. Gabaix and D. Laibson. Shrouded attributes, consumer myopia, and information suppression in competitive markets. The Quarterly Journal of Economics, 121(2):505-540, 2006.

J. Gallagher. Learning about an infrequent event: Evidence from flood insurance take-up in the united states. American Economic Journal. Applied Economics, 6(3):206-233, 2014.

Z. Gao, M. Sockin, and W. Xiong. Economic consequences of housing speculation. Processed - University of Texas at Austin, 2018.

J. T. Gasper and A. Reeves. Make it rain? retrospection and the attentive electorate in the context of natural disasters. American Journal of Political Science, 55(2):340-355, 2011.

A. Healy and N. Malhotra. Myopic voters and natural disaster policy. American Political Science Review, 103(3):387-406, 2009. 
P. Jakiela and O. Ozier. The impact of violence on individual risk preferences: evidence from a natural experiment. Review of Economics and Statistics, 101(3):547-559, 2019.

B. Jovanovic. Truthful disclosure of information. The Bell Journal of Economics, 13(1): 36-44, 1982.

M. E. Kahn. The death toll from natural disasters: the role of income, geography, and institutions. Review of Economics and Statistics, 87(2):271-284, 2005.

M. E. Kahn. Environmental disasters as risk regulation catalysts? the role of bhopal, chernobyl, exxon valdez, love canal, and three mile island in shaping us environmental law. Journal of Risk and Uncertainty, 35(1):17-43, 2007.

I. Kant. On Perpetual Peace. Broadview Press, Peterborough, Ontario, 1795.

A. Leiserowitz. Climate change risk perception and policy preferences: The role of affect, imagery, and values. Climatic Change, 77(1-2):45-72, 2006.

C. S. Lim, J. Snyder, and D. Strömberg. The judge, the politician, and the press: newspaper coverage and criminal sentencing across electoral systems. American Economic Journal: Applied Economics, 7(4):103-35, 2015.

U. Malmendier and S. Nagel. Depression babies: do macroeconomic experiences affect risk taking? The Quarterly Journal of Economics, 126(1):373-416, 2011.

P. R. Milgrom. Good news and bad news: Representation theorems and applications. The Bell Journal of Economics, pages 380-391, 1981.

T. A. Myers, E. W. Maibach, C. Roser-Renouf, K. Akerlof, and A. A. Leiserowitz. The relationship between personal experience and belief in the reality of global warming. Nature Climate Change, 3(4):343-347, 2013.

E. Pattachini, D. Paserman, and S. Gagliarducci. Hurricanes, climate change and electoral accountability. NBER Working Paper No. 25835, 2019.

A. Prat and D. Strömberg. The political economy of mass media. Advances in Economics and Econometrics, 2:135-187, 2013. 
J. Roback. Wages, rents, and the quality of life. Journal of Political Economy, 90(6): 1257-1278, 1982.

S. Rosen. Hedonic prices and implicit markets: product differentiation in pure competition. Journal of Political Economy, 82(1):34-55, 1974.

R. Singh. Seismic risk and house prices: Evidence from earthquake fault zoning. Regional Science and Urban Economics, 75:187-209, 2019.

J. Snyder and D. Strömberg. Press coverage and political accountability. Journal of Political Economy, 118(2):355-408, 2010.

G. J. Stigler and G. S. Becker. De gustibus non est disputandum. The American Economic Review, 67(2):76-90, 1977.

D. Strömberg. Radio's impact on public spending. The Quarterly Journal of Economics, 119(1):189-221, 2004.

D. Strömberg. Natural disasters, economic development, and humanitarian aid. Journal of Economic Perspectives, 21(3):199-222, 2007.

R. Sylves. Disaster policy and politics: Emergency management and homeland security. CQ Press, Washington, D.C., 2019.

N. N. Taleb. The Black Swan: The impact of the highly improbable, volume 2. Random house, New York, 2007.

M. J. Voors, E. E. Nillesen, P. Verwimp, E. H. Bulte, R. Lensink, and D. P. Van Soest. Violent conflict and behavior: a field experiment in burundi. American Economic Review, 102(2):941-64, 2012. 


\section{Appendices}

\section{A Proof of Proposition 2.1}

The timeline is described in Section 2. We are interested in unraveling the local government's best mitigation strategy given an exogenous information shock on the local disaster dangers, all else being equal. In particular, we assume the distribution of rent prices before the information shock is similar in both municipalities, i.e., $p=p_{i}=p_{-i}$. Several papers in the literature study how the information of a local natural disaster is dynamically captured in prices (Barrage and Furst, 2019; Coulomb and Zylberberg, 2019; Singh, 2019; Bakkensen and Barrage, 2017). We further assume that the information shock occurs immediately after the natural disaster, so we study the agents' decision in the immediate aftermath of the catastrophe. Finally, we acknowledge that in this setting, only the local authorities can invest in public mitigation, but one can easily extend the framework to allow sophisticated residents to invest in private mitigation without changing the main results. The analysis then consists in comparing each government's payoffs in the following cases: when $(1) m_{i}=m_{-i}=0$, (2) $m_{i}>0$ and $m_{-i}=0$, respectively when (3) $m_{i}=0$ and $m_{-i}>0$, and finally, when $m_{i}=m_{-i}>0$. This is done by inferring the individuals' sorting in city $i \in\{A ; B\}$ from their anticipated surplus. This anticipated surplus will depend on whether the individual is a resident $(r)$, a non-resident $(n r)$, sophisticated $(s)$ or myopic $(m)$.

- Case 1: $m_{i}=m_{-i}=0$

The net anticipated surplus for each group of individuals is:

$$
\left\{\begin{array}{l}
x_{i, s, n r}=\left[-p_{i}-\hat{p}\right]-\left[-p_{-i}-\hat{p}\right]=0 \\
x_{i, m, n r}=\left[-p_{i}\right]-\left[-p_{-i}\right]=0 \\
x_{i, s, r}=\left[-p_{i}-\hat{p}\right]-\left[-p_{-i}-\hat{p}-c\right]=c \\
x_{i, m, r}=\left[-p_{i}-\hat{p}\right]-\left[-p_{-i}-c\right]=c-\hat{p} \\
x_{-i, s, r}=\left[-p_{-i}-\hat{p}\right]-\left[-p_{i}-\hat{p}-c\right]=c \\
x_{-i, m, r}=\left[-p_{-i}-\hat{p}\right]-\left[-p_{i}-c\right]=c-\hat{p}
\end{array}\right.
$$


Non-residents will split evenly between each municipality as there is no mitigation measures, making each city similar for both informed and myopic individuals. Residents are always aware of the risks in their own town. Myopic residents will then move to the other city if $c<\hat{p}$, that is to say, if the cost of migration is lower than bearing the disasters' costs if staying. In this case, municipalities will swap myopic residents. Informed residents will remain in their town of origin as they understand that there is no apparent reason of moving at a cost $c$. The distribution of the population in this economy remains unchanged.

In this case, governments' revenues are similar: $\Pi_{i}=\Pi_{-i}=p / 2$.

- Case 2: $m_{i}>0$ and $m_{-i}=0$

The net anticipated surplus for each group of individuals is:

$$
\left\{\begin{array}{l}
x_{i, s, n r}=\left[-p_{i}-\hat{p}+m_{i}\right]-\left[-p_{-i}-\hat{p}\right]=m_{i} \\
x_{i, m, n r}=\left[-p_{i}-\hat{p}+m_{i}\right]-\left[-p_{-i}\right]=m_{i}-\hat{p} \\
x_{i, s, r}=\left[-p_{i}-\hat{p}+m_{i}\right]-\left[-p_{-i}-\hat{p}-c\right]=m_{i}+c \\
x_{i, m, r}=\left[-p_{i}-\hat{p}+m_{i}\right]-\left[-p_{-i}-c\right]=m_{i}+c-\hat{p} \\
x_{-i, s, r}=\left[-p_{-i}-\hat{p}\right]-\left[-p_{i}-\hat{p}+m_{i}-c\right]=c-m_{i} \\
x_{-i, m, r}=\left[-p_{-i}-\hat{p}\right]-\left[-p_{i}-\hat{p}+m_{i}-c\right]=c-m_{i}
\end{array}\right.
$$

Because of the mitigation measures taken by $i$, the risk of disaster is always observed in city $i$. Sophisticated non-residents will choose to locate in $i$ since the known dangers are not mitigated in city $-i$. However, uninformed non-residents will prefer to move to the virtually safer city $-i$, where there is no apparent risks rather than moving to a hazardous area, even if the risks are alleviated by $m_{i}$. Sophisticated residents of city $i$ will stay in their town of origin: they are aware they benefit from mitigation measures that do not exist for their neighbors. Myopic residents of city $i$, however, will move if the net cost of staying in $i, \hat{p}-m_{i}$, is larger than $c$, the cost of moving to $-i$. Residents of $-i$, who are aware of the dangers in both cities will only move if the gains from mitigatiion, $m_{i}$, compensate the costs of migration, $c$. 
This leads to four possible subcases ${ }^{27}$ :

a) $c>m_{i}$ and $c>\hat{p}-m_{i}$; which implies $\Pi_{i}=p \cdot\left[\lambda+\alpha\left(\frac{1}{2}-\lambda\right)\right]$;

b) $c<m_{i}$ and $c>\hat{p}-m_{i}$; which implies $\Pi_{i}=p \cdot[\lambda+\alpha(1-\lambda)]$;

c) $c>m_{i}$ and $c<\hat{p}-m_{i}$; which implies $\left.\Pi_{i}=p \cdot \lambda(1-\alpha / 2)\right]$;

d) $c<m_{i}$ and $c<\hat{p}-m_{i}$; which implies $\Pi_{i}=p \cdot\left[\lambda+\frac{\alpha}{2}(1-\lambda)\right]$.

Therefore, conditional on $m_{-i}=0$, it is always in the best interest city $i$ to take mitigation measures if:

a) $\lambda>\frac{1}{2}$; when $c>m_{i}$ and $c>\hat{p}-m_{i}$;

b) $\lambda>\frac{1-2 \alpha}{2-2 \alpha} \in\left[-\infty ; \frac{1}{2}\right] \forall \alpha \in[0 ; 1]$ when $c<m_{i}$ and $c>\hat{p}-m_{i}$;

c) $\lambda>\frac{1}{2-\alpha} \in\left[\frac{1}{2} ; 1\right] \forall \alpha \in[0 ; 1]$ when $c>m_{i}$ and $c<\hat{p}-m_{i}$;

d) $\lambda>\frac{1-\alpha}{2-\alpha} \in\left[-\infty ; \frac{1}{2}\right] \forall \alpha \in[0 ; 1]$ when $c<m_{i}$ and $c<\hat{p}-m_{i}$.

It follows that, conditional on $m_{-i}=0$, it is always in the best interest of city $i$ to take mitigation measures if at least a share $\frac{1}{2-\alpha}$ of the population is sophisticated. Consider now the cases where the neighboring city takes mitigation measures:

- Case 3: $m_{i}=0$ and $m_{-i}>0$

The net anticipated surplus for each group of individuals is:

$$
\left\{\begin{array}{l}
x_{i, s, n r}=\left[-p_{i}-\hat{p}\right]-\left[-p_{-i}-\hat{p}+m_{-i}\right]=-m_{-i} \\
x_{i, m, n r}=\left[-p_{i}\right]-\left[-p_{-i}+\hat{p}+m_{-i}\right]=\hat{p}-m_{-i} \\
x_{i, s, r}=\left[-p_{i}-\hat{p}\right]-\left[-p_{-i}-\hat{p}+m_{-i}-c\right]=c-m_{-i} \\
x_{i, m, r}=\left[-p_{i}-\hat{p}\right]-\left[-p_{-i}+\hat{p}+m_{-i}-c\right]=c-m_{-i} \\
x_{-i, s, r}=\left[-p_{-i}-\hat{p}+m_{-i}\right]-\left[-p_{i}-\hat{p}-c\right]=c+m_{-i} \\
x_{-i, m, r}=\left[-p_{-i}-\hat{p}+m_{-i}\right]-\left[-p_{i}-c\right]=c+m_{-i}-\hat{p}
\end{array}\right.
$$

This case is symmetric to Case 2. The four possible subcases are:

\footnotetext{
${ }^{27}$ Note that if the share of residents in the economy, $\alpha$, is null, $\Pi_{i}=p \cdot \lambda$ and $\Pi_{-i}=p \cdot(1-\lambda)$ in every subcases.
} 
a) $c>m_{-i}$ and $c>\hat{p}-m_{-i}$; which implies $\Pi_{i}=p \cdot[(1-\lambda)(1-\alpha)+\alpha / 2]$;

b) $c<m_{-i}$ and $c>\hat{p}-m_{-i}$; which implies $\Pi_{i}=p \cdot[(1-\lambda)(1-\alpha)]$;

c) $c>m_{-i}$ and $c<\hat{p}-m_{-i}$; which implies $\Pi_{i}=p \cdot[1-\lambda .(1-\alpha / 2)]$;

d) $c<m_{-i}$ and $c<\hat{p}-m_{-i}$; which implies $\Pi_{i}=p \cdot[(1-\lambda)(1-\alpha / 2)]$.

- Case 4: $m_{i}>0$ and $m_{-i}>0$

The net anticipated surplus for each group of individuals is:

$$
\left\{\begin{array}{l}
x_{i, s, n r}=\left[-p_{i}-\hat{p}+m_{i}\right]-\left[-p_{-i}-\hat{p}+m_{-i}\right]=m_{i}-m_{-i} \\
x_{i, m, n r}=\left[-p_{i}-\hat{p}+m_{i}\right]-\left[-p_{-i}-\hat{p}+m_{-i}\right]=m_{i}-m_{-i} \\
x_{i, s, r}=\left[-p_{i}-\hat{p}+m_{i}\right]-\left[-p_{-i}-\hat{p}+m_{-i}-c\right]=m_{i}-m_{-i}+c \\
x_{i, m, r}=\left[-p_{i}-\hat{p}+m_{i}\right]-\left[-p_{-i}-\hat{p}+m_{-i}-c\right]=m_{i}-m_{-i}+c \\
x_{-i, s, r}=\left[-p_{-i}-\hat{p}+m_{-i}\right]-\left[-p_{i}-\hat{p}+m_{i}-c\right]=m_{-i}-m_{i}+c \\
x_{-i, m, r}=\left[-p_{-i}-\hat{p}+m_{-i}\right]-\left[-p_{i}-\hat{p}+m_{i}-c\right]=m_{-i}-m_{i}+c
\end{array}\right.
$$

In this case, both municipalities decide to take mitigation measures. Therefore, the dangers are revealed to everyone, unconditional on individuals' sophistication level. In this case, the decision to move either to $i$ or $-i$ depends entirely on the net difference in mitigation levels. Non-residents will move to city $i$ if it implements more mitigation than $-i$, and residents will move to the neighboring town if the mitigation gains offset the migration costs. In equilibrium, both cities will then supply the same level of mitigation, i.e. $m_{i}=m_{-i}$, and governments revenues will be $\Pi_{i}=\Pi_{-i}=p / 2$.

Consequently, conditional on $m_{-i}>0$, it is always in the best interest city $i$ to take mitigation measures if:

a) $\lambda>\frac{1}{2}$; when $c>m_{-i}$ and $c>\hat{p}-m_{-i}$;

b) $\lambda>\frac{1-2 \alpha}{2-2 \alpha} \in\left[-\infty ; \frac{1}{2}\right] \forall \alpha \in[0 ; 1]$ when $c<m_{-i}$ and $c>\hat{p}-m_{-i}$;

c) $\lambda>\frac{1}{2-\alpha} \in\left[\frac{1}{2} ; 1\right] \forall \alpha \in[0 ; 1]$ when $c>m_{-i}$ and $c<\hat{p}-m_{-i}$;

d) $\lambda>\frac{1-\alpha}{2-\alpha} \in\left[-\infty ; \frac{1}{2}\right] \forall \alpha \in[0 ; 1]$ when $c<m_{-i}$ and $c<\hat{p}-m_{-i}$. 
That is to say, conditional on $m_{-i}>0$, it is always in the best interest of city $i$ to take mitigation measures if $\lambda \geq \frac{1}{2-\alpha}$.

Finally, if the migration costs offset the mitigation gains, like in subcases (a) and (c), unprotected residents will remain in their town of origin. In this case, the larger the share of non-residents, the smaller should be the share of informed individuals for the government to choose mitigation. However, for subcases (b)-(d) - i.e., when mitigation gains offset migration costs, the larger is the share of non-residents, the larger should be the share of informed individuals for the government to choose mitigation. As the share of non-residents converges to 1 , the share of informed individuals for the government to adopt protective measures should be higher than $\frac{1}{2}$. Generally, since $\frac{1-2 \alpha}{2-2 \alpha} \leq \frac{1-\alpha}{2-\alpha} \leq \frac{1}{2} \leq \frac{1}{2-\alpha}$, a Non-Shrouded equilibrium exists as both governments will always have a strategic interest in choosing to mitigate if $\lambda>\frac{1}{2-\alpha}$. Respectively, a Shrouded equilibrium exists for $\lambda<\frac{1-2 \alpha}{2-2 \alpha}$ - which is equivalent to $1-\lambda>\frac{1}{2-2 \alpha}$, as both governments will always have a strategic interest in choosing not to mitigate . 


\section{B The Real Estate Industry and Risks disclosure}

This section presents some recent anecdotal evidence that realtors are reluctant to any form of risk disclosure that could put them at a competitive disadvantage on the real estate market when buyers are unaware of the asset's exposure. There is some evidence that the real-estate industry lobbies brokers and State governments, while cities' revenues crucially depend on property taxes and transactions.

On February 15th, 2019, an anonymous developer expressed his view in the Guardian ${ }^{28}$ :

"I am surprised that people are still buying, building and investing in coastal Florida.". He estimated that "A decade ago, only one in 10 buyers asked about the property elevation, or expressed concerns about rising seas. Today, nearly six of 10 ask and many decide not to buy in these same critical areas." "I'm worried we're one bad storm away from a rush for the exits" he added.

To avoid a collapse for the industry, some realtors seem to be withholding valuable information on the risks of natural disasters. Albert Slap, owner of Coastal Risk Consulting, a company that help insurance companies and prospective buyers sizing up flood risks said that Florida's housing market kept afloat by "systemic fraudulent nondisclosure" from real-estate agents ${ }^{29}$.

In a New-York Times' inquiry published on Nov. 24th $2016^{30}$, Ian Urbina reported:

"Most real estate agents say they try to tackle the issue head-on, providing clients with maps indicating federally declared high-risk flood zones, and using climatechange preparedness as a selling point, emphasizing if the house has a backup generator or shingles that can withstand hurricane-strength winds. But real estate agents risk putting themselves at a competitive disadvantage by overstating threats. Good information is hard to come by. No one knows whether, when or by how much properties will depreciate, seas will encroach or flood insurance

\footnotetext{
${ }^{28}$ https://www.theguardian.com/environment/2019/feb/15/florida-climate-change-coastal-real-estaterising-seas

29 https://www.insurancejournal.com/news/southeast/2018/01/02/475789.htm

30 https://www.nytimes.com/2016/11/24/science/global-warming-coastal-real-estate.html
} 
policies will change. Valerie Amor, a real estate agent in Fort Lauderdale, said that, unlike most in her industry, she does a feasibility study before she assists in either buying or selling property."

It appears not to be an isolated agent case. The industry seems to lobby brokers and governments to avoid disclosing natural disaster risks. Urbina continues: "After strong objections from real estate companies, which threatened to stop providing data, Attom Data Solutions - "a multi-sourced national property data warehouse", took down its web page that integrated real estate listings with plot-by-plot information about the risks of floods, hurricanes, wildfires and other natural hazards."

Local governments are extremely dependent on the industry's good economic health. Indeed, local governments' revenues critically rely on property taxes and transactions. Interviewed about the role of cities in mitigation investments, James Murley, Miami-Dade's chief resilience officer, said it was "important to avoid spooking the [housing] market since real estate investment produces much of the revenue that pays for these upgrades."

Jim Cason, former mayor of Coral Gables confirmed this view in the Insurance Journal of January 2nd, $2018^{29}$ :

"Cason, who left office in May, attended a regular gathering of South Florida elected officials in Fort Lauderdale in December to talk about the effects of climate change. Unlike previous years, he said, the event this time was "totally sold-out." He said mayors and city managers shared their anxiety about what rising seas mean for their cities' property values. Those worries range from the mundane - finding more money to update infrastructure damaged by storms - to the existential: How long will banks keep issuing 30-year mortgages?"

States' budgets do not rely on property taxes and transactions. However, disclosure laws are set at the State government level. States' legislation varies regarding what real-estate agents and sellers must disclose about their property. Some, like California, Washington, or Pennsylvania, have strict legally-binding disclosure statements that must be signed upon sales. Others, like West Virginia or Alabama, do not have a standard disclosure document 
but instead, employ the "Caveat Emptor" or "Buyer Beware" rule ${ }^{31}$. This rule states that it is the buyer's responsibility to figure out if there are any issues with the home.

The real estate industry is also trying to influence states into passing laws preventing the disclosure of any sensitive information regarding potential natural disasters. Indeed, some states, like New-Jersey or Massachusetts, are moving towards stricter regulations. But it is not reflective of a general trend. For instance, in North Virginia, lawmakers confirmed the responsibility for discovering the risk exposure falls on the buyers ${ }^{30}$ :

Within a year, state lawmakers passed a real estate disclosure law that the industry hailed as a major step forward. "We are immensely satisfied," Deborah Baisden, then president of the Virginia Association of Realtors, said of the law. While the law encourages home buyers to exert due diligence in investigating the risk of living in a flood hazard area, it also explicitly states that the seller of a home is not obligated to disclose whether the home is in a zone that FEMA regards as high risk.

In some - yet more extreme - cases the industry sponsors policy-makers passing laws preventing from developing using building codes acknowledging climate risks ${ }^{32}$. This was the case in North-Carolina, where a 2012 law bans the state from basing coastal policies on the latest scientific predictions of how much the sea level will rise ${ }^{33}$. ABC's reporter Alon Harish wrote about McElraf, who drafted the law ${ }^{34}$ :

The largest industry contributors to McElraft's campaigns have been real estate agents and developers, according to the National Institute on Money in State Politics. Her top contributor since she was elected to the General Assembly in 2007 has been the North Carolina Association of Realtors, followed by the North Carolina Home Builders' Association. McElraft, who is a former real estate agent and lives on Barrier Island off the coast, denied that campaign contributions ever

\footnotetext{
${ }^{31}$ https://www.homelight.com/blog/mandated-disclosures-real-estate/

${ }^{32}$ https: / repository. wellesley.edu/cgi/viewcontent.cgi?article $=1100$ context=thesiscollection

${ }^{33}$ https://www.theguardian.com/us-news/2018/sep/12/north-carolina-didnt-like-science-on-sea-levels-sopassed-a-law-against-it

${ }^{34}$ https://abcnews.go.com/US/north-carolina-bans-latest-science-rising-sea-level/story?id=16913782
} 
influence her decisions as a lawmaker, and said her votes have not always favored increased development. 


\section{Figures and Tables}

Figure C.1: Publishing Cities (2010 - 2018)

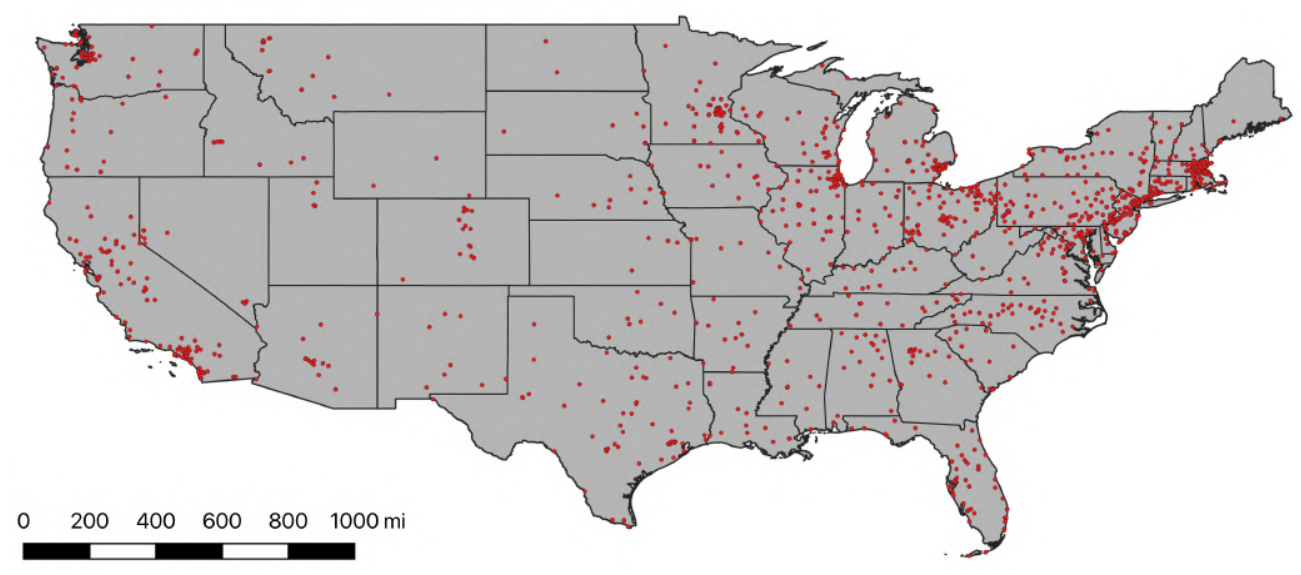

Notes: Spatial distribution publishing cities, defined as the city where a newspaper publisher is located, between 2010 and 2018. This information was graciously provided by the Alliance for Audited Media (AAM).

Figure C.2: Mitigation projects under the HMG Program (2010 - 2018)

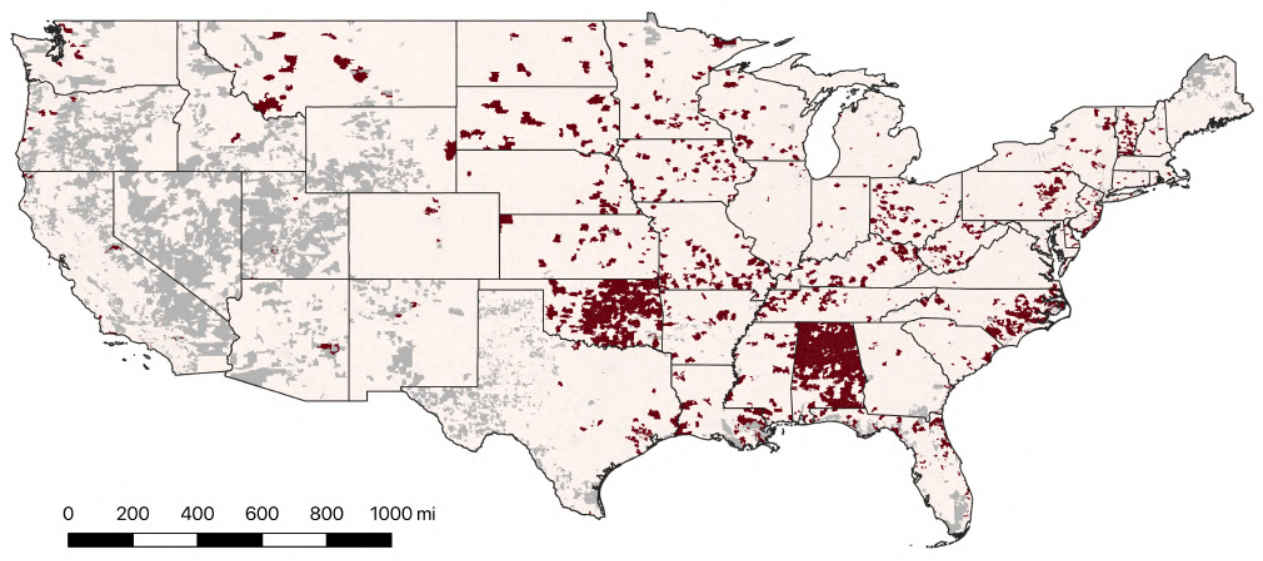

Notes: Spatial distribution of mitigation projects' ZIP code location under the HMG Program, between 2010 and 2018. This information was extracted from FEMA's online databases. Gray zones correspond to unpopulated areas. 
Figure C.3: New Residential Building Permits (2010 - 2018)

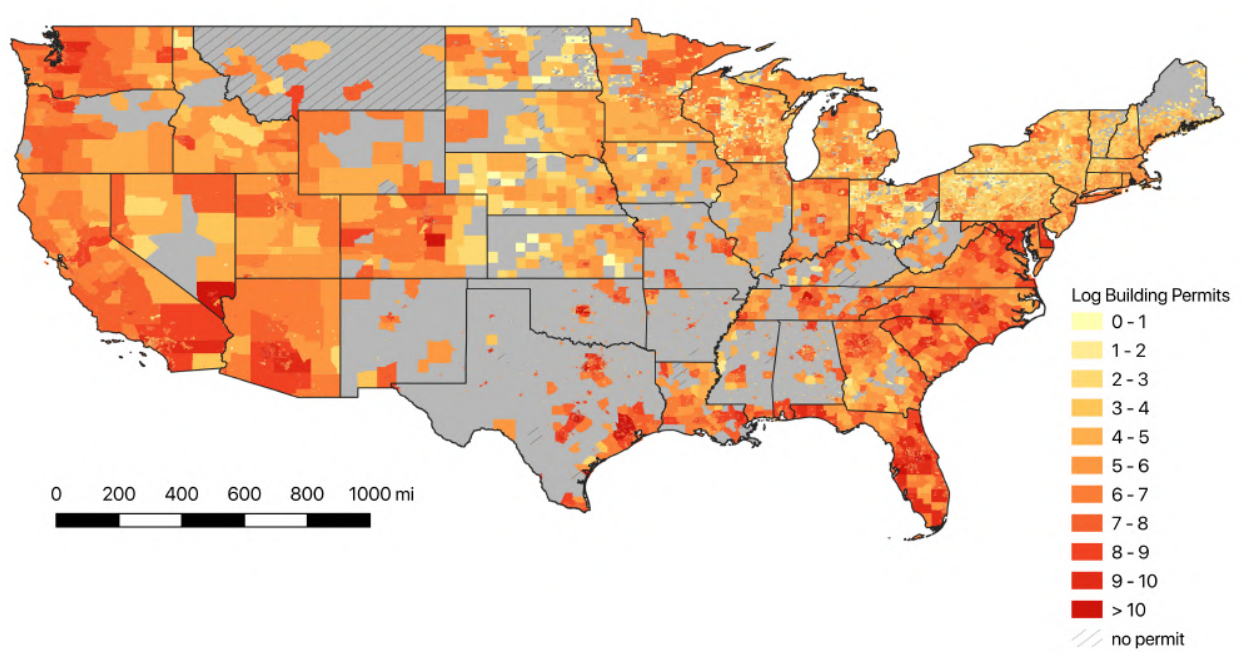

Notes: Spatial distribution of new residential building permits' location, by permit-issuing jurisdiction, between 2010 and 2018. This information was extracted from the Census Building Permits Survey. The sample contains 20,864 permit-issuing jurisdictions. Plain gray zones correspond to areas with unavailable information.

Figure C.4: Distribution of Coverage at the Permit-issuing Place level

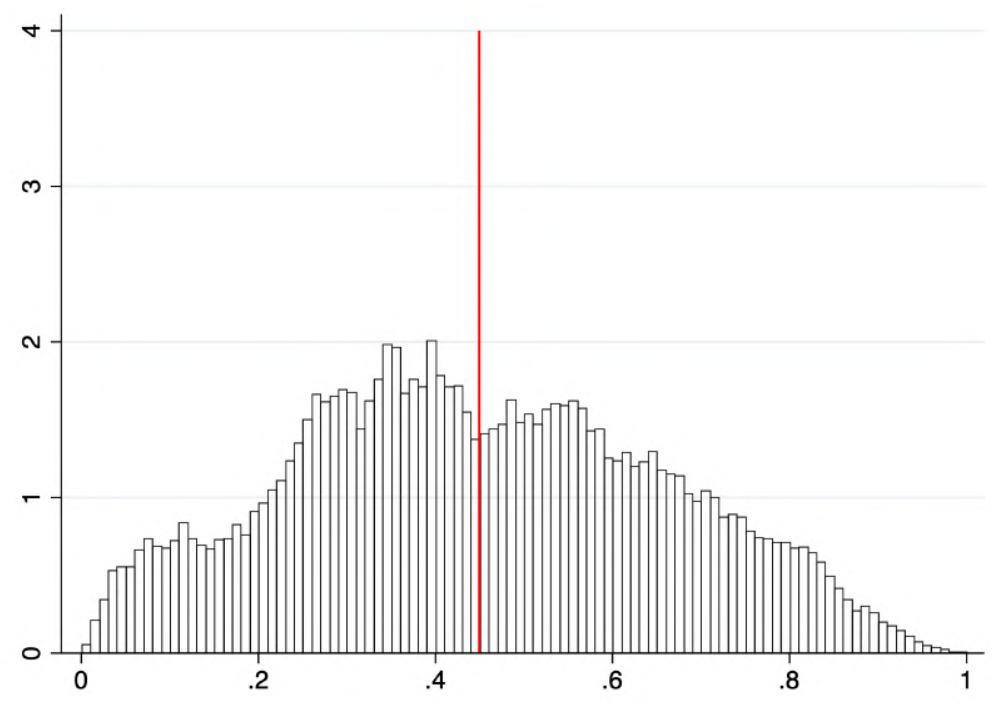

Notes: Information about storms and newspaper circulation has been aggregated at the permit-issuing jurisdiction level. Coverage has been computed following equation 1. The vertical red line corresponds to mean Coverage. 
Figure C.5: Distribution of Coverage at the ZIP code area level

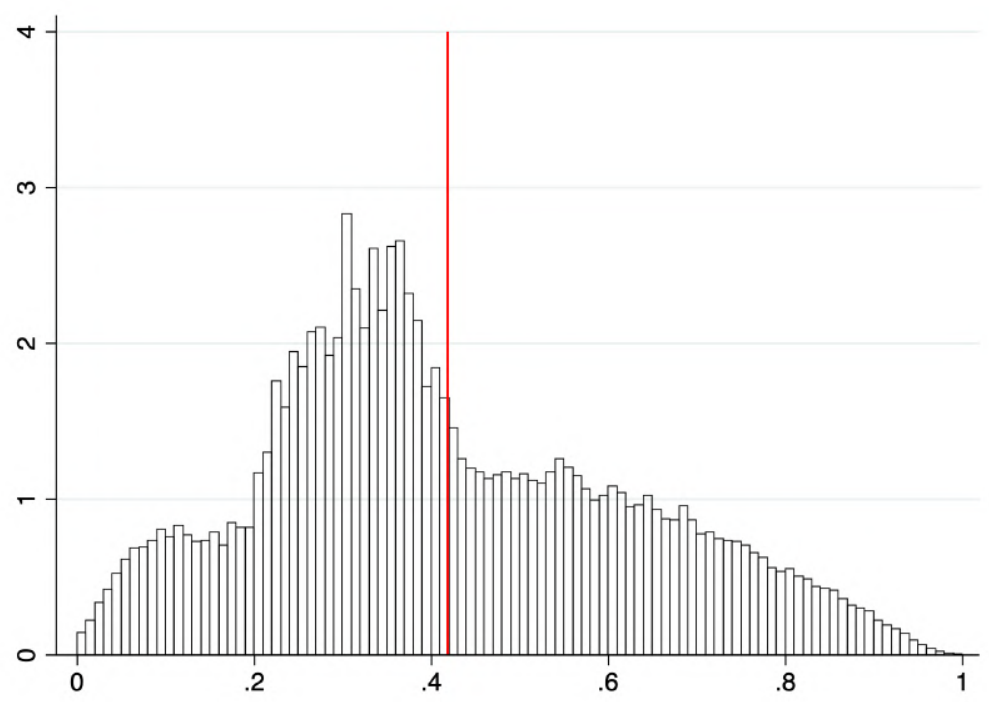

Notes: Coverage has been computed following equation 1. The vertical red line corresponds to mean Coverage.

Figure C.6: Distribution of Coverage at the ZIP code area level, and centered at its ZIP code mean

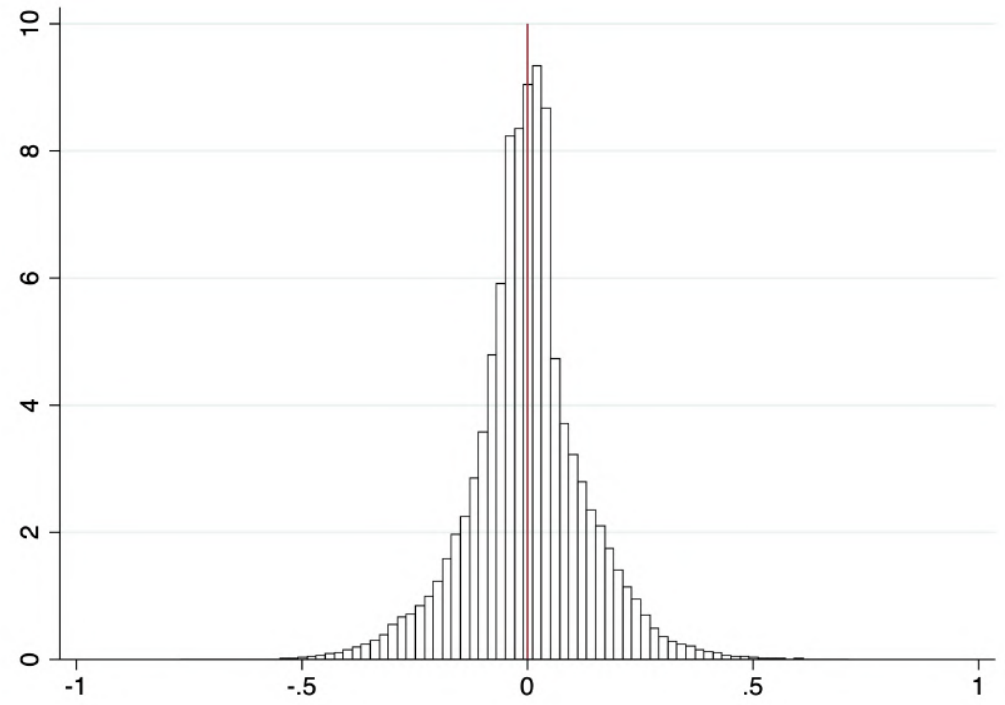

Notes: Coverage has been computed following equation 1. The vertical red line corresponds to mean Coverage, centered at its ZIP code mean. 


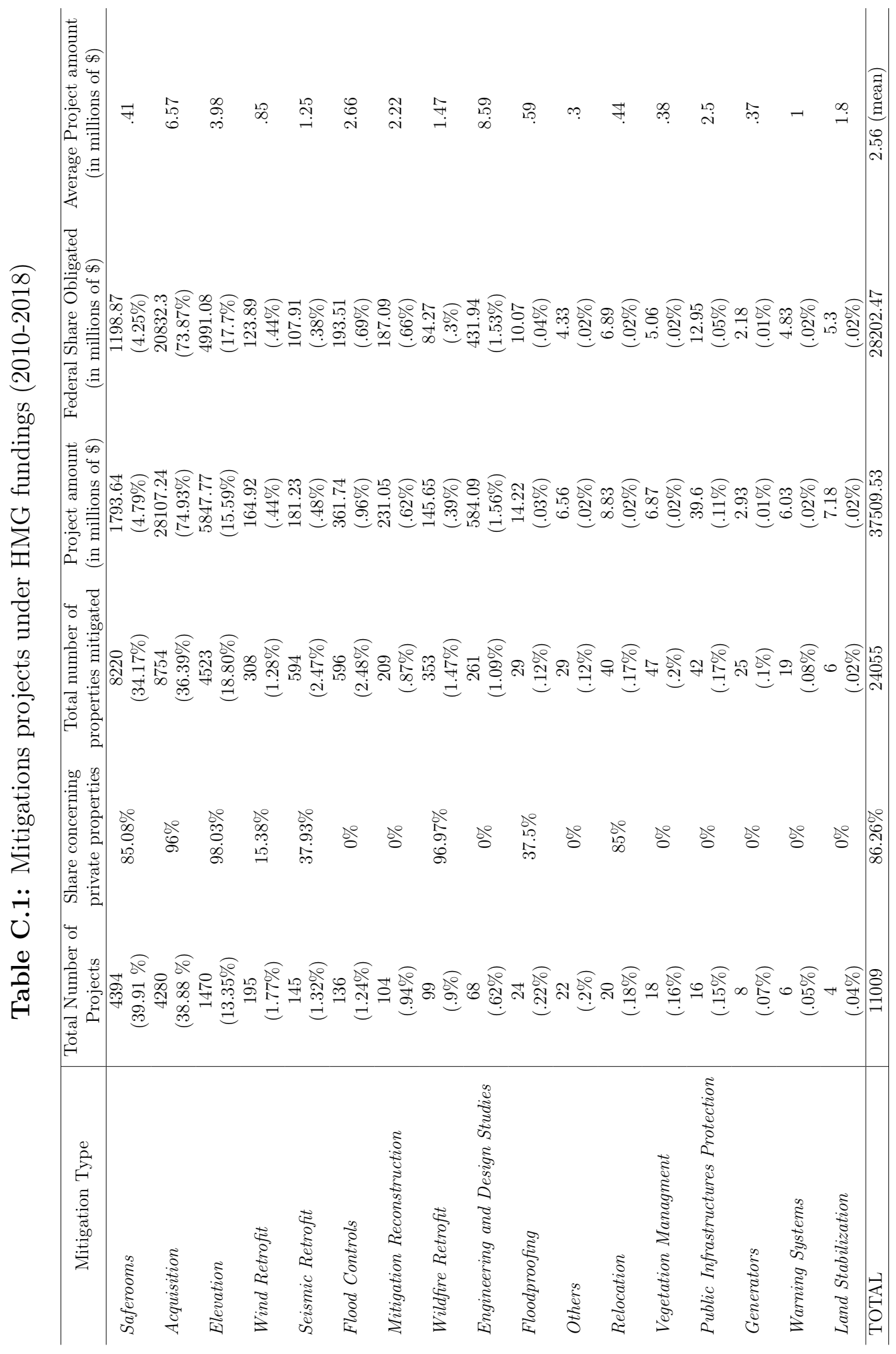


Table C.2a: Descriptive statistics

\begin{tabular}{|l|cccc|}
\hline \multicolumn{1}{|c|}{ Covariate } & Mean & Sd & Min & Max \\
\hline Demographics & & & & \\
\hline Log population & 7.950 & 1.919 & 0 & 11.79 \\
share above 65 year-old & 0.188 & 0.109 & 0 & 1 \\
Share of males & 0.487 & 0.073 & 0 & 1 \\
Share of immigrants & 0.058 & 0.071 & 0 & 1 \\
Share of non-native speakers & 0.109 & 0.158 & 0 & 1 \\
Share of foreign-born & 0.064 & 0.096 & 0 & 1 \\
Share of whites & 0.836 & 0.205 & 0 & 1 \\
Share of blacks & 0.081 & 0.162 & 0 & 1 \\
Share of natives & 0.015 & 0.075 & 0 & 1 \\
Share of asians & 0.022 & 0.054 & 0 & 1 \\
share of hawaiian & 0.001 & 0.010 & 0 & 0.729 \\
Share fo others & 0.024 & 0.057 & 0 & 1 \\
Log newspaper copies & 13.89 & 1.185 & 6.204 & 17.01 \\
& & & & \\
Income and Education & & & & \\
Log Income & 11.04 & 0.468 & 0 & 13.47 \\
Share less than highschool & 0.089 & 0.071 & 0 & 1 \\
Share of highschool dropout & 0.057 & 0.068 & 0 & 1 \\
Share of highschool diploma & 0.341 & 0.133 & 0 & 1 \\
Share of college dropout & 0.206 & 0.087 & 0 & 1 \\
Share of associate diploma & 0.079 & 0.054 & 0 & 1 \\
Share of Bachelor diploma & 0.148 & 0.101 & 0 & 1 \\
Share of Graduate diploma & 0.087 & 0.091 & 0 & 1 \\
& & & & \\
\hline
\end{tabular}


Table C.2b: Descriptive statistics

\begin{tabular}{|l|cccc|}
\hline \multicolumn{1}{|c|}{ Covariate } & Mean & Sd & Min & Max \\
\hline Weather & & & & \\
Log temperatures & 2.612 & 0.336 & 0.416 & 3.319 \\
Log wind speed & 1.898 & 0.298 & 0 & 3.539 \\
Log rainfalls & 4.401 & 0.522 & 1.206 & 5.718 \\
& & & & \\
Labor Composition & & & & \\
Share labor force & 0.470 & 0.125 & 0 & 1 \\
Share in the agriculture & 0.061 & 0.105 & 0 & 1 \\
Share in the construction & 0.077 & 0.067 & 0 & 1 \\
Share in the manufacture & 0.112 & 0.092 & 0 & 1 \\
Share in wholesales & 0.026 & 0.035 & 0 & 1 \\
Share in retail & 0.112 & 0.073 & 0 & 1 \\
Share in transportation & 0.056 & 0.057 & 0 & 1 \\
Share in information & 0.017 & 0.027 & 0 & 1 \\
Share in finance & 0.052 & 0.052 & 0 & 1 \\
Share in professorship & 0.082 & 0.071 & 0 & 1 \\
Share in education & 0.226 & 0.103 & 0 & 1 \\
Share in arts & 0.081 & 0.074 & 0 & 1 \\
Share in public administration & 0.053 & 0.062 & 0 & 1 \\
Share in others & 0.047 & 0.048 & 0 & 1 \\
Share unemployed & 0.086 & 0.089 & 0 & 1 \\
& & & & \\
\hline
\end{tabular}


Table C.2c: Descriptive statistics

\begin{tabular}{|l|cccc|}
\hline \multicolumn{1}{|c|}{ Covariate } & Mean & Sd & Min & Max \\
\hline Housing Composition & & & & \\
\hline Log housing units & & & & \\
Log housing sales & 7.142 & 1.889 & 0 & 10.77 \\
Log median value & 3.176 & 2.049 & 0 & 8.016 \\
Share under $\$ 50.000$ & 11.87 & 0.724 & 0 & 15.19 \\
Share $\$ 50.000-\$ 100.000$ & 0.157 & 0.171 & 0 & 1 \\
Share $\$ 100.000-\$ 150.000$ & 0.203 & 0.176 & 0 & 1 \\
Share $\$ 150.000-\$ 200.000$ & 0.144 & 0.118 & 0 & 1 \\
Share $\$ 200.000-\$ 300.000$ & 0.150 & 0.105 & 0 & 1 \\
Share $\$ 300.000-\$ 500.000$ & 0.128 & 0.157 & 0 & 1 \\
Share $\$ 300.000-\$ 1.000 .000$ & 0.071 & 0.135 & 0 & 1 \\
Share above $\$ 1.000 .000$ & 0.022 & 0.074 & 0 & 1 \\
Share built in the 2010's & 0.011 & 0.028 & 0 & 1 \\
Share built in the 2000's & 0.121 & 0.115 & 0 & 1 \\
Share built in the 1990's & 0.134 & 0.099 & 0 & 1 \\
Share built in the 1980's & 0.132 & 0.095 & 0 & 1 \\
Share built in the 1970's & 0.157 & 0.096 & 0 & 1 \\
Share built in the 1960's & 0.100 & 0.078 & 0 & 1 \\
Share built in the 1940-1950's & 0.153 & 0.120 & 0 & 1 \\
Share built before 1940's & 0.193 & 0.184 & 0 & 1 \\
Share of owner-occupied units & 0.735 & 0.178 & 0 & 1 \\
Share of vacant units & 0.166 & 0.152 & 0 & 1 \\
Share with mortgage & 0.562 & 0.180 & 0 & 1 \\
& & & & \\
\hline
\end{tabular}


Table C.3a: Balance tests for Storm and Coverage, separately.

\begin{tabular}{|c|c|c|c|c|c|c|}
\hline Pre-Treatment Outcome & \multicolumn{2}{|c|}{ Storm } & \multicolumn{3}{|c|}{ Coverage } & \multirow[t]{2}{*}{$\mu / \mathrm{sd}$} \\
\hline \multicolumn{6}{|l|}{ Demographics } & \\
\hline \multirow[t]{2}{*}{$\overline{\text { Log Population }}$} & -0.002 & -0.001 & $-0.096^{* * *}$ & - & - & 7.950 \\
\hline & $(0.002)$ & $(0.002)$ & $(0.025)$ & - & - & (1.919) \\
\hline \multirow[t]{2}{*}{ Share above 65 year-old } & 0.000 & 0.000 & $0.014^{* *}$ & 0.007 & $0.006^{*}$ & 0.188 \\
\hline & $(0.001)$ & $(0.001)$ & $(0.006)$ & $(0.006)$ & $(0.003)$ & $(0.109)$ \\
\hline \multirow[t]{2}{*}{ Share of males } & 0.000 & -0.000 & 0.006 & 0.006 & 0.002 & 0.487 \\
\hline & $(0.000)$ & $(0.000)$ & $(0.005)$ & $(0.005)$ & $(0.003)$ & $(0.073)$ \\
\hline \multirow[t]{2}{*}{ Share of immigrants } & -0.000 & -0.000 & 0.005 & 0.006 & 0.003 & 0.058 \\
\hline & $(0.000)$ & $(0.000)$ & $(0.004)$ & $(0.004)$ & $(0.002)$ & $(0.071)$ \\
\hline \multirow[t]{2}{*}{ Share of non native speakers } & 0.023 & 0.018 & 0.174 & -0.371 & -0.216 & 0.109 \\
\hline & $(0.041)$ & $(0.036)$ & $(0.391)$ & $(0.392)$ & $(0.220)$ & $(0.158)$ \\
\hline \multirow[t]{2}{*}{ Share of foreign-born } & -0.000 & -0.000 & 0.000 & 0.001 & -0.000 & 0.064 \\
\hline & $(0.000)$ & $(0.000)$ & $(0.003)$ & $(0.003)$ & $(0.002)$ & $(0.096)$ \\
\hline \multirow[t]{2}{*}{ Share of whites } & -0.000 & 0.000 & -0.003 & -0.003 & -0.002 & 0.836 \\
\hline & $(0.001)$ & $(0.000)$ & $(0.004)$ & $(0.004)$ & $(0.002)$ & $(0.205)$ \\
\hline \multirow[t]{2}{*}{ Share of blacks } & -0.000 & -0.000 & -0.001 & -0.001 & 0.000 & 0.081 \\
\hline & $(0.000)$ & $(0.000)$ & $(0.003)$ & $(0.003)$ & $(0.002)$ & $(0.162)$ \\
\hline \multirow[t]{2}{*}{ Share of natives } & -0.000 & 0.000 & 0.001 & 0.001 & 0.001 & 0.015 \\
\hline & $(0.000)$ & $(0.000)$ & $(0.001)$ & $(0.001)$ & $(0.001)$ & $(0.075)$ \\
\hline \multirow[t]{2}{*}{ Share of asians } & -0.000 & -0.000 & -0.000 & -0.000 & 0.000 & 0.022 \\
\hline & $(0.000)$ & $(0.000)$ & $(0.001)$ & $(0.001)$ & $(0.001)$ & $(0.054)$ \\
\hline \multirow[t]{2}{*}{ Share of hawaians } & -0.000 & -0.000 & 0.000 & 0.001 & 0.000 & 0.001 \\
\hline & $(0.000)$ & $(0.000)$ & $(0.001)$ & $(0.001)$ & $(0.000)$ & $(0.010)$ \\
\hline \multirow[t]{2}{*}{ Share of others } & 0.000 & 0.000 & 0.002 & 0.002 & 0.001 & 0.024 \\
\hline & $(0.000)$ & $(0.000)$ & $(0.002)$ & $(0.002)$ & $(0.001)$ & $(0.057)$ \\
\hline \multirow[t]{2}{*}{ Log newspaper copies } & 0.002 & -0.009 & 0.090 & 0.093 & 0.006 & 13.89 \\
\hline & $(0.005)$ & $(0.007)$ & $(0.071)$ & $(0.071)$ & $(0.062)$ & $(1.185)$ \\
\hline \multicolumn{7}{|l|}{ Income and Education } \\
\hline \multirow[t]{2}{*}{$\overline{\log \text { Income }}$} & 0.002 & 0.001 & -0.007 & 0.006 & -0.003 & 11.04 \\
\hline & $(0.003)$ & $(0.003)$ & $(0.028)$ & $(0.028)$ & $(0.017)$ & $(0.468)$ \\
\hline \multirow[t]{2}{*}{ Share less than highschool } & 0.001 & 0.001 & 0.007 & 0.008 & 0.003 & 0.089 \\
\hline & $(0.001)$ & $(0.000)$ & $(0.006)$ & $(0.006)$ & $(0.003)$ & $(0.071)$ \\
\hline Share highschool dropout & 0.000 & 0.000 & -0.002 & -0.002 & -0.000 & 0.057 \\
\hline & $(0.000)$ & $(0.000)$ & $(0.005)$ & $(0.005)$ & $(0.002)$ & $(0.068)$ \\
\hline Share highschool diploma & -0.000 & -0.000 & 0.002 & 0.003 & 0.000 & 0.341 \\
\hline & $(0.001)$ & $(0.001)$ & $(0.008)$ & $(0.008)$ & $(0.004)$ & $(0.133)$ \\
\hline Share college dropout & 0.001 & 0.000 & 0.004 & 0.003 & -0.001 & 0.206 \\
\hline & $(0.001)$ & $(0.001)$ & $(0.007)$ & $(0.007)$ & $(0.003)$ & $(0.087)$ \\
\hline Share associate diploma & -0.000 & -0.000 & -0.002 & -0.002 & 0.001 & 0.079 \\
\hline & $(0.000)$ & $(0.000)$ & $(0.004)$ & $(0.004)$ & $(0.002)$ & $(0.054)$ \\
\hline Share bachelor diploma & -0.000 & -0.000 & -0.007 & -0.007 & -0.002 & 0.148 \\
\hline & $(0.001)$ & $(0.000)$ & $(0.005)$ & $(0.005)$ & $(0.003)$ & $(0.101)$ \\
\hline Share graduate studies & -0.000 & -0.000 & -0.003 & -0.003 & -0.002 & 0.087 \\
\hline & $(0.000)$ & $(0.000)$ & $(0.004)$ & $(0.004)$ & $(0.002)$ & $(0.091)$ \\
\hline ZIP Code FE & $\mathrm{Y}$ & $\mathrm{Y}$ & $\mathrm{Y}$ & $\mathrm{Y}$ & $\mathrm{Y}$ & - \\
\hline County-Year FE & $\mathrm{Y}$ & $\mathrm{N}$ & $\mathrm{Y}$ & $\mathrm{Y}$ & $\mathrm{N}$ & - \\
\hline State-Year FE & $\mathrm{N}$ & $\mathrm{Y}$ & $\mathrm{N}$ & $\mathrm{N}$ & $\mathrm{Y}$ & - \\
\hline Baseline Population & $\mathrm{N}$ & $\mathrm{N}$ & $\mathrm{N}$ & $\mathrm{Y}$ & $\mathrm{Y}$ & - \\
\hline
\end{tabular}


Table C.3b: Balance tests for Storm and Coverage, separately.

\begin{tabular}{|c|c|c|c|c|c|c|}
\hline Pre-Treatment Outcome & \multicolumn{2}{|c|}{ Storm } & \multicolumn{3}{|c|}{ Coverage } & \multirow[t]{2}{*}{$\mu / \mathrm{sd}$} \\
\hline & & & & & & \\
\hline Log temperatures & $\begin{array}{l}-0.000 \\
(0.000)\end{array}$ & $\begin{array}{c}0.000 \\
(0.000)\end{array}$ & $\begin{array}{l}-0.001 \\
(0.001)\end{array}$ & $\begin{array}{l}-0.001 \\
(0.001)\end{array}$ & $\begin{array}{l}-0.003 \\
(0.002)\end{array}$ & $\begin{array}{c}2.612 \\
(0.336)\end{array}$ \\
\hline Log wind speed & $\begin{array}{c}0.002 \\
(0.001)\end{array}$ & $\begin{array}{l}0.003^{*} \\
(0.002)\end{array}$ & $\begin{array}{c}0.005 \\
(0.008)\end{array}$ & $\begin{array}{c}0.005 \\
(0.009)\end{array}$ & $\begin{array}{c}0.041^{* * *} \\
(0.013)\end{array}$ & $\begin{array}{c}1.898 \\
(0.298)\end{array}$ \\
\hline Log rainfalls & $\begin{array}{c}0.002 \\
(0.001)\end{array}$ & $\begin{array}{l}-0.001 \\
(0.002)\end{array}$ & $\begin{array}{c}0.003 \\
(0.007)\end{array}$ & $\begin{array}{c}0.003 \\
(0.007)\end{array}$ & $\begin{array}{c}0.016 \\
(0.015)\end{array}$ & $\begin{array}{c}4.401 \\
(0.522)\end{array}$ \\
\hline \multicolumn{7}{|l|}{ Labor Compostion } \\
\hline$\overline{\text { Share labor force }}$ & $\begin{array}{l}-0.026 \\
(0.060)\end{array}$ & $\begin{array}{l}-0.025 \\
(0.057)\end{array}$ & $\begin{array}{l}-0.554 \\
(0.696)\end{array}$ & $\begin{array}{c}0.258 \\
(0.690)\end{array}$ & $\begin{array}{l}-0.123 \\
(0.368)\end{array}$ & $\begin{array}{c}0.470 \\
(0.067)\end{array}$ \\
\hline Share in the agriculture & $\begin{array}{l}-0.000 \\
(0.001)\end{array}$ & $\begin{array}{l}-0.001 \\
(0.001)\end{array}$ & $\begin{array}{c}0.013^{* *} \\
(0.005)\end{array}$ & $\begin{array}{l}0.013^{* *} \\
(0.005)\end{array}$ & $\begin{array}{c}0.007^{* * * *} \\
(0.003)\end{array}$ & $\begin{array}{c}0.067 \\
(0.105)\end{array}$ \\
\hline Share in the construction & $\begin{array}{c}0.000 \\
(0.001)\end{array}$ & $\begin{array}{c}0.001 \\
(0.000)\end{array}$ & $\begin{array}{c}0.005 \\
(0.005)\end{array}$ & $\begin{array}{c}0.006 \\
(0.005)\end{array}$ & $\begin{array}{c}0.001 \\
(0.003)\end{array}$ & $\begin{array}{c}0.077 \\
(0.067)\end{array}$ \\
\hline Share in the manufacture & $\begin{array}{l}0.001^{*} \\
(0.001)\end{array}$ & $\begin{array}{l}0.001^{* *} \\
(0.001)\end{array}$ & $\begin{array}{l}-0.007 \\
(0.005)\end{array}$ & $\begin{array}{l}-0.007 \\
(0.005)\end{array}$ & $\begin{array}{l}-0.003 \\
(0.003)\end{array}$ & $\begin{array}{c}0.112 \\
(0.092)\end{array}$ \\
\hline Share in wholesales & $\begin{array}{l}-0.000 \\
(0.000)\end{array}$ & $\begin{array}{c}0.000 \\
(0.000)\end{array}$ & $\begin{array}{l}-0.001 \\
(0.003)\end{array}$ & $\begin{array}{l}-0.001 \\
(0.003)\end{array}$ & $\begin{array}{c}0.001 \\
(0.001)\end{array}$ & $\begin{array}{c}0.026 \\
(0.035)\end{array}$ \\
\hline Share in retail & $\begin{array}{l}-0.001^{*} \\
(0.001)\end{array}$ & $\begin{array}{l}-0.001^{*} \\
(0.001)\end{array}$ & $\begin{array}{c}0.002 \\
(0.005)\end{array}$ & $\begin{array}{c}0.003 \\
(0.005)\end{array}$ & $\begin{array}{l}-0.003 \\
(0.003)\end{array}$ & $\begin{array}{c}0.112 \\
(0.073)\end{array}$ \\
\hline Share in transportation & $\begin{array}{l}-0.001 \\
(0.000)\end{array}$ & $\begin{array}{l}-0.001 \\
(0.000)\end{array}$ & $\begin{array}{c}0.002 \\
(0.004)\end{array}$ & $\begin{array}{c}0.002 \\
(0.004)\end{array}$ & $\begin{array}{c}0.003 \\
(0.002)\end{array}$ & $\begin{array}{c}0.056 \\
(0.057)\end{array}$ \\
\hline Share in information & $\begin{array}{l}-0.000 \\
(0.000)\end{array}$ & $\begin{array}{l}-0.000 \\
(0.000)\end{array}$ & $\begin{array}{l}-0.001 \\
(0.002)\end{array}$ & $\begin{array}{l}-0.002 \\
(0.002)\end{array}$ & $\begin{array}{c}0.001 \\
(0.001)\end{array}$ & $\begin{array}{c}0.017 \\
(0.027)\end{array}$ \\
\hline Share in finance & $\begin{array}{c}0.000 \\
(0.000)\end{array}$ & $\begin{array}{c}0.000 \\
(0.000)\end{array}$ & $\begin{array}{l}-0.001 \\
(0.003)\end{array}$ & $\begin{array}{l}-0.001 \\
(0.003)\end{array}$ & $\begin{array}{c}0.001 \\
(0.002)\end{array}$ & $\begin{array}{c}0.052 \\
(0.052)\end{array}$ \\
\hline Share in professorship & $\begin{array}{l}-0.000 \\
(0.000)\end{array}$ & $\begin{array}{l}-0.000 \\
(0.000)\end{array}$ & $\begin{array}{l}-0.006 \\
(0.004)\end{array}$ & $\begin{array}{l}-0.006 \\
(0.004)\end{array}$ & $\begin{array}{l}-0.000 \\
(0.002)\end{array}$ & $\begin{array}{c}0.082 \\
(0.071)\end{array}$ \\
\hline Share in education & $\begin{array}{c}0.001 \\
(0.001)\end{array}$ & $\begin{array}{c}0.000 \\
(0.001)\end{array}$ & $\begin{array}{l}-0.005 \\
(0.008)\end{array}$ & $\begin{array}{l}-0.005 \\
(0.008)\end{array}$ & $\begin{array}{l}-0.006 \\
(0.004)\end{array}$ & $\begin{array}{c}0.226 \\
(0.103)\end{array}$ \\
\hline Share in arts & $\begin{array}{l}-0.000 \\
(0.001)\end{array}$ & $\begin{array}{l}-0.000 \\
(0.000)\end{array}$ & $\begin{array}{c}0.005 \\
(0.004)\end{array}$ & $\begin{array}{c}0.006 \\
(0.004)\end{array}$ & $\begin{array}{c}0.001 \\
(0.002)\end{array}$ & $\begin{array}{c}0.081 \\
(0.074)\end{array}$ \\
\hline Share in public administration & $\begin{array}{c}0.000 \\
(0.000)\end{array}$ & $\begin{array}{c}0.000 \\
(0.000)\end{array}$ & $\begin{array}{l}-0.001 \\
(0.004)\end{array}$ & $\begin{array}{l}-0.001 \\
(0.004)\end{array}$ & $\begin{array}{l}-0.001 \\
(0.002)\end{array}$ & $\begin{array}{c}0.053 \\
(0.062)\end{array}$ \\
\hline Share in others & $\begin{array}{l}-0.001 \\
(0.000)\end{array}$ & $\begin{array}{l}-0.000 \\
(0.000)\end{array}$ & $\begin{array}{l}-0.005 \\
(0.005)\end{array}$ & $\begin{array}{l}-0.006 \\
(0.005)\end{array}$ & $\begin{array}{l}-0.001 \\
(0.002)\end{array}$ & $\begin{array}{c}0.047 \\
(0.048)\end{array}$ \\
\hline Share unemployed & $\begin{array}{c}0.000 \\
(0.001)\end{array}$ & $\begin{array}{c}0.000 \\
(0.001)\end{array}$ & $\begin{array}{l}-0.004 \\
(0.006)\end{array}$ & $\begin{array}{l}-0.004 \\
(0.006)\end{array}$ & $\begin{array}{l}-0.001 \\
(0.003)\end{array}$ & $\begin{array}{c}0.086 \\
(0.089)\end{array}$ \\
\hline ZIP Code FE & $\mathrm{Y}$ & $\mathrm{Y}$ & $\mathrm{Y}$ & $\mathrm{Y}$ & $\mathrm{Y}$ & - \\
\hline County-Year FE & $\mathrm{Y}$ & $\mathrm{N}$ & Y & Y & $\mathrm{N}$ & - \\
\hline State-Year FE & $\mathrm{N}$ & Y & $\mathrm{N}$ & $\mathrm{N}$ & $\mathrm{Y}$ & - \\
\hline Baseline Population & $\mathrm{N}$ & $\mathrm{N}$ & $\mathrm{N}$ & Y & $\mathrm{Y}$ & - \\
\hline
\end{tabular}


Table C.3c: Balance tests for Storm and Coverage, separately.

\begin{tabular}{|c|c|c|c|c|c|c|}
\hline Pre-Treatment Outcome & \multicolumn{2}{|c|}{ Storm } & \multicolumn{3}{|c|}{ Coverage } & $\mu / \mathrm{sd}$ \\
\hline \multicolumn{7}{|l|}{ Housing Markets } \\
\hline \multirow[t]{2}{*}{$\overline{\text { Log housing Units }}$} & 0.001 & 0.001 & $-0.042^{*}$ & 0.005 & 0.001 & 7.142 \\
\hline & $(0.002)$ & $(0.002)$ & $(0.025)$ & $(0.022)$ & $(0.010)$ & $(1.889)$ \\
\hline \multirow[t]{2}{*}{ Log housing sales } & -0.000 & -0.006 & -0.037 & -0.035 & -0.057 & 3.176 \\
\hline & $(0.007)$ & $(0.008)$ & $(0.038)$ & $(0.038)$ & $(0.043)$ & $(2.049)$ \\
\hline \multirow[t]{2}{*}{ Log median value } & -0.001 & -0.002 & -0.017 & -0.015 & -0.010 & 11.87 \\
\hline & $(0.002)$ & $(0.002)$ & $(0.022)$ & $(0.021)$ & $(0.012)$ & $(0.724)$ \\
\hline \multirow[t]{2}{*}{ Share under $\$ 50.000$} & 0.000 & 0.001 & 0.008 & 0.008 & 0.005 & 0.157 \\
\hline & $(0.001)$ & $(0.001)$ & $(0.007)$ & $(0.007)$ & $(0.004)$ & $(0.171)$ \\
\hline \multirow[t]{2}{*}{ Share $\$ 50.000-\$ 100.000$} & 0.001 & 0.000 & 0.009 & 0.008 & 0.006 & 0.203 \\
\hline & $(0.001)$ & $(0.001)$ & $(0.008)$ & $(0.008)$ & $(0.004)$ & $(0.176)$ \\
\hline \multirow[t]{2}{*}{ Share $\$ 100.000$ - $\$ 150.000$} & -0.000 & -0.001 & -0.005 & -0.005 & -0.005 & 0.144 \\
\hline & $(0.001)$ & $(0.001)$ & $(0.006)$ & $(0.006)$ & $(0.004)$ & $(0.118)$ \\
\hline \multirow[t]{2}{*}{ Share $\$ 150.000-\$ 200.000$} & -0.000 & -0.000 & -0.002 & -0.003 & -0.001 & 0.125 \\
\hline & $(0.001)$ & $(0.001)$ & $(0.006)$ & $(0.005)$ & $(0.003)$ & $(0.105)$ \\
\hline \multirow[t]{2}{*}{ Share $\$ 200.000$ - $\$ 300.000$} & -0.001 & 0.000 & $-0.012^{* *}$ & $-0.012^{* *}$ & -0.004 & 0.150 \\
\hline & $(0.001)$ & $(0.001)$ & $(0.005)$ & $(0.005)$ & $(0.003)$ & $(0.133)$ \\
\hline \multirow[t]{2}{*}{ Share $\$ 300.000-\$ 500.000$} & 0.000 & 0.000 & 0.003 & 0.004 & -0.000 & 0.128 \\
\hline & $(0.001)$ & $(0.001)$ & $(0.005)$ & $(0.005)$ & $(0.003)$ & $(0.157)$ \\
\hline \multirow[t]{2}{*}{ Share $\$ 500.000-\$ 1.000 .000$} & -0.000 & -0.000 & -0.004 & -0.004 & -0.000 & 0.071 \\
\hline & $(0.000)$ & $(0.000)$ & $(0.003)$ & $(0.003)$ & $(0.002)$ & $(0.135)$ \\
\hline \multirow[t]{2}{*}{ Share above $\$ 1.000 .000$} & -0.000 & -0.000 & 0.003 & 0.003 & 0.001 & 0.022 \\
\hline & $(0.000)$ & $(0.000)$ & $(0.002)$ & $(0.002)$ & $(0.001)$ & $(0.074)$ \\
\hline \multirow[t]{2}{*}{ Share built in the 2010's } & 0.000 & $0.000^{*}$ & -0.001 & -0.001 & -0.000 & 0.011 \\
\hline & $(0.000)$ & $(0.000)$ & $(0.002)$ & $(0.002)$ & $(0.001)$ & $(0.028)$ \\
\hline \multirow[t]{2}{*}{ Share built in the 2000's } & -0.000 & -0.000 & 0.000 & 0.001 & 0.000 & 0.121 \\
\hline & $(0.001)$ & $(0.001)$ & $(0.005)$ & $(0.005)$ & $(0.003)$ & $(0.115)$ \\
\hline \multirow[t]{2}{*}{ Share built in the 1990's } & 0.000 & 0.000 & -0.003 & -0.003 & -0.001 & 0.134 \\
\hline & $(0.001)$ & $(0.001)$ & $(0.005)$ & $(0.005)$ & $(0.003)$ & $(0.099)$ \\
\hline \multirow[t]{2}{*}{ Share built in the 1980's } & -0.000 & -0.000 & 0.007 & 0.007 & 0.003 & 0.132 \\
\hline & $(0.001)$ & $(0.001)$ & $(0.005)$ & $(0.005)$ & $(0.003)$ & $(0.095)$ \\
\hline \multirow[t]{2}{*}{ Share built in the 1970's } & 0.000 & -0.000 & -0.002 & -0.001 & -0.003 & 0.157 \\
\hline & $(0.001)$ & $(0.001)$ & $(0.006)$ & $(0.006)$ & $(0.003)$ & $(0.096)$ \\
\hline \multirow[t]{2}{*}{ Share built in the 1960 's } & $-0.001^{*}$ & $-0.001^{*}$ & -0.005 & -0.006 & 0.000 & 0.100 \\
\hline & $(0.001)$ & $(0.000)$ & $(0.004)$ & $(0.004)$ & $(0.003)$ & $(0.078)$ \\
\hline \multirow[t]{2}{*}{ Share built in the $1940-1950$ 's } & 0.001 & 0.001 & 0.003 & 0.003 & -0.001 & 0.153 \\
\hline & $(0.001)$ & $(0.001)$ & $(0.005)$ & $(0.005)$ & $(0.003)$ & $(0.120)$ \\
\hline Share built before 1940 & 0.000 & 0.000 & 0.001 & 0.001 & 0.002 & 0.193 \\
\hline & $(0.001)$ & $(0.001)$ & $(0.006)$ & $(0.006)$ & $(0.003)$ & $(0.184)$ \\
\hline Share of owner-occupied units & -0.001 & -0.001 & -0.002 & -0.004 & 0.003 & 0.735 \\
\hline & $(0.001)$ & $(0.001)$ & $(0.007)$ & $(0.007)$ & $(0.004)$ & $(0.178)$ \\
\hline Share of vacant units & 0.009 & -0.002 & $1.091^{*}$ & 0.228 & 0.420 & 0.166 \\
\hline & $(0.065)$ & $(0.062)$ & $(0.618)$ & $(0.573)$ & $(0.335)$ & $(0.152)$ \\
\hline Share with mortgage & -0.001 & -0.001 & 0.008 & 0.011 & $0.012^{* * *}$ & 0.562 \\
\hline & $(0.001)$ & $(0.001)$ & $(0.008)$ & $(0.008)$ & $(0.004)$ & $(0.180)$ \\
\hline ZIP Code FE & $\mathrm{Y}$ & $\mathrm{Y}$ & $\mathrm{Y}$ & $\mathrm{Y}$ & $\mathrm{Y}$ & - \\
\hline County-Year FE & $\mathrm{Y}$ & $\mathrm{N}$ & $\mathrm{Y}$ & $\mathrm{Y}$ & $\mathrm{N}$ & - \\
\hline State-Year FE & $\mathrm{N}$ & $\mathrm{Y}$ & $\mathrm{N}$ & $\mathrm{N}$ & $\mathrm{Y}$ & - \\
\hline Baseline Population & $\mathrm{N}$ & $\mathrm{N}$ & $\mathrm{N}$ & $\mathrm{Y}$ & $\mathrm{Y}$ & - \\
\hline
\end{tabular}


Table C.3d: Balance tests for main specification

\begin{tabular}{|c|c|c|c|c|c|c|c|}
\hline \multirow[t]{2}{*}{ Pre-Treatment Outcome } & \multicolumn{3}{|c|}{ Model 1} & \multicolumn{3}{|c|}{ Model 2} & \multirow[t]{2}{*}{$\mu / \mathrm{sd}$} \\
\hline & $\beta_{1}$ & $\beta_{2}$ & $\beta_{3}$ & $\beta_{1}$ & $\beta_{2}$ & $\beta_{3}$ & \\
\hline \multicolumn{8}{|l|}{ Demographics } \\
\hline \multirow[t]{2}{*}{$\overline{\text { Log Population }}$} & $-0.105^{* * *}$ & -0.001 & 0.029 & - & - & - & 7.950 \\
\hline & $(0.028)$ & $(0.002)$ & $(0.020)$ & - & - & - & $(1.919)$ \\
\hline \multirow[t]{2}{*}{ Share above 65 year-old } & $0.016^{* *}$ & -0.000 & -0.004 & 0.008 & -0.000 & -0.002 & 0.188 \\
\hline & $(0.007)$ & $(0.001)$ & $(0.005)$ & $(0.006)$ & $(0.001)$ & $(0.005)$ & $(0.109)$ \\
\hline \multirow[t]{2}{*}{ Share of males } & 0.008 & 0.001 & -0.007 & 0.008 & 0.001 & -0.007 & 0.487 \\
\hline & $(0.006)$ & $(0.000)$ & $(0.004)$ & $(0.005)$ & $(0.000)$ & $(0.004)$ & $(0.073)$ \\
\hline \multirow[t]{2}{*}{ Share of immigrants } & 0.006 & -0.000 & -0.003 & 0.007 & -0.000 & -0.003 & 0.058 \\
\hline & $(0.005)$ & $(0.000)$ & $(0.004)$ & $(0.005)$ & $(0.000)$ & $(0.004)$ & $(0.071)$ \\
\hline \multirow[t]{2}{*}{ Share of non native speakers } & 0.281 & 0.040 & -0.367 & -0.308 & 0.036 & -0.230 & 0.109 \\
\hline & $(0.454)$ & $(0.042)$ & $(0.394)$ & $(0.447)$ & $(0.043)$ & $(0.380)$ & $(0.158)$ \\
\hline \multirow[t]{2}{*}{ Share of foreign born } & 0.000 & 0.000 & -0.000 & 0.001 & 0.000 & -0.000 & 0.064 \\
\hline & $(0.003)$ & $(0.000)$ & $(0.003)$ & $(0.003)$ & $(0.000)$ & $(0.003)$ & $(0.096)$ \\
\hline \multirow[t]{2}{*}{ Share of whites } & -0.002 & -0.000 & -0.003 & -0.002 & -0.000 & -0.003 & 0.836 \\
\hline & $(0.005)$ & $(0.001)$ & $(0.004)$ & $(0.005)$ & $(0.001)$ & $(0.004)$ & $(0.205)$ \\
\hline \multirow[t]{2}{*}{ Share of blacks } & -0.001 & 0.000 & 0.001 & -0.001 & 0.000 & 0.001 & 0.081 \\
\hline & $(0.004)$ & $(0.000)$ & $(0.003)$ & $(0.004)$ & $(0.000)$ & $(0.003)$ & $(0.162)$ \\
\hline \multirow[t]{2}{*}{ Share of natives } & 0.002 & -0.000 & -0.001 & 0.001 & -0.000 & -0.001 & 0.015 \\
\hline & $(0.001)$ & $(0.000)$ & $(0.001)$ & $(0.001)$ & $(0.000)$ & $(0.001)$ & $(0.075)$ \\
\hline \multirow[t]{2}{*}{ Share of asians } & -0.000 & -0.000 & 0.000 & -0.001 & -0.000 & 0.001 & 0.022 \\
\hline & $(0.001)$ & $(0.000)$ & $(0.001)$ & $(0.001)$ & $(0.000)$ & $(0.001)$ & $(0.054)$ \\
\hline \multirow[t]{2}{*}{ Share of hawaiians } & 0.001 & -0.000 & -0.000 & 0.001 & -0.000 & -0.000 & 0.001 \\
\hline & $(0.001)$ & $(0.000)$ & $(0.000)$ & $(0.001)$ & $(0.000)$ & $(0.000)$ & $(0.010)$ \\
\hline \multirow[t]{2}{*}{ Share of others } & 0.001 & 0.000 & 0.001 & 0.001 & 0.000 & 0.001 & 0.024 \\
\hline & $(0.002)$ & $(0.000)$ & $(0.002)$ & $(0.002)$ & $(0.000)$ & $(0.002)$ & $(0.057)$ \\
\hline \multirow[t]{2}{*}{ Log newspaper copies } & 0.111 & 0.004 & -0.075 & 0.115 & 0.004 & -0.077 & 13.89 \\
\hline & $(0.076)$ & $(0.005)$ & $(0.053)$ & $(0.076)$ & $(0.005)$ & $(0.053)$ & $(1.185)$ \\
\hline \multicolumn{8}{|l|}{ Income and Education } \\
\hline \multirow[t]{2}{*}{$\overline{\log \text { income }}$} & -0.030 & -0.001 & $0.070^{*}$ & -0.016 & -0.000 & 0.066 & 11.04 \\
\hline & $(0.034)$ & $(0.003)$ & $(0.041)$ & $(0.034)$ & $(0.003)$ & $(0.040)$ & $(0.468)$ \\
\hline Share less than highschool & 0.006 & 0.000 & 0.005 & 0.006 & 0.000 & 0.004 & 0.089 \\
\hline & $(0.007)$ & $(0.001)$ & $(0.005)$ & $(0.007)$ & $(0.001)$ & $(0.005)$ & $(0.071)$ \\
\hline Share highschool dropout & -0.003 & -0.000 & 0.002 & -0.003 & -0.000 & 0.002 & 0.057 \\
\hline & $(0.005)$ & $(0.000)$ & $(0.003)$ & $(0.005)$ & $(0.000)$ & $(0.003)$ & $(0.068)$ \\
\hline Share highschool diploma & 0.006 & 0.000 & $-0.014^{*}$ & 0.007 & 0.000 & $-0.014^{*}$ & 0.341 \\
\hline & $(0.009)$ & $(0.001)$ & $(0.008)$ & $(0.009)$ & $(0.001)$ & $(0.008)$ & $(0.133)$ \\
\hline Share college dropout & 0.004 & 0.001 & -0.002 & 0.004 & 0.001 & -0.001 & 0.206 \\
\hline & $(0.007)$ & $(0.001)$ & $(0.005)$ & $(0.007)$ & $(0.001)$ & $(0.005)$ & $(0.087)$ \\
\hline Share associate diploma & 0.000 & -0.000 & -0.006 & 0.000 & -0.000 & -0.006 & 0.079 \\
\hline & $(0.004)$ & $(0.000)$ & $(0.004)$ & $(0.004)$ & $(0.000)$ & $(0.004)$ & $(0.054)$ \\
\hline Share bachelor diploma & $-0.010^{*}$ & -0.001 & $0.012^{* * *}$ & $-0.011^{*}$ & -0.001 & $0.013^{* * *}$ & 0.148 \\
\hline & $(0.006)$ & $(0.001)$ & $(0.005)$ & $(0.006)$ & $(0.001)$ & $(0.005)$ & $(0.101)$ \\
\hline Share graduate diploma & -0.003 & -0.000 & 0.002 & -0.004 & -0.000 & 0.002 & 0.087 \\
\hline & $(0.005)$ & $(0.000)$ & $(0.004)$ & $(0.005)$ & $(0.000)$ & $(0.004)$ & $(0.091)$ \\
\hline ZIP Code FE & $\mathrm{Y}$ & $\mathrm{Y}$ & $\mathrm{Y}$ & $\mathrm{Y}$ & $\mathrm{Y}$ & $\mathrm{Y}$ & - \\
\hline County-Year FE & $\mathrm{Y}$ & $\mathrm{Y}$ & $\mathrm{Y}$ & $\mathrm{Y}$ & $\mathrm{Y}$ & $\mathrm{Y}$ & - \\
\hline State-Year FE & $\mathrm{N}$ & $\mathrm{N}$ & $\mathrm{N}$ & $\mathrm{N}$ & $\mathrm{N}$ & $\mathrm{N}$ & - \\
\hline Baseline Population & $\mathrm{N}$ & $\mathrm{N}$ & $\mathrm{N}$ & $\mathrm{Y}$ & $\mathrm{Y}$ & $\mathrm{Y}$ & - \\
\hline
\end{tabular}


Table C.3e: Balance tests for main specification

\begin{tabular}{|c|c|c|c|c|c|c|c|}
\hline \multirow[t]{2}{*}{ Pre-Treatment Outcome } & \multicolumn{3}{|c|}{ Model 1} & \multicolumn{3}{|c|}{ Model 2} & \multirow[t]{2}{*}{$\mu / \mathrm{sd}$} \\
\hline & $\beta_{1}$ & $\beta_{2}$ & $\beta_{3}$ & $\beta_{1}$ & $\beta_{2}$ & $\beta_{3}$ & \\
\hline \multicolumn{8}{|l|}{ Weather } \\
\hline$\overline{\log \text { temperatures }}$ & $\begin{array}{l}-0.001 \\
(0.001)\end{array}$ & $\begin{array}{l}-0.000 \\
(0.000)\end{array}$ & $\begin{array}{c}0.002^{* *} \\
(0.001)\end{array}$ & $\begin{array}{c}-0.001 \\
(0.001)\end{array}$ & $\begin{array}{c}-0.000 \\
(0.000)\end{array}$ & $\begin{array}{c}0.002^{* *} \\
(0.001)\end{array}$ & $\begin{array}{c}2.612 \\
(0.336)\end{array}$ \\
\hline Log wind speed & $\begin{array}{c}0.001 \\
(0.009)\end{array}$ & $\begin{array}{c}0.001 \\
(0.001)\end{array}$ & $\begin{array}{c}0.009 \\
(0.009)\end{array}$ & $\begin{array}{c}0.002 \\
(0.009)\end{array}$ & $\begin{array}{c}0.001 \\
(0.001)\end{array}$ & $\begin{array}{c}0.009 \\
(0.009)\end{array}$ & $\begin{array}{c}1.898 \\
(0.298)\end{array}$ \\
\hline Log rainfalls & $\begin{array}{c}0.005 \\
(0.008)\end{array}$ & $\begin{array}{c}0.002 \\
(0.001)\end{array}$ & $\begin{array}{l}-0.006 \\
(0.008)\end{array}$ & $\begin{array}{c}0.004 \\
(0.008)\end{array}$ & $\begin{array}{c}0.002 \\
(0.001)\end{array}$ & $\begin{array}{l}-0.006 \\
(0.008)\end{array}$ & $\begin{array}{c}4.401 \\
(0.522)\end{array}$ \\
\hline \multicolumn{8}{|l|}{ Labor Compostion } \\
\hline$\overline{\text { Share labor force }}$ & $\begin{array}{l}-0.850 \\
(0.798)\end{array}$ & $\begin{array}{l}-0.061 \\
(0.063)\end{array}$ & $\begin{array}{c}0.962 \\
(0.665)\end{array}$ & $\begin{array}{c}0.028 \\
(0.779)\end{array}$ & $\begin{array}{l}-0.055 \\
(0.064)\end{array}$ & $\begin{array}{c}0.757 \\
(0.642)\end{array}$ & $\begin{array}{c}0.470 \\
(0.125)\end{array}$ \\
\hline Share in the agriculture & $\begin{array}{c}0.014^{* *} \\
(0.006)\end{array}$ & $\begin{array}{l}-0.000 \\
(0.001)\end{array}$ & $\begin{array}{c}-0.003 \\
(0.005)\end{array}$ & $\begin{array}{c}0.015^{* * *} \\
(0.006)\end{array}$ & $\begin{array}{l}-0.000 \\
(0.001)\end{array}$ & $\begin{array}{c}-0.003 \\
(0.005)\end{array}$ & $\begin{array}{c}0.067 \\
(0.105)\end{array}$ \\
\hline Share in the construction & $\begin{array}{c}0.008 \\
(0.006)\end{array}$ & $\begin{array}{c}0.001 \\
(0.001)\end{array}$ & $\begin{array}{c}-0.010^{* *} \\
(0.005)\end{array}$ & $\begin{array}{c}0.009 \\
(0.006)\end{array}$ & $\begin{array}{c}0.001 \\
(0.001)\end{array}$ & $\begin{array}{c}-0.010^{* *} \\
(0.005)\end{array}$ & $\begin{array}{c}0.077 \\
(0.067)\end{array}$ \\
\hline Share in the manufacture & $\begin{array}{l}-0.010^{*} \\
(0.006)\end{array}$ & $\begin{array}{l}0.001^{*} \\
(0.001)\end{array}$ & $\begin{array}{l}0.009^{*} \\
(0.005)\end{array}$ & $\begin{array}{c}-0.011^{*} \\
(0.006)\end{array}$ & $\begin{array}{l}0.001^{*} \\
(0.001)\end{array}$ & $\begin{array}{l}0.009^{*} \\
(0.005)\end{array}$ & $\begin{array}{c}0.112 \\
(0.092)\end{array}$ \\
\hline Share in wholesales & $\begin{array}{l}-0.001 \\
(0.003)\end{array}$ & $\begin{array}{l}-0.000 \\
(0.000)\end{array}$ & $\begin{array}{l}-0.000 \\
(0.002)\end{array}$ & $\begin{array}{l}-0.001 \\
(0.003)\end{array}$ & $\begin{array}{l}-0.000 \\
(0.000)\end{array}$ & $\begin{array}{l}-0.000 \\
(0.002)\end{array}$ & $\begin{array}{c}0.026 \\
(0.035)\end{array}$ \\
\hline Share in retail & $\begin{array}{c}0.002 \\
(0.006)\end{array}$ & $\begin{array}{c}-0.001^{*} \\
(0.001)\end{array}$ & $\begin{array}{c}0.001 \\
(0.005)\end{array}$ & $\begin{array}{c}0.003 \\
(0.006)\end{array}$ & $\begin{array}{c}-0.001^{*} \\
(0.001)\end{array}$ & $\begin{array}{c}0.001 \\
(0.005)\end{array}$ & $\begin{array}{c}0.112 \\
(0.073)\end{array}$ \\
\hline Share in transportation & $\begin{array}{c}0.003 \\
(0.005)\end{array}$ & $\begin{array}{l}-0.000 \\
(0.000)\end{array}$ & $\begin{array}{l}-0.001 \\
(0.004)\end{array}$ & $\begin{array}{c}0.003 \\
(0.005)\end{array}$ & $\begin{array}{l}-0.000 \\
(0.000)\end{array}$ & $\begin{array}{l}-0.002 \\
(0.004)\end{array}$ & $\begin{array}{c}0.056 \\
(0.057)\end{array}$ \\
\hline Share in information & $\begin{array}{l}-0.001 \\
(0.002)\end{array}$ & $\begin{array}{l}-0.000 \\
(0.000)\end{array}$ & $\begin{array}{c}0.000 \\
(0.002)\end{array}$ & $\begin{array}{l}-0.002 \\
(0.002)\end{array}$ & $\begin{array}{l}-0.000 \\
(0.000)\end{array}$ & $\begin{array}{c}0.000 \\
(0.002)\end{array}$ & $\begin{array}{c}0.017 \\
(0.027)\end{array}$ \\
\hline Share in finance & $\begin{array}{l}-0.001 \\
(0.004)\end{array}$ & $\begin{array}{c}0.000 \\
(0.000)\end{array}$ & $\begin{array}{l}-0.001 \\
(0.003)\end{array}$ & $\begin{array}{l}-0.001 \\
(0.004)\end{array}$ & $\begin{array}{c}0.000 \\
(0.000)\end{array}$ & $\begin{array}{l}-0.001 \\
(0.003)\end{array}$ & $\begin{array}{c}0.052 \\
(0.052)\end{array}$ \\
\hline Share in professorship & $\begin{array}{l}-0.005 \\
(0.004)\end{array}$ & $\begin{array}{c}0.000 \\
(0.000)\end{array}$ & $\begin{array}{l}-0.004 \\
(0.004)\end{array}$ & $\begin{array}{l}-0.005 \\
(0.004)\end{array}$ & $\begin{array}{c}0.000 \\
(0.000)\end{array}$ & $\begin{array}{l}-0.004 \\
(0.004)\end{array}$ & $\begin{array}{c}0.082 \\
(0.071)\end{array}$ \\
\hline Share in education & $\begin{array}{l}-0.009 \\
(0.009)\end{array}$ & $\begin{array}{l}-0.000 \\
(0.001)\end{array}$ & $\begin{array}{c}0.013^{* *} \\
(0.006)\end{array}$ & $\begin{array}{l}-0.009 \\
(0.009)\end{array}$ & $\begin{array}{l}-0.000 \\
(0.001)\end{array}$ & $\begin{array}{c}0.013^{* *} \\
(0.006)\end{array}$ & $\begin{array}{c}0.226 \\
(0.103)\end{array}$ \\
\hline Share in arts & $\begin{array}{c}0.007 \\
(0.005)\end{array}$ & $\begin{array}{c}0.000 \\
(0.001)\end{array}$ & $\begin{array}{l}-0.006 \\
(0.004)\end{array}$ & $\begin{array}{c}0.008 \\
(0.005)\end{array}$ & $\begin{array}{c}0.000 \\
(0.001)\end{array}$ & $\begin{array}{l}-0.006 \\
(0.004)\end{array}$ & $\begin{array}{c}0.081 \\
(0.074)\end{array}$ \\
\hline Share in public administration & $\begin{array}{l}-0.002 \\
(0.004)\end{array}$ & $\begin{array}{c}0.000 \\
(0.000)\end{array}$ & $\begin{array}{c}0.003 \\
(0.003)\end{array}$ & $\begin{array}{l}-0.002 \\
(0.004)\end{array}$ & $\begin{array}{c}0.000 \\
(0.000)\end{array}$ & $\begin{array}{c}0.003 \\
(0.003)\end{array}$ & $\begin{array}{c}0.053 \\
(0.062)\end{array}$ \\
\hline Share in others & $\begin{array}{l}-0.005 \\
(0.005)\end{array}$ & $\begin{array}{l}-0.000 \\
(0.000)\end{array}$ & $\begin{array}{c}0.000 \\
(0.003)\end{array}$ & $\begin{array}{l}-0.006 \\
(0.005)\end{array}$ & $\begin{array}{l}-0.000 \\
(0.000)\end{array}$ & $\begin{array}{c}0.001 \\
(0.003)\end{array}$ & $\begin{array}{c}0.047 \\
(0.048)\end{array}$ \\
\hline Share unemployed & $\begin{array}{c}-0.002 \\
(0.006)\end{array}$ & $\begin{array}{c}0.001 \\
(0.001)\end{array}$ & $\begin{array}{l}-0.007 \\
(0.005)\end{array}$ & $\begin{array}{l}-0.002 \\
(0.006)\end{array}$ & $\begin{array}{c}0.001 \\
(0.001)\end{array}$ & $\begin{array}{l}-0.007 \\
(0.004)\end{array}$ & $\begin{array}{c}0.086 \\
(0.089)\end{array}$ \\
\hline ZIP Code FE & $\mathrm{Y}$ & $\mathrm{Y}$ & $\mathrm{Y}$ & $\mathrm{Y}$ & $\mathrm{Y}$ & $\mathrm{Y}$ & - \\
\hline County-Year FE & $\mathrm{Y}$ & $\mathrm{Y}$ & $\mathrm{Y}$ & $\mathrm{Y}$ & $\mathrm{Y}$ & $\mathrm{Y}$ & - \\
\hline State-Year FE & $\mathrm{N}$ & $\mathrm{N}$ & $\mathrm{N}$ & $\mathrm{N}$ & $\mathrm{N}$ & $\mathrm{N}$ & - \\
\hline Baseline Population & $\mathrm{N}$ & $\mathrm{N}$ & $\mathrm{N}$ & $\mathrm{Y}$ & $\mathrm{Y}$ & $\mathrm{Y}$ & - \\
\hline
\end{tabular}


Table C.3f: Balance tests for main specification

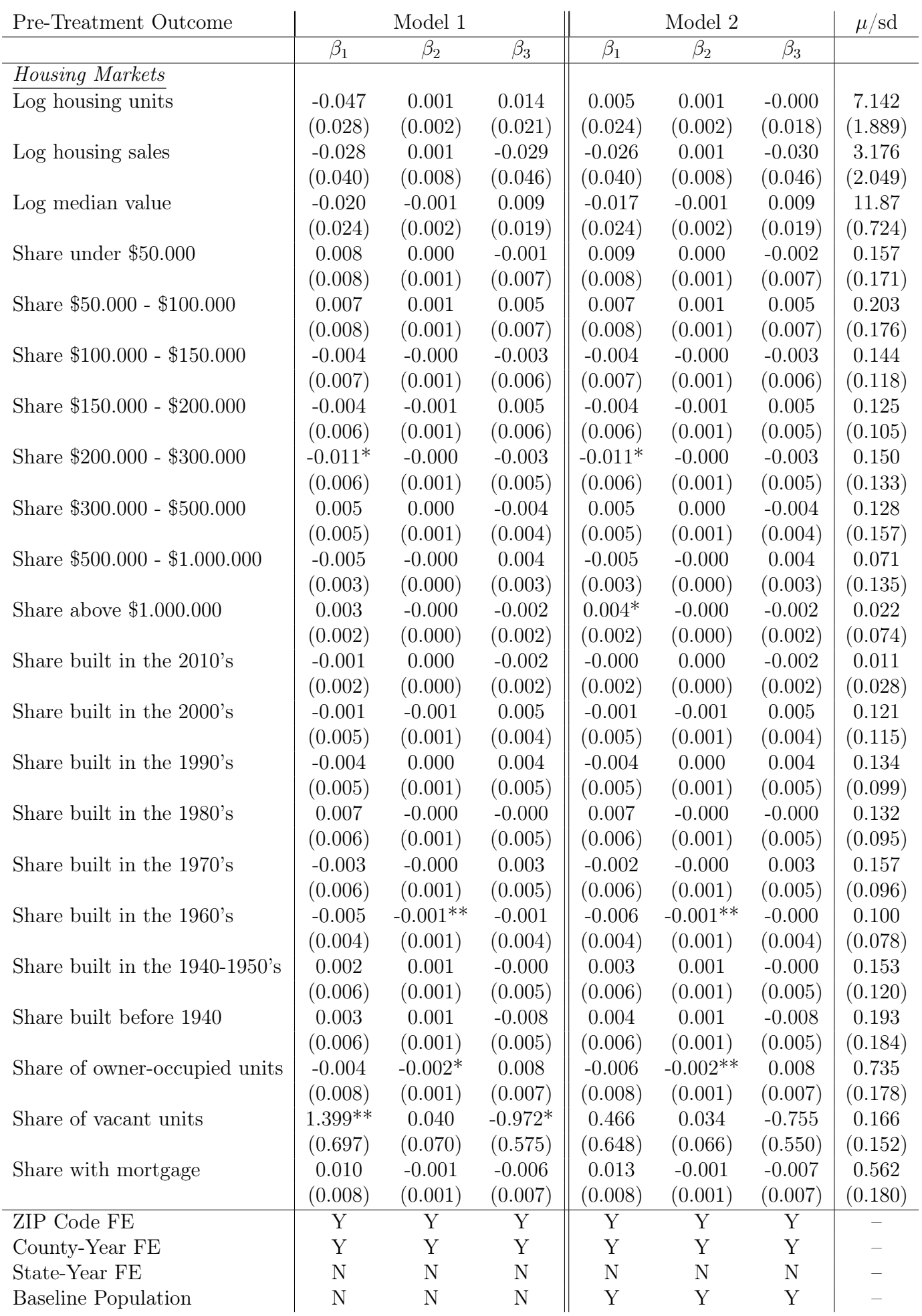




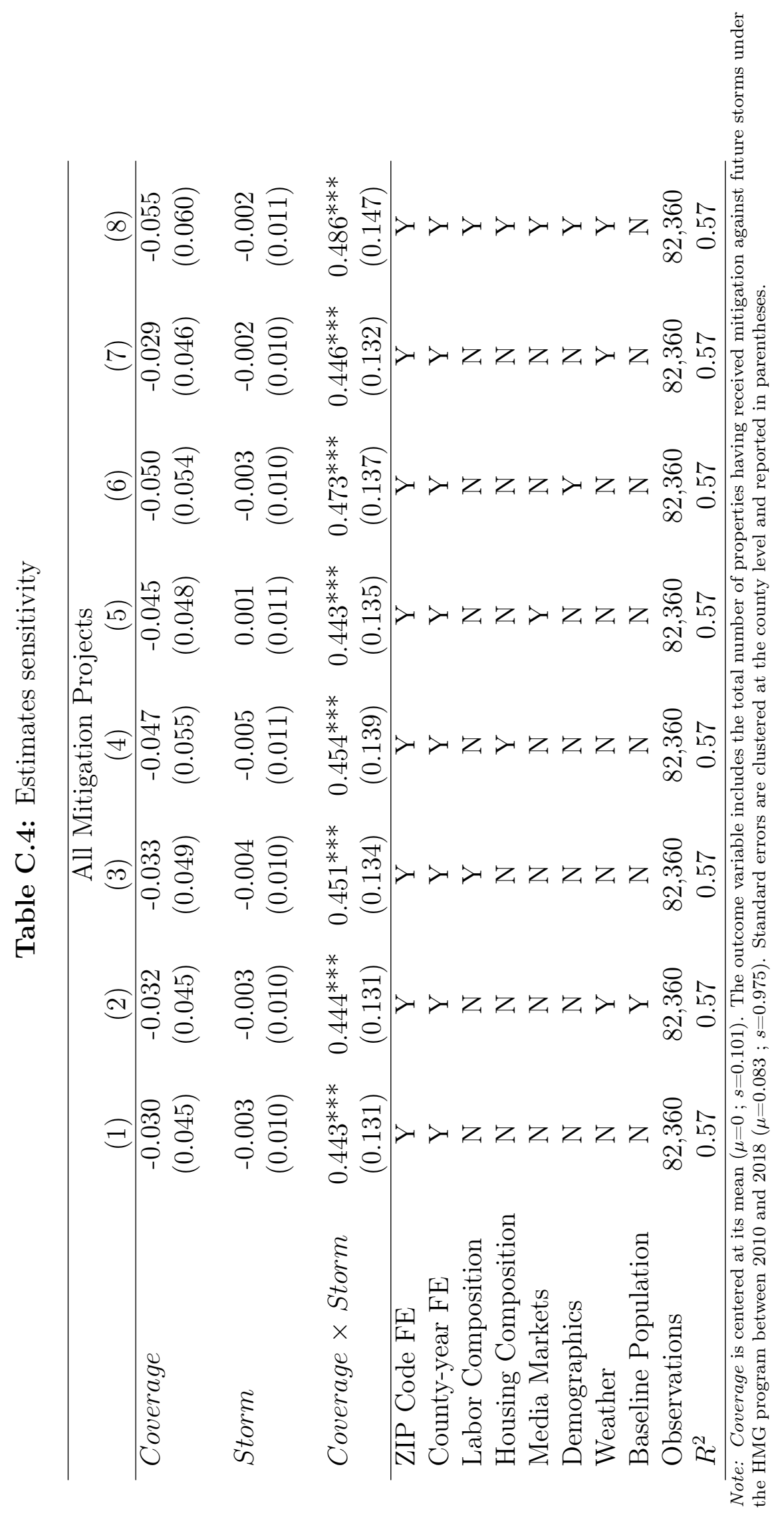




\section{Center for Regional Economic Development (CRED)}

University of Bern

Schanzeneckstrasse 1

P.O.Box

CH-3001 Bern

Telephone: +41 (0)31 6313711

E-Mail: info@cred.unibe.ch

Website: http://www.cred.unibe.ch

The Center for Regional Economic Development (CRED) is an interdisciplinary hub for the scientific analysis of questions of regional economic development. The Center encompasses an association of scientists dedicated to examining regional development from an economic, geographic and business perspective.

\section{Contact of the authors:}

Pierre Magontier

University of Bern

Schanzeneckstrasse 1

P.O.Box

CH-3001 Bern

Telephone: +41 (0)31 6314997

Email: pierre.magontier@cred.unibe.ch

This paper can be downloaded at:

https://www.cred.unibe.ch/forschung/publikationen/cred_research_papers/index_ger.html 